Andrews University

Digital Commons @ Andrews University

1992

\title{
Inclusion of Gregorc's Mind Styles Concepts in Physical Therapy Curriculum and Instruction in Selected Baccalaureate and Post- Baccalaureate Programs
}

Keith R. Gaden

Andrews University

Follow this and additional works at: https://digitalcommons.andrews.edu/dissertations

Part of the Curriculum and Instruction Commons, Health and Physical Education Commons, and the Physical Therapy Commons

\section{Recommended Citation}

Gaden, Keith R., "Inclusion of Gregorc's Mind Styles Concepts in Physical Therapy Curriculum and Instruction in Selected Baccalaureate and Post-Baccalaureate Programs" (1992). Dissertations. 383. https://digitalcommons.andrews.edu/dissertations/383 https://dx.doi.org/10.32597/dissertations/383

This Dissertation is brought to you for free and open access by the Graduate Research at Digital Commons @ Andrews University. It has been accepted for inclusion in Dissertations by an authorized administrator of Digital Commons@ Andrews University. For more information, please contact repository@andrews.edu. 


\section{Andrews \$university}

Seek Knowledge. Affirm Faith. Change the World.

Thank you for your interest in the

\section{Andrews University Digital Library of Dissertations and Theses.}

Please honor the copyright of this document by not duplicating or distributing additional copies in any form without the author's express written permission. Thanks for your cooperation. 


\section{INFORMATION TO USERS}

This manuscript has been reproduced from the microfilm master. UMI films the text directly from the original or copy submitted. Thus, some thesis and dissertation copies are in typewriter face, while others may be from any type of computer printer.

The quality of this reproduction is dependent upon the quality of the copy submitted. Broken or indistinct print, colored or poor quality illustrations and photographs, print bleedthrough, substandard margins, and improper alignment can adversely affect reproduction.

In the unlikely event that the author did not send UMI a complete manuscript and there are missing pages, these will be noted. Also, if unauthorized copyright material had to be removed, a note will indicate the deletion.

Oversize materials (e.g., maps, drawings, charts) are reproduced by sectioning the original, beginning at the upper left-hand corner and continuing from left to right in equal sections with small overlaps. Each original is also photographed in one exposure and is included in reduced form at the back of the book.

Photographs included in the original manuscript have been reproduced

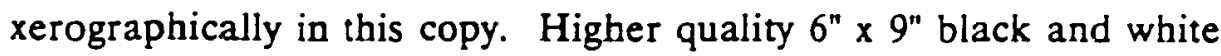
photographic prints are available for any photographs or illustrations appearing in this copy for an additional charge. Contact UMI directly to order.

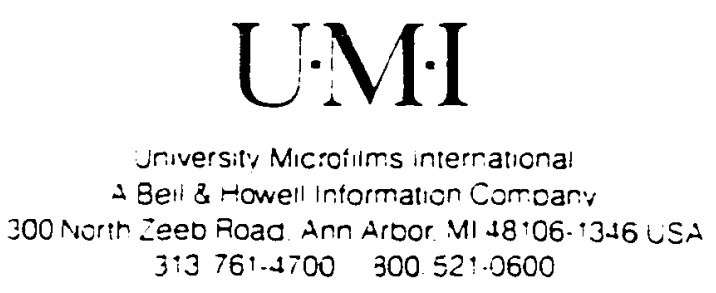


Reproduced with permission of the copyright owner. Further reproduction prohibited without permission. 
Inclusion of Gregorc's mind styles concepts in physical therapy curriculum and instruction in selected baccalau.eate and post-baccalaureate programs

\author{
Gaden, Keith Raymond, Ph.D.
}

Andrews University, 1992

Copyright (c) 1992 by Gaden, Keith Raymond. All rights reserved.

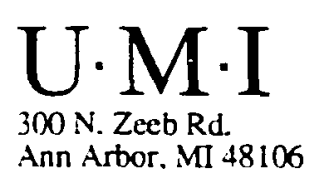




\title{
Andrews University \\ School of Education
}

\section{INCLUSION OF GREGORC'S MIND STYLES CONCEPTS IN PHYSICAL THERAPY CURRICULUM AND INSTRUCTION IN SELECTED BACCALAUREATE AND POST-BACCALAUREATE PROGRAMS}

\author{
A Dissertation \\ Presented in Partial Fulfillment \\ of the Requirements for the Degree \\ Doctor of Philosophy
}

by

Keith R. Gaden

August 1992 
- Copyright by Keith R. Gaden 1992

All Rights Reserved 


\title{
INCLUSION OF GREGORC'S MIND STYLES CONCEPTS IN PHYSICAL THERAPY CURRICULUM AND INSTRUCTION \\ IN SELECTED BACCALAUREATE AND POST-BACCALAUREATE PROGRAMS
}

\author{
A dissertation \\ presented in partial fulfillment \\ of the requirements for the degree \\ Doctor of Philosophy
}

by

Keith R. Gaden

APPROVAL BY THE COMMITTEE:
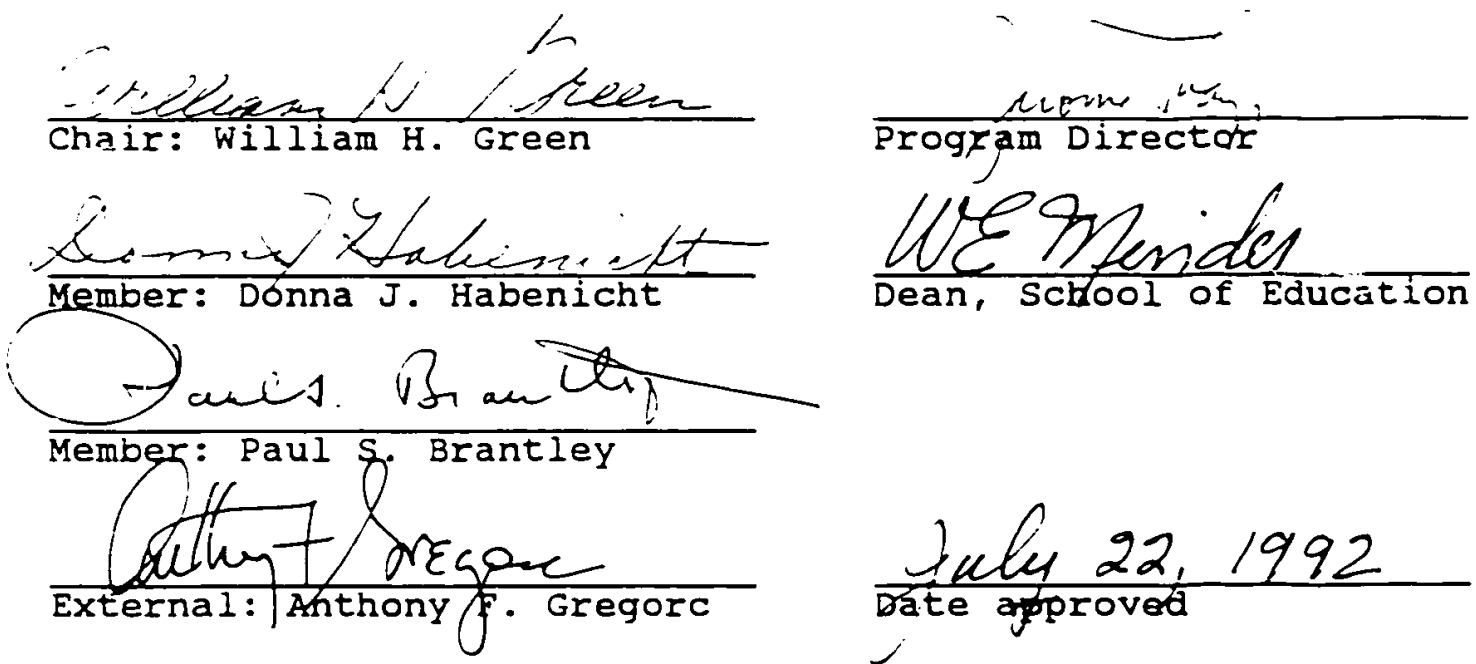


\title{
ABSTRACT
}

\section{INCLUSION OF GREGORC'S MIND STYLES CONCEPTS IN PHYSICAL THERAF $\because$ CURRICULUM AND INSTRUCTION IN SELECTED BACCALAUREATE AND POST-BACCALAUREATE PROGRAMS}

\author{
by \\ Keith R. Gaden
}

Chair: William H. Green 


\title{
ABSTRACT OF GRADUATE STUDENT RESEARCH
}

Dissertation

\author{
Andrews University \\ School of Education \\ Title: INCLUSION OF GREGORC'S MIND STYLES CONCEPTS IN \\ PHYSICAL THERAPY CURRICULUM AND INSTRUCTION IN \\ SELECTED BACCALAUREATE AND POST-BACCALAUREATE \\ PROGRAMS \\ Name of researcher: Keith $R$. Gaden \\ Name and degree of faculty chair: William H. Green, Ph.D. \\ Date Completed: August 1992
}

Topic

The topic under study in this paper was the application of Gregorc's mind styles concepts in two baccalaureate and two post-baccalaureate physical therapy programs.

Purpose

The purpos was to determine how these concepts were used while addressing the teaching and learning theory competency of the accreditation standards.

\section{Sources}

I examined intra- and extra-classroom activities, noting how information on styles was given and/or modeled to 
the students. Gregorc's Energic Model of Styles formed the basis for style determination. The research design was multiple-case study (embedded). Accreditation documents, curriculum file materials, handout materials, and videotaped classroom sessions were interpreted to determine how the teachers' and students' stïle needs were met. The students and teachers completed the Gregorc Style Delineator Research Instrument.

Conclusions
Including intra- and extra-classroom activities, all four programs addressed tine needs and abilities of all four mind styles of Gregorc's model. Within the classroom, three of the four programs addressed the four mind styles, and the remaining program addressed three of the four mind styles. Abilities of each of the four mind styles were acdressed during the teaching and learning theory unit or course in the four physical therapy programs studied. It must be borne in mind that these findings are based on only four physical therapy programs when interpreting the results of this research. 
To Delores, in deep

appreciation for her tolerance of,

encouragement in, enthusiasm for, and belief in this project 
TABLE OF CONTENTS

LIST OF TABLES

viii

CHAPTER

I. INTRODUCTION . . . . . . . . . . . . . . . . . 1

What Is Style? . . . . . . . . . . . 5

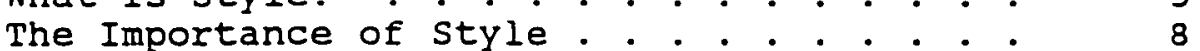

Research Questions . . . . . . . . . . . 9

Propositions . . . . . . . . . . . . . . . 12

Purpose of the study . . . . . . . . . . . 14

Importance of the study . . . . . . . . . 15

Definition of Terms . . . . . . . . . . . . 16

Style Models Utilized in the study . . . . 19

II. REVIEW OF LITERATURE . . . . . . . . . . . . . 21

Sources of Style . . . . . . . . . . . . 22

Hereditary, Innate, or Acquired ...$\quad \cdot \quad 22$

Mind vs. Brain . . . . . . . . . . . . . . 22

The Onion Skin Model of Learning Styles. . 24

Learning style vs. Mind Style. . . . . . 25

Representative Philosophies of Style . . . 25

Dunn and Dunn . . . . . . . . . . . . 26

McCarthy's 4MAT System . . . . . . . . 27

Gregorc . . . . . . . . . . . . . . . . 30

Comparison of the Models of Dunn and
Dunn, McCarthy, and Gregorc. . . . $\quad 32$

Testing Instruments for Style . . . . . 37

Can All Teachers Teach All students

With Equal Success?. . . . . . . . . 38

The Use of Media in the Classroom . . . 39

Natural Style vs. Role-based Style . . . . 40

Flexibility of Style . . . . . . . . . . . 41

Teaching Style vs. Learning Style... . . 43

Dominant Style Characteristics. . . . . 44

Concrete-sequential (CS) . . . . . . 45

Abstract-sequential (AS) . . . . . . 45

Abstract-random (AR) . . . . . . . . 46

Concrete-random (CR) . . . . . . . . 47

Research Using the Gregorc
Style Delineator. . . . . . . . . . 48

Responsibility of Styles Awareness . . . . 50

Summary . . . . . . . . . . . . . . 50

iv

Reproduced with permission of the copyright owner. Further reproduction prohibited without permission. 
III. RESEARCH DESIGN AND METHODOLOGY . . . . . .

Research Design . . . . . . . . . . . . . 52

Topic and Focus of the Study . . . . . . 52

Selecting the Research Setting . . . . . 54

Establishing Criteria for Subject Selection . . . . . . . 54

Establishing Contact with

the Programs... . . . . . . 55

Addition of Drograin Using New Standards . . . . . . . . 58

Data Gathering Techniques . . . . . . . 59

Self Study and Handout Materials . . 59

Videotaped Class Sessions. . . . . 59

Gregorc Style Delineator
Research Instrument . . . . . . 60

Data Analysis ............. . . . 62

Teacher's' Mind Styles. . . . . . . . 62

Students' Mind Styles.. . . . . . . 63

The self study . . . . . . . . . . . 63

Handouts . . . . . . . . . . . . . . 64

Oral Presentations . . . . . . . . . 64

Sudiovisual Aids . . . . . . . . . . 65

Classroom Design . . . . . . . . . 65

IV. CASE STUDY I. . . . . . . . . . . . . 67

Overview . . . . . . . . . . . . . . . 68

Teachers' Mind styles.. . . . . . . . . 69

Dr. Allen . . . . . . . . . . . . 69

Ms. Boone . . . . . . . . . . . . 70

Ms. Clark . . . . . . . . . . . . . 70

Students' Mind Styles............ . 71

The Self study . . . . . . . . . . . . . . 74

Form E . . . . . . . . . . . . . . . . . 74

Course outlines . . . . . . . . . . . . 74

Handouts . . . . . . . . . . . . . . . . . . 74

Oral Presentations . . . . . . . . . 76

Dr. Allen . . . . . . . . . . . . . 76

Ms. Boone . . . . . . . . . . . . . 79

Dr. Allen . . . . . . . . . . . . . . 80

Ms. Clark . . . . . . . . . . . . . 81

Audiovisual Aids . . . . . . . . . . . 83

Classroom Design . . . . . . . . . . . 84

Summary . . . . . . . . . . . . . . . . 85

V. CASE STUDY II . . . . . . . . . . . . . . . . 89

Overview . . . . . . . . . . . . . . . . . 90

Teacher's Mind Style . . . . . . . . . . 91

Students' Mind Styles... . . . . . . . . 91

The self study . . . . . . . . . . . . . . 95

Form E. . . . . . . . . . . . . . . . 95

$\checkmark$ 


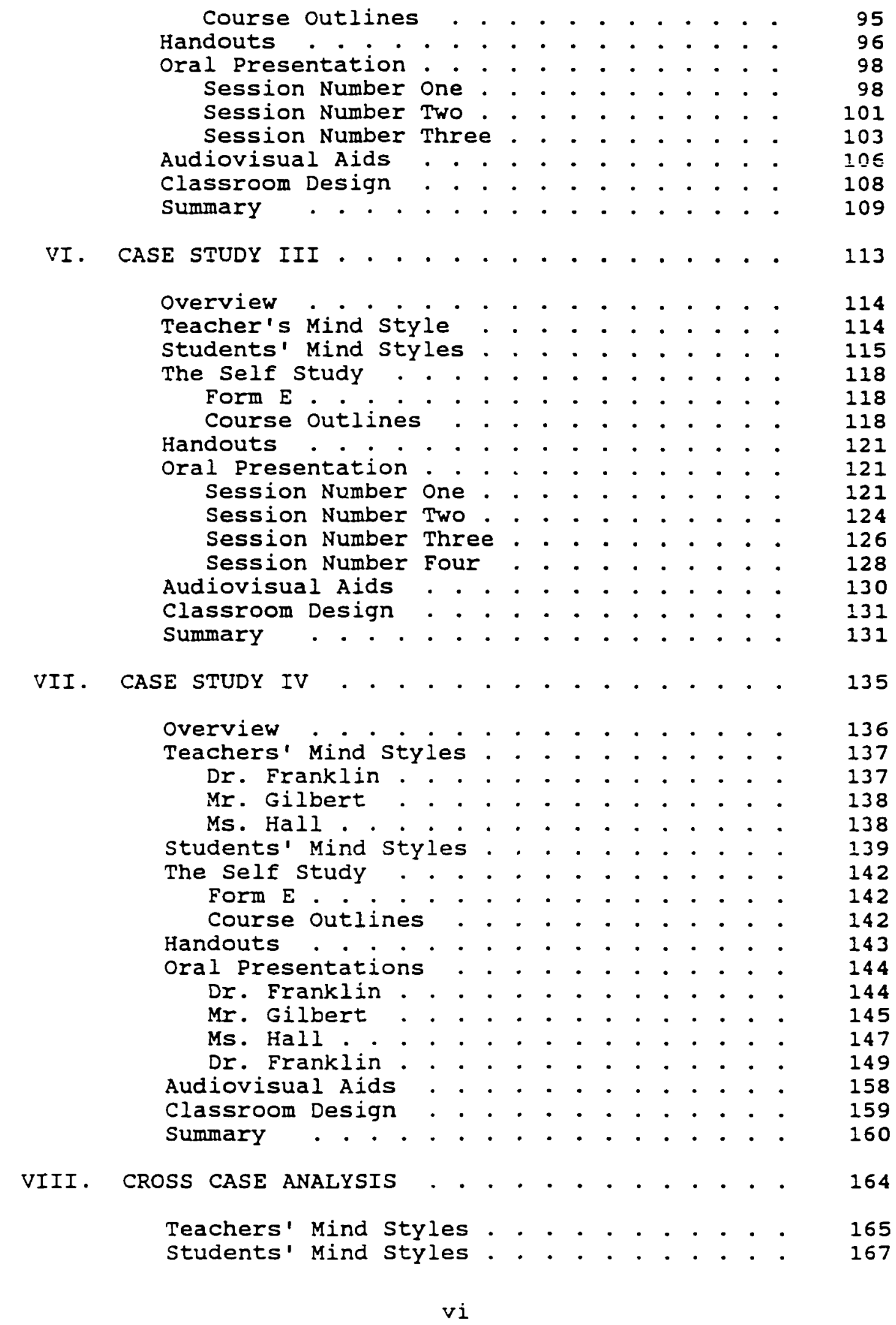




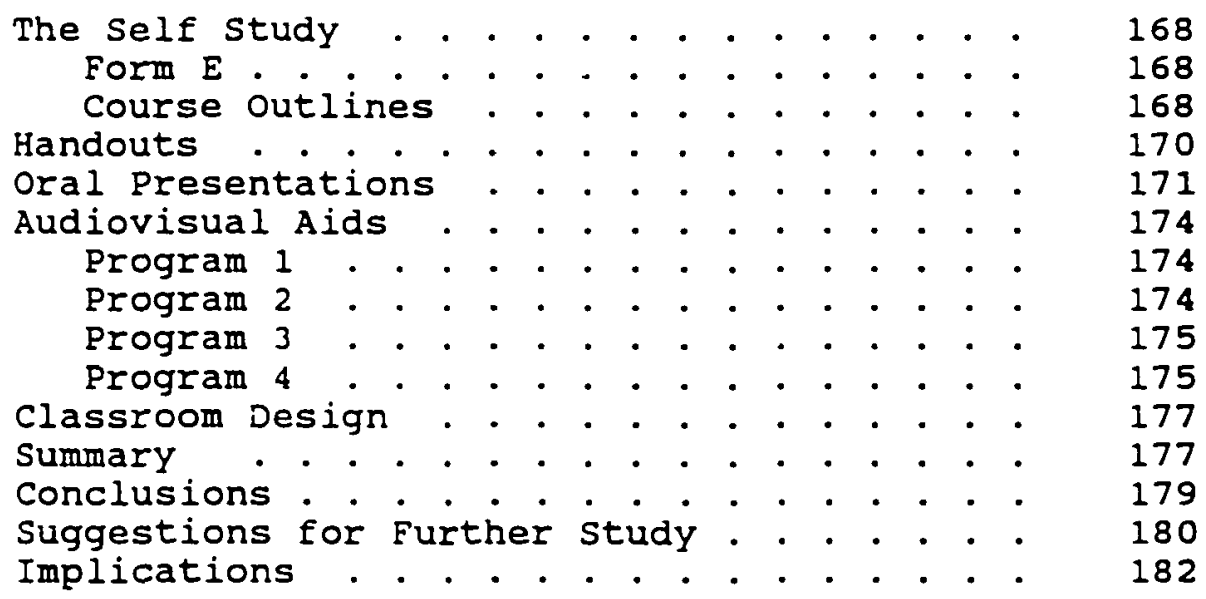

\section{APPENDIX A :}

Preferred Teaching strategies by Dominant Mind style

APPENDIX B:

Learner Behaviors, Attitudes, and Preferences . . 185

APPENDIX C:

The Four Continua of the Myer-Briggs

Type Indicator . . . . . . . . . . . . 187

REFERENCE LIST. . . . . . . . . . . . . . . . . . 188

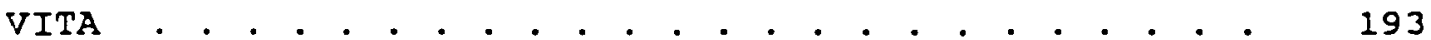

vii 


\section{LIST OF TABLES}

1. Dominant Styles of Program one students . . . . . . 72

2. Dominant Styles of Program Two students . . . . . . 93

3. Dominant Styles of Program Three students . . . . . 116

4. Dominant Styles of Program Four students . . . . . 140

5. Dominant Styles of Teachers of Each Program and Their Own Styles Addressed in

Their Oral Presentations. . . . . . . . . . . 166

6. Styles Addressed in the Self-study Report

Course Outline objectives of Each

Program . . . . . . . . . . . . . . 169

7. Styles Addressed in the Handout Materials of

Each Teacher in Each Program . . . . . . . . 170

8. Dominant Styles Addressed in the oral

Presentations of Each Program . . . . . . . . 172

viii 


\section{CHAPTER I}

\section{INTRODUCTION}

Physical therapy education programs must include a competency which deals with the presentation of teaching and learning theory. In daily practice the physical therapist must teach patients, patients' families, or other professionals. In recent years practitioners of teaching and learning theory have noticed differences in learning styles of teachers and students. Claxton and Murrell (1987) describe 16 different learning styles models. Included among them is the Energic Model of Styles developed by Anthony F. Gregorc (Gregorc, 1982*, 1985). The model addresses mind styles which include learning, teaching, supervising, and administrating (Gregorc, 1985; Dempsey \& Gregorc, 1988). These are a few of several ways that we deal with reality. "Gregorc's mind styles were developed to enable individuals to interact more successfully with the outside world by understanding their own and others' styles" (Radebaugh, Nicely-Leach, Morrill, Shreeve, \& Slatton, 1988, p. 329). This research used Gregorc's model to study the mind styles of physical therapy professors and students. The classroom strategies and materials used for educational 
purposes were also examined from this perspective. When interpreting the results of this research it must be borne in mind that the findings were based on only four physical therapy programs.

In 1974, Geneva Johnson predicted that physical therapy education, in the future,

will concentrate on the personal, as well as the professional, development of the individual. Patterns of education will be adaptable and flexible, furthermore, permitting each student to adjust the pace to meet a personal learning style or to work while studying. (Johnson, 1974, p. 41)

Various teaching strategies, which address various styles, have been reported in the physical therapy literature. Barker (1988) compared videodisc and lecture-demonstration for teaching one of the physical therapy psychomotor skills and found no significant difference between the groups. Bukowski, Jensen, and Morrison (1980) compared textbook and self-instructional methods. They found no significant difference between the skill levels of their groups. They did note that the self-instruction units took less time and that the subjects using those materials had greater retention after 6 months than those who used the textbooks. Campbell and Kohli (1970) tested an audiotutorial approach to teaching a physical therapy evaluation procedure. Their results demonstrated that the audiotutorial approach was as effective as the lecturedemonstration method with significantly reduced learning time. In 1985, Day discussed the use of the inquiry and 
simulation models in the classroom. Other studies also reported comparable learning using alternative strategies (Bickley, MCDougall, \& Fepe, 1973; Rutan, 1973).

In 1979, Payton, Hueter, and McDonald reported a study on learning style preferences using the Canfield and Lafferty Learning styles Inventory. I attempted to acquire this instrument to use in another study and found that it was no longer available.

One other study was located involving physical therapy students with other allied health professional students (Rahr, 1987). Rahr used the Gregorc Style Delineator and a self-designed instrument modeled after the Dunn, Dunn, and Price instrument (Rahr, 1987). He found that the dominant concrete-sequential style predominated among the allied health students.

After attending the first Gregorc mind styles workshop, I decided that I should study three styles models in depth. I chose the two additional ones based on their frequent advertisements for workshops, as compared to other models. I interpreted this frequency as indicative of their popularity among educators. These were the 4MAT system and the Dunn and Dunn models.

I eliminated the Dunn, Dunn, and Price instrument as unusable for my research because of the greater number of elements described by their instrument. Their instrument reflects scores on 18 elements. My personal experience with 
this instrument was that it required more than 30 minutes to administer. I wished to make a minimal impact on the classroom schedules during my data collecting, therefore this instrument would not fit that criterion. The kolb instrument, which defines four styles, has a scoring system that is slightly more involved than Gregorc's instrument. The Gregorc style Delineator ${ }^{\mathrm{TM}}$, which also defines four styles, was selected because of its quaternary design (fewer than the 18 elements) and simplicity of scoring.

I chose to use Gregorc's model as the instrument of anaiysis in this case study for two additional reasons: (1) its broader coverage of human activity including more than just learning style (Gregorc, 1985), and (2) as compared to the other two models I studied in detail, its more accurate explanation of my relationship to the real world. This latter reason is important because I was the only observer and analyzer of the data gathered. I needed a framework that was natural to me to increase the consistency of interpretation of the data. If the researcher has to refer constantly to a list of characteristics which he or she has difficulty relating to, the research process is hampered. Any "judgment calls" might be based on an incomplete "feeling" for or incomplete understanding of the criteria used in the analysis process. 
What Is style?

Gregorc defines style as consisting

of outer behavior, characteristics, and mannerisms which are symptomatic of the psyche and of particular mental qualities. Specifically, an individual's outer, visible style characteristics provide clues as to the inner invisible nature and capacity of his psychclogical and mental makeup. (Gregorc, 1985, p. 7)

Many researchers have noted differences of learning behaviors among individuals (Dunn \& Dunn, 1978; Gregorc, 1985; Keirsey \& Bates, 1984; Kolb, 1984; McCarthy, 1987; Myers \& McCaulley, 1985). Several studies have been done which support the idea of higher achievement scores through matching of teaching style with learning style of the student (Adams, 1983; Bennet, 1979; Bogue, 1982; Brown, 1978; Bruno, 1988; McCain \& Brown, 1969; Shmaefsky, 1987). Physical therapy students are instructed in individual psychological differences due to physical disability or other pathological conditions. One of my research questions asked if they are instructed in styles and if so, how is it done? (Commission on Accreditation in Physical Therapy Education, [CAPTE], 1986).

Gregorc (1985) has developed a model of mind styles that includes learning styles, based on his phenomenological research with students and teachers. He calls his model the Energic Model of styles.

Gregorc discusses learning and teaching styles, but he has been led, through his research, to the study of the psychology of style. Psychology has its roots in the mind 
6

(Gregorc, 1985). Gregorc discusses mind styles rather than

just learning styles because he has observed that

individuals deal with the environment in certain ways.

These ways are consistent regardless of whether they are

learning, administering, supervising, or teaching.

The Energic Model of styles was developed through

phenomenological research methodology. This qualitative

method includes observation and interview techniques to

determine the internal forces responsible for the observable behaviors of an individual or group of individuals. The basic premise is that a person can describe his feelings, reactions, and purposes for particular overt actions

exhibited. Sume of the interview questions asked are: "Why did you do what you did?"; "How do you feel when someone does to you?"; "What conditions make you feel comfortable?"; "What conditions make you feel uncomfortable?"

The Energic Model of styles is a subset of the ORGANON system of Gregorc (Gregorc, 1985). It is based upon the following philosophical principle: "The primary purpose of life is to realize and actualize one's individuality, spirituality, and collective humanness" (Gregorc, 1985, p. 44). Among the basic tenets of the ORGANON System are those expressing the uriversality and uniqueness of the human being.

The ORGANON System views the human mind as an instrument of thought that determines the ways realization and 
actualization will be achieved. To varying degrees, the mind is free to align or not align elements of the psychic life with the outer world. In this sense, every hLian being has degrees of free will or free choice to realize or not realize his goals and potential. When the outer world is in harmony with an individual's psychic life, that individual is said to be fulfilled, satisfied, and at peace. Lack of harmony and alignment can, however, retard, frustrate, and prevent

fulfillment. (Gregorc, $1982^{4}$, p. v)

The human mind operates on several continua or dualities. One of the continua that Gregorc describes is that of perception. Abstract and concrete are the polar extremes of the perception continuum. An individual perceives the world in concrete and abstract terms, but tends to perceive in one way more than the other. The ordering continuum has sequential and random at its extremes. A person orders what he/she perceives sequentially and randomly, but, as in the perception continuum, he/she usually prefers one ordering mode over the other. Gregorc describes other continua, but the perception and ordering continua are the ones he uses for naming the four mind styles.

The four mind styles are: Concrete-sequential (CS), Abstract-sequential (AS), Abstract-random (AR), and Concrete-random (CR). Preferred unique abilities that the individual uses to interact with the environment characterize each style (see Appendices A \& B). Any two individuals who are dominant in one style do not share, however, all of the characteristics of that style. They 
share some characteristics, but not others. Inherent also in each of the styles are strengths and limitations of some abilities. Contrasting the dominant concrate-sequential person's use of language with that of the dominant concreterandom person would be an example. A dominant concretesequential person uses words literally or as labels. A dominant concrete-random person uses words in the belief they cannot entirely convey his meaning (Gregorc, 1982'). Since every human being is a unique combination of the four mind styles (and the characteristics of those styles), considerable variation exists in ways of interacting with the environment. As stated above, alignment with the environment promotes fulfiliment and satisfaction, but misalignment can lead to frustration. The question then arises whether the higher education experience prepares the physical therapist to deal with natural variations of human interaction due to the differences in the therapist's and the patient's mind styles.

The Importance of style

"Some studies show that identifying a student's style and then providing instruction consistent with that style contribute to more effective learning" (claxton \& Murrell, 1987, p. iii). Since physical therapists are teaching patients daily, an awareness of natural variation 
in styles is important. As stated above, this has sometimes increased effectiveness of learning.

"Learning style can be an extremely important

element in the move to improve curricula and teaching in

higher education" (Claxton \& Murrel1, 1987, p. 1).

Increased effectiveness of the teaching and learning

environment in the physical therapy program is ultimately

important to the patient in the clinic.

"Students who learn about their own style achieve

higher grades and have more positive attitudes about their studies, greater self-confidence, and more skill in applying their knowledge in college courses generally" (claxton \& Murrel1, 1987, p. 54). This argument supports greater and better retention of the knowledge and skills base for the new physical therapist who enters the clinic. This also could potentially decrease patient-therapist relationship problems, thus enhancing treatment results.

\section{Research Questions}

Since various research reports indicate that matching learning styles and teaching styles results in either increased learning and/or a more positive attitude toward their learning experience (Claxton \& Murrell, :987; Dunn \& Dunn, 1978), I decided to evaluate mind styles in several physical therapy programs. I chose the teaching and learning theory course as my research setting because this course provides the skills and knowledge base for the 
educational tasks of the physical therapist. Research data examining various aspects of learning styles have been gathered in the teaching/learning setting. I decided that to be more consistent with other research, I would use a similar setting.

This study proposed to answer the following questions:

1. In fulfilling the teaching and learning theory competency, how do physical therapy entry-level programs address variation in mind styles?

2. Within the context of teaching and learning theory, how are objectives about styles expressed in the curriculum documents?

3. How are the various mind styles of the physical therapy students addressed in the learning environment within the teaching and learning theory or styles unit or course?

4. How do the teachers address their own mind styles in the classroom situation within the teaching and learning theory or styles unit?

5. How are the mind styles of the physical therapy students addressed in the $=$ lassroom situation within the teaching and learning theory or styles unit?

one way to answer question 1 is to look for four possible scenarios. The first scenario would be that styles information is taught and that strategies of three or four 
styles of the Gregorc model are used in the presentation. The second would be that styles information is given by a program but strategies of only one or two of the four styles of the Gregorc model are used in the presentation. The third would be that styles information is not given but strategies of three or four styles of the Gregorc model are used during the teaching and learning theory presentation. The last scenario is that styles information is not given and that strategies of two or less of the styles of the Gregorc model are used in the teaching and learning theory presentation.

The second question asks whether various style needs are being addressed by the course objectives. Each objective does not have to address several styles but all the objectives collectively address multiple styles' needs.

The third question considers the entire learning situation for the course being evaluated. Reading and writing assignments as well as lectures and other required projects were interpreted according to the style needs addressed.

The fourth and fifth questions rated the classroom environment relative to the teachers' and students' style needs. Lectures and group discussions meet different teacher/learner needs (Gregorc, 1982"; Gregorc, 1985). 
Propositions

The case study includes a list of ideas that should receive attention during the research process (Yin, 1989). Yin calls these ideas "propositions." The following list identifies those areas in teaching and learning that were given attention in this research.

1. Every human being is a unique combination of mind styles.

2. Every human being has a preferred way (mind style) of interacting with his/her environment and those persons who are in it.

3. Every human being at one time or another finds himself/herself in an environment or situation that is incongruent with his/her preferred mind style.

4. Understanding and accepting the uniqueness of our own mind styles combination is important.

5. Individuals who recognize and accept their own strengths and limitations are better equipped to deal with variations in their environmental and interpersonal surroundings.

6. Individuals who are aware of their own strengths and limitations may be more aware of the strengths and limitations of those with whom they interact.

7. Understanding and accepting the uniqueness of other individuals' mind styles combinations is important. 
8. The possibility exists that those who are aware of the strengths and limitations of those about them will develop into a team. All individuals' strengths complement one another.

9. Physical therapists deal with individuals whose unique mind style combination may be similar but are nevertheless unique and different from their own.

10. Physical therapists must develop treatment approaches and methods of teaching patients, patients' families, peers, and the community-at-large. These methods should be congruent with various mind styles met in such situations.

The above list of propositions was developed out of my study of mind styles. As this study progressed, only propositions $1,2,3,6,7,9$, and 10 emerged from my data. Those seven propositions are addressed in the case studies (chapters 4 through 7). Propositions 1, 2, and 3 are addressed in all four case studies under the headings "Teachers" Mind Styles" and "Students' Mind Styles." Propositions $6,7,9$, and 10 are addressed in case studies 2 and 4 (chapters 5 and 7) under the heading "Oral Presentations." Propositions 4, 5, and 8 could form the basis for further research in both physical therapy education programs and the clinical setting. 


\section{Purpose of the study}

The purpose of this research was to determine how physical therapy education programs teach physical therapy students to recognize and use Gregorc's mind styles as part of the learning and teaching process. This was studied within the course addressing the learning and teaching accreditation competency. The 1986 and 1991 competencies are:

As a professional health care provider the physical therapist will be able to apply basic educational concepts of learning theories in designing, implementing, and evaluating learning experiences in order to teach patients and families, and to design and implement community education in-service programs. (CAPTE, 1986, p. 29)

The program graduates are able to apply concepts of teaching and learning theories in designing, implementing, and evaluating learning experiences used in the education of patients, students, colleagues, and the community. (CAPTE, 1990, p. 15)

The physical therapist must be aware of disabilityinduced style changes as well as natural mind styles. When people are injured or otherwise rendered physically disabled they must interact with their environment differently, not only physically but mentally. They carry with them, however, their pre-injury mind style. All of their lives each has interacted uniquely with the environment. Much of the physical therapists' work is teaching patients, patients' families, and the community-at-large. If the physical therapist is to rate learning experiences, he/she must have a knowledge of "basic educational concepts 
of learning theories" (CAPTE, 1986, p. 29; CAPTE, 1990, p.

15). This knowledge would include styles.

\section{Importance of the study}

All graduates of physical therapy programs must be competent in the knowledge and use of learning theory (CAPTE, 1986; CAPTE, 1990). Since various learning style models include information processing and instructional preference facets, styles should be addressed by the physical therapy program. Learning styles models are also based on personality and interpersonal relationships. These models address other aspects of the therapist/patient as well as other of the many relationships within the healthcare system.

The benefit of this study to the field of physical therapy, because of the description and interpretation of the physical therapy learning environment, will be the recognition and encouragement of the development of natural mind styles. This would incluce the development of the unique collection of abilities that accompanies the individuai's combination of styles. By using an unfoldment or development of inherent strengths approach in physical therapy education, there will be empowerment of the individual. With that empowerment comes the possibility of an increased amount of complementary activities and flexibility between professionals. The result would be greater unity and a much stronger profession. 
The benefit to the field of education will be an expansion of research-based knowledge in mind styles. This could help teachers to reduce stress and psychological and emotional disequilibrium or trauma in schools on all educational levels. With the creation of an environment that provides for a variety of mind styles, more efficient and effective learning should take place.

\section{Definition of Terms}

Case: An individual program that has been studied by examination of the program's self study document, on-site curriculum files, and class handout materials. Also information has been gathered from direct classroom observation, mind style testing of teacher(s), and mind style testing of students.

Competency: A stated level of performance required of entry-level physical therapists. The student must meet this competency by the time of completion of the professional program.

Embedded: A descriptive term meaning that two or more units of analysis (data sources) have been examined to gather information about a program.

Form E: A part of the self study Report that lists all of the accreditation competencies keyed to course objectives. 
Learning environment: The combination of classroom and extra-classroom activities required during the teaching and learning theory unit or course.

Learning style: The combination of external behaviors of a person that are observable during the learning process (see Appendix B; Gregorc, 1984 ).

Mind style: The combination of indicators that reveal the whole system of thought and the unique qualities of the mind that are used by an individual when linking with reality (Gregorc, $1984^{\circ}$ ). In this document it will refer specifically to Gregorc's Mind styles concepts.

Natural style: The combination of behaviors being used in a situation that is congruent with an individual's dominant style(s).

on-site curriculum files: The files containing all course outlines, handout materials, and examinations used in teaching a course.

Role-based style: That combination of behaviors expected in the performance of a given task and being used, though they may not be congruent with an individual's dominant style.

Program: The sequence of professional level physical therapy education courses housed within a university or college.

Proposition: A statement that directs attention to something that is to be studied. It states an important 
theoretical issue and says where to find relevant evidence (Yin, i989).

Psyche: (And/or self or soul) consists "of the weightless and formless properties of purpose, perception, conception, apperception, love, and will" (Gregorc, 1982", p. v; Gregorc, 1985, pp. 44, 45).

Replication logic: Logic that is analogous to the logic used in multiple experiments. If the data of one or two cases supports that of another case, then replication is said to have occurred (Yin, 1989).

Self: (And/or psyche or soul) consists "of the weightless and formless properties of purpose, perception, conception, apperception, love, and will" (Gregorc, 1982", p. v; Gregorc, 1985, pp. 44, 45) .

Self Study Report: A written document submitted as part of the accreditation process. This document contains information on course objectives "keyed" to the physical therapy competencies (Form E).

Soul: (And/or psyche or Self) consists "of the weightless and formless properties of purpose, perception, conception, apperception, love, and will" (Gregorc, 1982", p. vi Gregorc, 1985, pp. 44, 45).

Style: In this document, will be used as the generic term when Gregorc's Mind styles concepts or learning styles is not clearly referenced. 
Unit of analysis: One aspect, characteristic, or part of a case that is analyzed for collecting information describing the case ( $Y$ in, 1989).

\section{style Models otilized in the study}

This study was based on Gregorc's Energic Model of Styles (Gregorc, 1985). Also included were discussions of McCarthy's (McCarthy, 1987) and Dunn and Dunn's models (Dunn \& Dunn, 1978). These three models are being widely taught by their developers. Gregorc's and the Dunns' models have been extensively researched in the last 8 years. These three models have been chosen because they represent the current work done in style and are among the most popular now.

Gregorc's (Gregorc \& Ward, 1977) model was chosen to study physical therapy education because it allows teachers a choice in the teaching style that they will use. It also allows the students a choice in the style in which they will learn. This investigation observed those choices of strategies in various classroom environments. A discussion of McCarthy's model is included because it teaches to all four styles in presenting a lesson but does not allow the teacher or student a choice of teaching or learning in only one style. The discussion of the Dunn and Dunn model is included because it stresses the preferred environmental, emotional, sociological, physiological, and processing 
inclination conditions for learning as well as media and teaching strategies.

A second reason for selecting the Energic Model of Styles was that, of the three models, this one is the most natural and comfortable for me. The case study design requires the researcher to be the data gathering instrument. It therefore was important to this study that I concentrate my efforts on developing my ability to interpret materials and behaviors and classify them into the various dominant styles. The Review of Literature highlights those facets of the Energic Model of Styles that I believe essential to forming the knowledge base from which application emanates. 
CHAPTER II

\section{REVIET OF LITERATURE}

Guild and Garger (1985) and Claxton and Murrell

(1987) give brief histories of styles awareness beginning with ancient times. They also indicate a declining interest in research in styles since Allport's and others' work in the 1940s through the early 1960s. They give as reason for this situation that style appeared to be a neutral factor in research on student success (Guild \& Garger, 1985). Claxton and Murrell (1987) indicate, however, that other research, upon which mastery learning is based, shows that almost any student can achieve successful learning if allowed appropriate methods and adequate time. Hilgersom-Volk suggests that "proper use of learning styles entails an attitude first, and then a method" (Hilgersom-Volk, 1987, p. 9). This chapter discusses some general considerations of style as well as compares three style models. The chapter concludes with a discussion of the teachers' and learners' responsibilities after becoming aware of variation in mind styles. 


\section{sources of style}

Hereditary, Innate, or Acquired

There appears to be wide acceptance of the idea that style is both inherited and molded through experience (Guild \& Garger, 1985; Claxton \& Murrell, 1987; Caine \& Caine, 1991). Kolb, on whose model McCarthy's 4MAT system is based, says that our learning abilities are molded by heredity, past experience, and present environmental demands (Wolfe \& Kolb, 1979).

Gregorc (1985) differs from the above authors. He introduces as a fourth force in style the Psyche, self, or Soul. He agrees that the environment affects persons and that genetics provides a support structure, but he believes that the Psyche is the dominant force in style. Although genetics are important in physical determinants he does "not believe an individual is genetically the combination of his parents' intellect, emotions, or other mental qualities" (Gregorc, 1985, p. 54).

Mind vs. Brain
Caine and Caine (1991) appear to equate the mind and the brain in their discussion of brain-based learning. Restak (1991) says that the brain and the mind are inseparable. Mccarthy (1987) appears to utilize at least the right/left hemispheric brain learning ideas in her approach. Rita Dunn (Dunn \& Dunn, in press) has only in recent years added "processing inclinations" to her other 
four stimuli groups. These processing inclination elements are global/analytic cognitive style, right/left hemisphericity, and impulsive/reflective. She apparently does not differentiate between the brain and the mind. Gregorc distinguishes between the brain and the mind.

The mind is the metaphysical instrument used by the Ego and self for building thought and creating reality. It responds to environmental stimuli and directs mental qualities such as physical sensation, intellect, intuition, and emotion. It also coordinates memories and constructs forms for revelation. The mind produces various time/space realities which permit the fixing of one's attention, for identifying oneself as an existing being, and for paying testimony to one's self. (Gregorc, 1985, p. 71)

The brain is a physical organ which serves as a concrete anchor and a primary organ of reception for inner and outer stimuli. It also serves as a transmitter to other parts of the physical body. The brain is not an originator, any more than the physical heart is the originator of emotions or love. Scientist and neurosurgeon Wilder Penfield states that the brain is the vastly complicated master organ within the body that makes thought and consciousness possible. (Gregorc, 1985, p. 72)

My model focuses upon the mind as an instrument for creating and experiencing the multiple aspects of reality. However, it does not consider the brain as the instrument for consciousness and decision-making. (Gregorc, 1985, p. 74)

Gregorc makes a clear cut division between the

functioning of the brain and the mind. He agrees with

Penfield that the brain is an integrator and a coordinator.

The brain processes the environmental (internal and

external) stimuli with which the mind builds thought and reality (Gregorc, 1985). This can be a crucial concept 
depending on whether one looks upon an individual as simply a stimulus/response organism or a reasoning being.

Having dealt with these two general factors, the field of learning styles can now be described. Some styles models emphasize personality characteristics; some, information manipulation; others, interpersonal relationships; and still others, importation of information from the environment.

The Onion Skin Model of Learning styles Claxton and Murrell (1987) have described various learning styles models by classifying them within one of four categories. For that classification they use the onion as a visualization of learning styles. Those models that deal with the innermost aspects of the learner, which characteristics are less flexible, are at the center of the onion. The next level of the onion that overlies the center are the models that are descriptive of characteristics that are more flexible. As one continues from the center of the onion to the surface through the four levels, each set of models describe characteristics of the learner that are more flexible than those in the underlying levels. The categories are, from inside to out: the personality models, the information processing models, the social interaction models, and the instructional preference models. Kolb's model, on which the 4MAT system is based, and Gregorc's model are classified as information processing 
models. The Dunns' model is not described by claxton and Murrell.

\section{Learning style vs. Mind style}

Learning style can be defined as those observable behaviors used by a person in a learning situation (see Appendix B). Mind style is defined as those observable behaviors used by a person when interacting with reality whether learning, teaching, supervising, administering, or interacting with life in general. Specific comparisons of the three models that I studied in-depth are undertaken in the following sections.

\section{Representative Philosophies of style}

The Dunns' model (Dunn \& Dunn, 1978) and McCarthy's 4MAT System (McCarthy, 1987) model are teaching/learning styles models because they are applied to the classroom teaching/learning situation. In recent years Mccarthy has been applying her model to industry. Although these two models promote self-awareness, they also encourage schoolwide adoption. This is helpful in continuing application because it creates a local support system. Gregorc does not encourage a schoolwide or school systemwide adoption, but rather individual adoption. He would not discourage schoolwide adoption if every teacher in the school voluntarily chose to adopt his model. This is 
consistent with his philosophy of providing freedom of choice to not only learners but teachers (Gregorc, 1985). To apply a style model easily an individual must feel comfortable and natural with it. If a model is imposed upon a teacher and that teacher does not resonate with that model or it does not make sense to her, she is limited to using it in a "cookbook" manner. When he does not naturally mesh with the model being used he is limited in the ability to sense whether the situation is progressing as it should or if it is going awry.

The following sections discuss the philosophy of the models named above. An awareness of the model developers' belief systems is extremely important because he or she is presenting his or her personal view of reality. To apply a model to my reality I also must have some idea of the authors' definitions of terms, psychological assumptions, and research methodologies (Gregorc, 1985). These are in part stated in the philosophy statements of the various models. Gregorc clearly states his philosophy, but the same is not true of the Dunns or Mccarthy. Below is a description of their philosophies based on their recommended practices and applications as noted in their publications.

Dunn and Dunn

I found nothing in the Dunn's publications specifying their learning style philosophy. I contacted Dr. Rita Dunn by telephone in September, 1991. She recommended 
that I acquire one reference and she sent me another from a book in press. Upon examining these items I found nothing specified as "philosophy." What was listed as "theoretical assumptions" appeared to approximate a statement of philosophy. With this in mind I contacted Dr. Dunn in October, 1991. I suggested this application and she confirmed that those assumptions were a statement of philosophy. The philosophy of the Dunn and Dunn model therefore includes the following:

1. Most individuals can learn.

2. Instructional environments, resources, and approaches respond to diversified learning style strengths.

3. Everyone has strengths, but people have very different strengths from each other.

4. Individual instructional preferences exist and can be measured reliably.

5. Given responsive environments, resources, and approaches, students attain statistically higher achievement and attitude test scores in matched, rather than mismatched treatments.

6. Most teachers can learn to use learning styles as a cornerstone of their instruction.

7. Many students can learn to capitalize on their learning style strengths when concentrating on new/or difficult academic material. (Dunn \& Dunn, in press, pp. 8, 9)

Mccarthy's 4MAT system

In examining Mccarthy's materials I also found no formal statement of philosophy. I contacted Excel, Inc. to discuss the philosophy of the 4 MAT system and they agreed to 
send materials to me. I received and reviewed these materials. They included a mission statement and several other statements from which I believe that the following paraphrased and quoted statements of philosophy may be advanced. Bernice McCarthy and Susan Morris also reviewed and approved this statement.

[1.] Every student can learn.

[2.] Every teacher can succeed.

[3.] Every school can be structured to realize individual potential.

[4.] 4MAT gives educators the skills to...

[a.] identify and teach core concepts.

[b.] recognize the fundamental connections between ideas.

[c.] make ideas relevant to students by relating them to individual lives and learning styles.

[d.] transfer knowledge across all disciplines and learning situations. (4MAT A Framework for Excellence in Education, [1991])

[5.] Educational roles can be transformed through teacher empowerment. "It enables teachers not only to develop new skills, but to expand them into the broader realm of curriculum planning and coordination" (4MAT'A Framework for Excellence in Education, [1991]).

[6.] 4MAT provides teachers with...

[a.] an interdisciplinary approach to teaching that begins with core concepts.

[b.] a clear, coherent basis for applying learning-styles theory in the classroom.

[c.] a new sophistication in peer coaching. 
[d.] a systemwide view of content planning and coordination. (4MAT' A Framework for Excellence in Education, [1991])

[7.] "The 4MAT model helps educators...

[a.] capitalize on learning style strengths.

[b.] empathize with diverse motivations of students.

[c.] draw on student experience to illustrate core concepts.

[d.] relate concepts to skills, making them relevant to life" ( $4 M A T^{\circ}$ A Framework for Excellence in Education, [1991]).

[8.] 4MAT training provides educators with... [a.] a deep understanding of the nature of learners and learning.

[b.] a clear vision of the conceptual essence and structure of content.

[c.] the instructional skills for communicating concepts to all learners. [d.] a classroom delivery method that addresses all learners. (4MAT Because Great Minds Don't Think Alike, [1991])

[9.] Teachers can "learn to invest content with personal meaning" ( $4 M A T^{\circ}$ Because Great Minds Don't Think Alike, (1991]).

[10.] Students can "learn to associate ideas with experience" ( $4 M A T^{*}$ Because Great Minds Don't Think Alike, [1991]).

[11.] It is important to address not only the four learning styles but the hemisphericity in each of those styles. 
[12.] The 4MAT System mirrors the process of learning.

[13.] Learning style testing is unnecessary if one teaches to all styles and both hemispheres in an appropriate sequence $\left(4 \mathrm{MAT}^{\circ}\right.$ Because Great Minds Don't Think Alike, (1991]).

[14.] "If, at any time or in any way, 4MAT becomes a hindrance to the authority and efficacy of the teacher, its use should be reconsidered" (Mccarthy, 1989).

\section{Gregorc}

Gregorc's ORGANON system rests upon the philosophical principle that "the primary purpose of life is to realize and actualize one's individuality, spirituality, and collective humanness" (Gregorc, 1982*, p. v; 1985, p.

44). From that the following tenets have emerged:

[1.] Every human being has universal qualities common to all other human beings.

[2.] Every human being is unique unto himself, physically, emotionally, intellectually, and intuitively.

[3.] Every human being is equipped to realize and actualize both his universal and unique qualities.

[4.] Every human being is goal-oriented to survive and be fulfilled physically, emotionally, intellectually, intuitionally, and spiritually.

[5.] Every human being exists within an outer, objective world which can promote or frustrate the reaiization and actualization of his universality and uniqueness. 
[6.] Every human being has an inner, subjective psychic life called the SELF, or psyche, consisting of the weightless and formless properties of purpose, perception, conception, apperception, love, and will.

[7.] Every human being has a mind which functions as a reality-creating instrument to align his inner psychic life with the outer world.

[8.] Every human being's purposes in life are fulfilled and experienced when a product and/or performance of that human being is expressed and manifested in the outer world.

The ORGANON System views the human mind as an instrument of thought that determines the ways realization and actualization will be achieved. To varying degrees, the mind is free to align or not align elements of the psychic life with the outer world. In this sense, every human being has degrees of free will or free choice to realize or not realize his goals and potential. When the outer world is in harmony with an individual's psychic life, that individual is said to be fulfilled, satisfied, and at peace. Lack of harmony and alignment can, however, retard, frustrate, and prevent

fulfillment. (Gregorc, 1982, p. v; Gregorc, 1985, pp. $44,45)$

Gregorc emphasizes that one must know oneself first

before attempting to evaluate others or the physical and

mental environment in which one finds oneself. It is basic

that we must "have all our own ducks in a row" before trying

to help others to deal with their own realities. The next

step is that one must know one's environment. An individual

must realize the demands that are being placed on his mental

equipment in order to function appropriately and

efficiently.

since every social unit, such as the family,

classroom, or workplace, "honors, reinforces, supports and 
facilitates specific mental qualities" (Gregorc, 1985, p. 68) a person should be able to sense if he is being "(1) accepted; (2) tolerated; (3) ignored; (4) converted; (5) exiled; or (6) extinguished" (Gregorc, 1985, p. 68). The caveat "Above all, do no harm" is stressed by Gregorc. It is a person's duty to make situations or environments that are not hostile to others' styles. By creating other than a nurturing environment one can do harm to another. When one becomes aware of variation in learning (or mind) styles, then one becomes morally responsible to discontinue being neutral or hostile to other individuals' styles combinations whether they are similar or different from one's own.

\section{Comparison of the Models of \\ Dunn and Dunn, McCarthy, and Gregorc}

Because my research used Gregorc's Energic Model of styles, I will restate each of his tenets and compare the other two models with them.

1. "Every human being has universal qualities common to all other human beings" (Gregorc, 1982", p. v). The philosophies of Dunn and Dunn, and of Mccarthy, do not appear to address the universal qualities of learners. They address the differences.

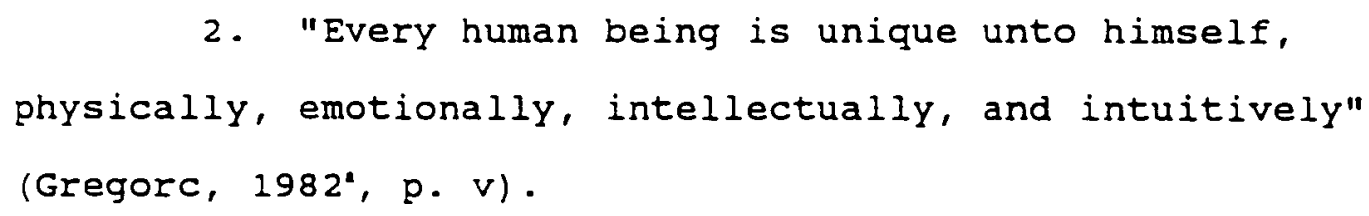


Dunn and Dunn's philosophy states that most people can learn and that all people have strengths but these strengths are very different from each other. Mccarthy's philosophy asserts that every student can learn and that addressing hemisphericity is important as well as individual learning styles.

3. "Every human being is equipped to realize and actualize both his universal and unique qualities" (Gregorc, $1982^{4}$, p. v) .

Dunn and Dunn believe that "many students can learn to capitalize on their learning style strengths" (Dunn \& Dunn, in press, p. 9). This leads me to believe that they also believe that there may be individuals who cannot capitalize on their strengths. Mccarthy indicates "students can learn to associate ideas with experience" (4MAT' Because Great Minds Don't Think Alike, [1991]). McCarthy appears to agree with Gregorc's above stated belief.

4. "Every human being is goal-oriented to survive and be fulfilled physically, emotionally, intellectually, intuitionally, and spiritually" (Gregorc, 1982*, p. v). Dunn and Dunn agree in part with this statement. They believe that most individuals can learn and that they can capitalize on their learning styles. Mccarthy fully agrees that all students can learn. Neither model appears 
to address the goal-oriented drive behind the intellectual fulfillment.

5. "Every human being exists within an outer, objective world which can promote or frustrate the realization and actualization of his universality and uniqueness" (Gregorc, 1982*, p. v) .

Dunn and Dunn believe that given responsive environments students can achieve higher test and attitude scores. They therefore would agree that unresponsive environments exist which may not promote the most efficient learning. Aside from the learning environment the Dunns do not appear to address this tenet. Mccarthy addresses the learning aspect of Gregorc's belief by saying that the school can be structured to promote the realization of the student's potential.

6. "Every human being has an inner, subjective psychic life called the SELF, or psyche, consisting of the weightless and formless properties of purpose, perception, conception, apperception, love, and will" 'Gregorc, 1982", p. v).

Neither McCarthy nor Dunn and Dunn address this tenet of Gregorc's philosophy. This is a logical finding since their models address only the learning aspect of an individual while Gregorc addresses many functions of the mind. 
7. "Every human being has a mind which functions as a reality-creating instrument to align his inner psychic life with the outer world" (Gregorc, 19824, p. v).

Dunn and Dunn address the learning aspect of this tenet through their belief that students can capitalize on their learning style strengths to adapt to new and difficult material. They support the concept that the teacher is to provide the appropriate (aligned) learning conditions for each student. McCarthy agrees with this through her belief that students can associate ideas with experience. She also believes that the $4 \mathrm{MAT}^{\circ}$ system mirrors the natural learning process. This is an alignment of the learning system with the learning process of the individual rather than as Gregorc has stated above.

8. "Every human being's purposes in life are fulfilled and experienced when a product and/or performance of that human being is expressed and manifested in the outer world" (Gregorc, 19824, p. v).

Dunn and Dunn deal with the above by their belief that students have different strengths and if those strengths are matched appropriately they can achieve higher test scores and attitude scores. They also indicate that students can learn to use those strengths. Mccarthy addresses this with students associating ideas with experience, that the environment can be designed to address 
learning style differences as well as hemispheric function differences.

The ORGANON system views the human mind as an instrument of thought that determines the ways realization and actualization will be achieved. To varying degrees, the mind is free to align or not align elements of the psychic life with the outer world. In this sense, every human being has degrees of free will or free choice to realize or not realize his goals and potential. When the outer world is in harmony with an individual's psychic life, that individual is said to be fulfilled, satisfied, and at peace. Lack of harmony and alignment can, however, retard, frustrate, and prevent fulfillment. (Gregorc, 1982*, p. v)

Neither Dunn and Dunn nor McCarthy appear to address the mind or freedom of choice. Both models describe only the learner and teacher and their environments. They teach the teacher to align the environment to the learner. Dunn and Dunn say that the environment should be tailored to each learner. Mccarthy (1987) says to teach in a variety of styles and hemispheric strategies to address all learners part of the total lesson time. Dunn and Dunn support their beliefs with research results demonstrating improved test and attitude scores (Dunn \& Dunn, 1978).

The philosophies of the Dunns, McCarthy, and Gregorc agree in many ways and contradict in others. The attitude toward diagnosis of learning style and prescription of learning strategy is approached differently by the three models. Each utilizes an instrument to determine an individual's style. The basic belief of the necessity of 
testing and who is to be tested differs among the three models.

Testing Instruments for style

The Dunns believe that all grade levels of students should be tested to determine their individual learning styles. They give as the reason for testing the assertion that one cannot observe all of the various aspects of style (Dunn \& Dunn, in press). McCarthy uses the Kolb Learning style Inventory and a hemisphericity test to increase teacher awareness of variation in learning styles. She is de-emphasizing student testing because of the $4 \mathrm{MAT}^{\circ}$ system's use of a variety approach to teaching. That approach uses an eight-step lesson that addresses four styles and both hemispheric modes in each of the styles during a lesson or topic (McCarthy, 1987).

Gregorc's instrument is used for adults and not younger students. He has designed it as a self-awareness tool (Gregorc, 1982'). He does not subscribe to testing as a mandatory step in addressing learning styles. He recommends the provision of a rich environment that offers a learner the freedom to choose between several different strategies of learning. Since the learner is not always functioning in his/her dominant style but may be in any of the three other of his/her points, he/she may choose the particular strategy he/she feels most like using at the 
time. This approach diminishes the chance of misdiagnosis of a student and a subsequent wrong prescription of learning activities (Gregorc, 1985).

The potential of misdiagnosis is a possibility because the learners may answer the questions reflecting the way they would like to be, what may be consistent with social requirements, or even what they believe the teacher wants to know. Should one prescribe strategies that were not congruent with the learner's particular learning preference at the time raises ethical questions of responsibility for lower levels of accomplishment. The $4 \mathrm{MAT}^{\circ}$ System matches each student's style approximately $25 \%$ of the time and then mismatches the other 758 of the time. With that approach misdiagnosis is not an issue. If less than optimal outcomes occur, perhaps the learners are unable to learn as easily as they might like during the mismatched phases of the lesson. Because the ethical aspect of the application and results of the use of mind styles is beyond the scope of this paper it will not be discussed any further.

Can All Teachers Teach All students With Equal Success?

The Dunns believe that most teachers can learn to use learning styles in their instruction. Said in another way, most teachers can meet all students' learning style needs (Dunn \& Dunn, in press). McCarthy says that every 
teacher can develop the instructional skills for communicating concepts to all learners. Gregorc advances the idea that one teacher cannot reach all learners (Gregorc, 1985). He suggests team teaching--two or more teachers of different styles, as a partial remedy for this situation. The team teachers will address a greater variety learning needs within the classroom through the provision of a rich environment.

The Use of Media in the Classroom

Dunn and Dunn (in press) describe the perceptual strengths of visual, auditory, tactual, and kinesthetic. They believe that new and difficult information should be presented first in the learner's strongest modality and reinforced through the secondary and tertiary modalities (Dunn \& Dunn, in press). This would imply that all media cannot be equally utilized by every learner.

I was unable to locate any comments on physical media in McCarthy's writings. She does advance various strategies such as role playing, skits, poetry, and movement activities which may be considered to address different styles of learning within the confines of her model. Gregorc says that all media are biased. A person who uses certain media rather than others uses them because of his/her own bias. The dominant concrete-sequential (CS) (see page 7 for the four mind styles) may prefer computerassisted instruction; the dominant Abstract-sequential (AS), 
40

reading assignments; the dominant Abstract-random (AR), group discussion; and the dominant concrete-random ( $C R$ ), games (see Appendices $A$ and $B$ ). The teacher may use only one or two media that are his/her preferences. If that is the case, those learners who are unable to utilize such media easily and naturally will be discriminated against within that classroom. The students should have the freedom to choose which media they prefer to use in a given learning exercise (Gregorc, 1985).

\section{Natural style vs. Role-based style}

"Natural learning style is synonymous with our personal intake style" (Gregorc, 1985, p. 179). This is the most comfortable style used by an individual. "Role-based learning style consists of patterns of behaviors and mental qualities which are socially expected to be displayed as part of the schooling process" (Gregorc, 1985, p. 179). These are the behaviors expected or demanded by our particular environments and may not be our natural style. A role-based style can be one's natural style if it is congruent with one's natural style. It is not always possible to live, learn, and work in one's natural environment. If this is the case, one must decide whether to be true to his/her natural style or to assume the rolebased style required at the time.

The Dunns encourage learning style diagnosis and prescription of learning activities congruent with the 
41

diagnosis. In this manner, then, the learners operate only in their preferred "natural" style. This is possible if the instrument accurately reflects the learners' style. If the individuals did not answer the questions accurately for one reason or another, the prescribed experiences may not reflect their natural style.

McCarthy's (McCarthy, 1987) 4MAT' system allows the learners to work in their natural style approximately 25 of the time and requires them to exercise their other styles the rest of the time. These other styles could be considered role-based styles for that particular individual.

\section{Flexibility of style}

Style flex is the ability of an individual to "align appropriate mediation channels with environmental demands" (Gregorc, 1985, p. 205). Gregorc believes that all points must be developed to be a balanced individual or person. This is to be done, however, within our natural limitations. our limits can be reflected by our scores on the Gregorc Style DelineatoriM. One can score as high as 40 or as low as 10 in a point, or mediation channel, with the four scores totaling 100. If, for instance one scores 36 (CS), 23 (AS), $18(A R)$, and $23(C R)$, then he/she should strive to develop to his/her maximum natural limits in each of his/her points. As the score increases so does the number of characteristics, abilities, or preferences increase. This 
then allows for a degree of natural style flexibility. He warns against prolonged efforts beyond one's natural limits. Working beyond the AR score of 18 , for instance, to the level of a score of $i s$ would be overachieving. Gregorc believes that overachieving in oñe puint causes underachieving in other points by drawing energy away from them. Prolonged exercising of talents beyond natural capabilities creates stress and a feeling of working in unfamiliar territory. It is not that this cannot be done successfully by a person, but prolonged exposure of oneself to that unnatural demand can be harmful.

Both of the above suggestions fall within style flexibility. The first describes natural style flexibility and the second, overachievement in style flexibility. Gregorc encourages the fulfillment of each person's potential in his/her style combination. The time spent living beyond one's natural limitations in any of his/her style points should be limitad.

The Dunns believe that most--and Mccarthy that all-teachers can learn to teach in any style that is demanded by a given situation. They do not address the stress issues inherent to that practice, however. Children have certain style needs that must be met within the learning environment. Implied above is that when one becomes a teacher an ability can be developed that, regardless of the natural teaching style, a teacher is capable of learning to 
be all things to all styles of learners. This is contrary to Gregorc's teaching. He advances the idea that not all teachers can reach students of all styles equally well. Our natural flexibility, therefore, is limited. He does indicata that most persons can learn the behaviors of their non-dominant points. Again, these behaviors might be applied in a non-natural way, beyond the comfort zone of the particular person's style ability.

Developing all of our gifts and talents within our style limits to become a whole person is important. It is equally important not to dwell on developing and using our gifts and talents beyond our natural capabilities for extended periods. The result of this could cause harm to ourselves as teachers and learners and harm to our students (Gregorc, 1985).

\section{Teaching style vs. Learning style}

"Teaching styles are behaviors, characteristics, and mannerisms symptomatic of underlying mental qualities used for presenting data to the environment" (Gregorc, 1985, p. 195). The mediation abilities are used for importing and exporting information from and to the environment and these are synonymous with the points CS, AS, AR, and CR (defined on page 7). A teacher then, if allowed to exercise his/her preference, will teach and learn in the same style (see Appendices $A$ and $B$ ). 
The Dunns and Mccarthy both believe that most teachers can learn to teach in a variety of styles. Gregorc also states that this is the case. However, he adds that the level of natural achievement or abilities in the various points are different. This means that although one can learn to teach in various styles, he/she will not be equally natural, comfortable, stress-free, or effective in all styles.

\section{Dominant style Characteristics}

Gregorc determined the mind style characteristics by observation, interview, and testing (Gregorc, 1985). He observed that not all gifted students in his school achieved at high levels. He then observed classroom activities and the structure of learning environments within the classrooms as well as interviewed the students. From those observations and interviews, he noted that there was a mismatch of some of the students' styles and the environmental demands. Those students who were matched achieved at higher levels than those who were not matched. These matches and mismatches were not intentional. From these early findings he continued his research and interviewed various educators and developed a style instrument. As part of the instrument development process, he was able to discover and list characteristics and preferences for each of the four mind styles (Gregorc, 1985). A partial list follows. 
concrete-sequential (CS)

The dominant cs teacher is most comfortable using hands-on types of materials such as duplicated sheets, computer-assisted instruction, programmed instruction, work/study experiences, field trips, and laboratory manuals. The dominant cs learner prefers a classroom in which the teacher is in charge and the information is presented in a logical order. They also want the information to be of a practical nature. Regarding classroom arrangement, they prefer not to be seated in a circle and looking at one another. The dominant $C S$ is a hands-on oriented learner preferring physical objects to abstract theories. They prefer short reading assignments over long ones and are concerned with precision and exactness. Attention to detail and the following of sequential instructions characterize their mode of work and study. They expect timely feedback with straight to the point criticism of errors. They also work with material as discrete parts rather than requiring that it all fit into a big picture (Gregorc \& Butler, 1984 ; Gregorc, 1985; see Appendices A and B).

\section{Abstract-sequential (AS)}

Textbooks, books, lectures, audiotapes, and guided individual instruction characterize the dominant As teacher. This lends itself to the preference for theories, documented facts, and abstract ideas using symbols to represent them. 
Unlike their dominant CS counterparts, they prefer the vicarious experience over direct concrete experience. This learner uses words as his tools to deal with all of reality. The dominant As prefers the lecture more than do any of the other learners. This is helped with their ability to handle words. They are able to deal with the big picture and place information into that scheme. They believe that the expertise that the teacher brings to the classroom is to be reflected upon and so do not like group discussion as a learning method. The dominant As utilizes analytical and evaluative strategies well. They like guidelines, not detailed sequential instructions (Gregorc \& Butler, 1984; Gregorc, 1985; see Appendices A and B) .

\footnotetext{
Abstract-random (AR)

The dominant AR teacher uses personal interviews, group discussions, television, movies, and assignments with reflection time. This is congruent with their attraction toward the experience of the abstract, subjective, and affective.

The dominant AR learner prefers a variety of approaches in learning rather than no option. They prefer a collegial learning experience with guidelines and little structure. They are subjective in the manner of their interpretation of stories, conversations, and movies. They are able to read body language and sense moods of
} 
situations. Since they see the gestalt they have difficulty with yes/no, black/white interpretations used in learning, and testing situations. These learners need to know why they are doing something rather than being told that it is for their own good. They do not, however, necessarily follow directions carefully. They may miss details such as time limits and deadlines. The dominant AR learner tolerates a high level of distraction very well. They can study with the television on surrounded with books, papers, and snacks (Gregorc \& Butler, 1984; Gregorc, 1985; see Appendices $A$ and $B$ ).

\section{Concrete-random (CR)}

The dominant $C R$ teacher will use mini-lectures with opportunity to explore the topic in addition to strategies such as games, simulations, problem solving, and independent study projects. This is natural to them because of their interest in problem solving, applications, and experiencing variety.

The dominant $C R$ learner does not mind taking risks or trying new things. They like change and do not like detailed sequential directions. They like teachers who both guide and instruct. Intuition is a characteristic of the $C R$ learner that gives them insight and answers without realizing the steps that their sequential counterparts will utilize. They prefer an environment that is rich in 
resources and readily available to them (Gregorc \& Butler, 1984; Gregorc, 1985; see Appendices A and B).

\section{Research Using the Gregorc Style Delineator \\ Wheeler (1991) reported her case study of a student} teacher and supervising teacher at the American Educational Research Association meeting in 1991. The student teacher tested as dominant $A R$ and the supervising teacher dominant CS. These two styles are polar opposites. She evaluated the case in terms of time and structure. The supervising teacher had everything well planned and organized, whereas the student teacher usually worked one day at a time. Those scheduling and organizing behaviors that were natural to the supervising teacher were difficult for the student teacher. Wheeler's conclusion was that it is not realistic to match student and supervising teachers. It also would be helpful to have an understanding of the natural behaviors of the various styles. Based on that knowledge, one might predict the interaction outcomes, thus enhancing the student teaching experience.

Thompson and O'Brien (1991) also reported their research on learning styles and achievement at the same meetings. This study was done at the post-secondary level. Their significant findings were that dominant CS, AS, and AR teachers gave higher grades to students over 25 years of age than to the younger students; the dominant $C R$ teachers did the opposite. They found no significant differences in 
achievement between students and teachers who were matched or mismatched.

Herbster, Abel, Hargrove, and Weems (1987) studied learning styles and models of teaching. They used the earlier instrument developed by Gregorc, the Transaction Ability Inventory. They matched the various models of Joyce and Weil to the four styles described by Gregorc. The matches were: (1) the Information Processing strategies to dominant CS; (2) the Behavioral systems models to dominant AS; (3) the Personal Family strategies to the dominant AR; and (4) the Social Family models to the dominant CR. Their findings were that the majority of dominant CS and AS preferred the Information Processing models, the majority of dominant AR preferred Personal Family strategies, and the majority of dominant $C R$ did not have a strong preference for any of the model families.

Abel, Herbster, and Prince (1989) presented their research on "Learning Style and Inservice Teacher Stress" at the Association of Teacher Educators in 1989. Their conclusions were there was a very limited relationship, if indeed any, between stress levels and learning styles.

A group of sixth-grade reading students were studied using four different learning style instruments including the Gregorc style Delineator ${ }^{T M}$. The Delineator is an adult instrument and so it is not surprising that they found it was not useful for decision-making (Atchison \& Brown, 1988). 


\section{Responsibility of styles Awareness}

An individual cannot claim ignorance once the concepts, principles, and philosophy of individual differences and the Energic Model of Styles become valid in an individual's mind. From that moment on, he cannot excuse or rationalize his dealings or relationships with others. He cannot excuse his ignorance or his responsibility for his attitudes and behaviors toward them either. He has accepted a transformation in consciousness. Therefore, he's no longer innocent. He is now personally accountable (Gregorc, 1985, p. 124).

\section{Summary}

This chapter has pointed out that regardless of one's view of reality, differences are evident in personality, information processing, interpersonal relationships, and instructional preferences. The observable behaviors are called style and reflect deeper thought-processing. A person's exhibited style may be either natural or false. When one's environmental demands are congruent with his/her style he/she will feel natural and comfortable, but when he/she is in a neutral or hostile environment he/she will experience varying degrees of stress and discomfort.

Researchers have demonstrated greater achievement and satisfaction with the learning experience when the learning environment and learners' styles are matched. Most important is that if an educator accepts the concept that there are natural differences between human beings, it becomes his/her responsibility to draw out those natural 
abilities of the learner. To do this he/she must create a nurturing environment. 
CHAPTER III

\title{
RESEARCH DESIGN AND METHODOLOGY
}

This chapter describes the procedure followed in identifying criteria and selecting physical therapy programs for this research. The data gathering process is also discussed.

\begin{abstract}
Research Design
Topic and Focus of the study

"In general, case studies are the preferred strategy when 'how' or 'why' questions are being posed, when the investigator has little control over events, and when the focus is on a contemporary phenomenon within some real-life context" (Yin, 1989, p. 13). As noted in chapter 1, this research tries to answer "how" questions.

After experiencing a variety of teaching strategies, none of which worked for all learners, and gaining an awareness of variation in mind styles, I determined to study mind styles application in physical therapy. As noted in chapter 1 in the "Purpose of the study," the accrediting body evaluates physical therapy programs regarding the level of their students' achievement of a competency. The competency I am dealing with addresses teaching and learning 52
\end{abstract}


theory. To do this I wanted to examine what the physical therapy programs indicated to the accrediting body and the students, in writing, about coverage of styles information while presenting teaching and learning theory. I wanted to witness what information was given verbally and the strategies and environment used for delivery. I also wanted to know if the teachers were addressing their own as well as their students' mind style needs.

These various interests required evaluation of a variety of aspects of each program. To address these interests and to answer all of my research questions (see page 10) I chose to implement an embedded design. This design is used in a case study when gathering information from several sources to answer each research question (see "Definition of Terms" in chapter 1).

Because there are two different entry levels into the field of physical therapy, I decided to study both levels. To accomplish this I needed to include baccalaureate and post-baccalaureate programs. These factors required the implementation of the multiple-case (embedded) design (Yin, 1989). To reduce chance bias, I decided to study two programs of each type. 
Selecting the Research setting

Establishing criteria for

subject selection

Several problems came to mind while deciding which

programs would yield the greatest amount of information.

One of the problems was currency. Written materials

submitted for accreditation are submitted every 5 to 8 years

depending upon the number of years of accreditation a

program is granted. I wanted to have the most current

information available so the criterion of impending

accreditation review was instituted. This would insure that

the self study documents would be up-to-date.

I contacted the Commission on Accreditation in

Physical Therapy Education to find out which physical

therapy programs were preparing to go through the

accreditation process. At that time there were about 120

accredited programs. I explained my research interests to

the Associate Director of the Commission and she furnished a list of programs to be visited in 1990 and 1991 . She also

sent a current listing of the accredited programs. From

those documents I compiled a list of programs being visited

by an accreditation team in fall of 1990 or later as

potential research sites.

I decided that another criterion of i subject

program should be that they state several objectives that

address the education competency. The present accreditation standards, which state the competency, are slated to be 
replaced by new standards. The "new" standards also state the same competency in different language but the same spirit. For simplicity I decided to study only programs being accredited under the "old" standards. This eliminated only three of the programs. My contact list comprised 34 programs, including four new ones.

A third criterion that I established was that the subject program would have a course specifically addressing the education competency. This would make data gathering a more efficient process timewise.

The last criterion was that the course be taught during the summer or fall term of 1990. This was done to expedite completion of my dissertation.

I decided early in the design process to visit programs during the presentation of styles materials. If they did not teach that topic I would visit them during the presentation of teaching and learning theory. With these criteria established, I began contacting the potential subject programs.

\section{Establishing contact With the Programs}

I wrote a letter to the chairpersons of the 21 baccalaureate level programs and the 13 post-baccalaureate programs. The letter introduced myself, briefly explained my research, and informed them of my criteria. It also told 
them that in about two weeks I would be contacting them by telephone. The letters were mailed July 11, 1990.

I beqan to make phone calls to the potential subject programs on July 23, 1990. During my telephone conversations it became apparent that the third criterion requiring a specific course devoted to the education competency was too limiting. A few programs had such a course and many had a block of one course covering that material. Some programs included teaching and learning theory with the information that would be taught to various groups of individuals. I decided to add to this criterion a course containing a block of education information within it.

Many programs that I contacted said they included styles information but the presentation schedule did not fit into my timeframe. I could include in my study only two programs that presented such materials. By the end of August, 1990, three programs, two baccalaureate and one post-baccalaureate, had agreed to participate in my research. I continued to try to secure one more postbaccalaureate program but was unable to do so. This was because I could not meet their class schedules or they did not fit my criteria.

In December, 1990, after I had completed my data gathering at the above three physical therapy programs, I decided to return a call to one of the program chairs. He 
had said, when I initially talked to him, that if I really needed his participation I could check back with him. When I did so, the program's site visit had passed and he said that his program would have time to help in my study. I visited that program in January, 1991.

During the scheduling process I found that I would not be able to attend the first two presentations at the subject I program. My original research design required that I observe, take notes, and audiotape the sessions. I asked the chair of the program if he could re-schedule the lectures and he said that he would try. A short time later I received a telephone call from him and he said that he would be glad to videotape those sessions. I could then continue the videctaping of the sessions after my arrival. This sounded more efficient because I could review what I may have missed in teaching styles and strategies while taking notes.

I called the other two scheduled physical therapy programs and asked if I could videotape their presentations rather than audiotape and they agreed to the change. This change was also approved by the Andrews University Human Subjects Review Board.

The telephone conversations covered such items as housing, transportation, and videotaping capabilities of the program. Also discussed were the university's equivalent of a human subjects review process. 
There was considerable interest in my research. One of the programs at each academic level asked that I make a presentation of the Energic Model of Styles. This was a scheduled part of the class. I agreed to do so after completing my data gathering. Two of the four programs scheduled an optional attendance lecture for the students to hear about the model. At one baccalaureate level and one post-baccalaureate programs I gave an additional presentation to the physical therapy faculty.

\section{Addition of Program Using New standards}

Upon arrival at one of the post-baccalaureate programs when I asked for the self study materials, I was told that they were not completed. This was because since I had arranged to study his program the chairperson had applied and been approved for review under the new standards. I again compared the education criteria of the "old" and "new" standards. I determined that the spirit was indeed the same although the wording was altered somewhat. I consulted with my dissertation chairperson by telephone. During this conversation I assured him that the spirit of the two criteria were the same. He advised that I include this program in my study as previously planned. 
Data Gathering Techniques

self study and Handout Materials

Upon arrival at the various physical therapy program offices I made copies of the self study materials pertaining to the education competency. I also collected copies of handout materials from the teacher of the class in which I was gathering data. I needed these materials to answer the question on how the objectives about styles were expressed. They also answered in part how the teachers' and students' mind style needs were addressed in the learning environment.

Before I started to write my case studies, I reviewed these materials. I noted in the margins next to various objectives and activities what mind styles were being addressed. This gave me a picture of what the programs were stating in writing to the accrediting body and the students. Dauna Browne ([1986]) stated that "researchers interpret what they see" (p. 6). The margin notes were my interpretations of how the programs were addressing mind styles while presenting teaching and learning theory.

\section{Videotaped class sessions}

I was given time to set up the video camera before class started. During the first class meeting I attended I was introduced. The teacher briefly stated what I was doing and why I was there. He also told the students that I would be given time to explain more to them. 
While I videotaped, I took minimal notes. I reviewed the videotapes twice after I returned from my data gathering trips and took notes. The notes included type of information given as well as strategies used, classroom design, and how the teacher performed in the class. The classroom design, strategies used, and the teachers' actions were interpreted according to the style needs being met or style behaviors used. This interpretation helped to answer the questions of how the teachers' and students' style needs were being addressed in the classroom situation and the learning environment.

I visited Programs one, Two, and Four twice each. The original design of this study called for videotaping samples of student presentations of projects, if any were done. Programs one and Four did have student project presentations so I returned to those campuses to videotape a few of those presentations. Upon re-examination of my research questions, I noted that the student project data did not directly relate to any of them. At that time I decided that I would not use those data, thus those videotapes were never evaluated.

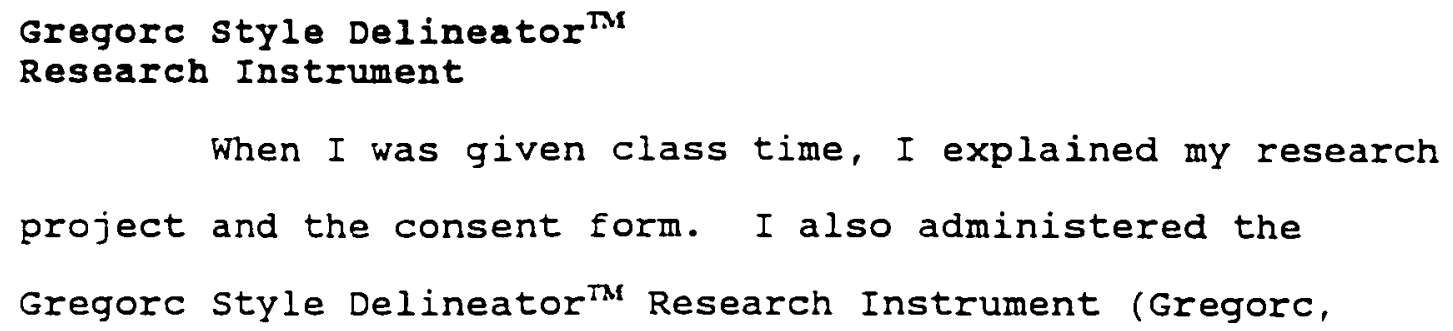


$\left.1982^{\circ}\right)$. This instrument was given only to the students and teachers of the class who volunteered. All eight teachers involved in my data gathering in the four programs volunteered. All the students in three of the four programs volunteered and all but five in the fourth program volunteered. This gave me a total of 147 students out of 152 for my data base.

Gregorc tested his instrument's reliability in internal consistency and repeatability for each of the four styles. The internal consistency standardized alpha coefficient scores ranged from 0.89 to 0.93 . The testretest correlation coefficients ranged from 0.85 to 0.88 , indicating stability of results over time. The predictive validity study findings ranged from $r=0.55$ to $r=0.76$ (Gregorc, 1984"). To determine the predictive validity, he gave 110 subjects the Delineator and an attribute list of the four styles' characteristics randomly arranged. Their selection of attributes were then correlated with their Delineator scores (Gregorc, 1984).

Sewall (1986) evaluated Gregorc's instrument and had little that was positive to say about it. He questioned Gregorc's validity and reliability studies and believed that they do not measure what Gregorc purports that they do. Joniak and Isaksen (1988) also consider the instrument weak. O'Brien (1990) also tested the Delineator, but did not find results similar to those of Sewall, or Joniak and Isaksen. 
He did not, however, have the high numerical findings of Gregorc. He did find that the internal consistency of the four scales was within acceptable ranges. The Gregorc style Delineator ${ }^{\mathrm{MM}}$ is a self-awareness instrument (Gregorc, 1982') and this research was an awareness study.

The videotape and the Delineator scores would help me to answer the questions about how the teachers' and students' mind styles were addressed in the classroom situation. The Delineator scores, with the self study and handout materials, and the videotape notes would help me to answer the questions about how the teachers' and students' style needs were addressed in the learning environment. All of the data would provide answers to the question about how physical therapy education programs address variation in mind styles.

\section{Data Analysis}

\section{Teachers' Mind styles}

The dominant styles of the teachers were compared to their presentations in the videotapes. Dominance is determined by achieving a score of 27 or higher on the Gregorc Style Delineator ${ }^{\mathrm{TM}}$ Research Instrument. This was done to determine if they were using teaching strategies congruent with their mind styles as shown by their delineator scores. To determine that, as I viewed the videotape I would note particular strategies, materials, and 
audiovisual aids used by the teacher. Based on my understanding of the Energic Model of Styles, I categorized that information as a particular style and made a note of it. As I wrote the case studies I reviewed my notes and compared the style of the particular strategy with that instructor's dominant style(s) (see "Teacher(s)' Mind Style(s)," chapters 4 through 8 ).

\section{students' Mind styles}

The 147 student participants' styles, $96.71 \%$ of all students asked to participate, were analyzed by school. I listed the dominant styles and combinations of dominant styles. Percentages of the class based on combinations of dominant styles, including each of the four dominant styles, were calculated--for instance, all dominant cs styles plus combinations of two or more dominant styles including dominant cs within a class. The teaching strategies were compared with the preferred learning strategies of that particular student style.

\section{The self study}

Form E

The Form E (see "Definition of Terms", chapter 1) was used primarily as a guide. It helped determine which course outlines should be collected for use in this research. It listed course numbers and titles addressing the educatinn competency. 
Course outlines

Each objective listed on the course outlines was interpreted according to the style requirements, behaviors, or needs used to achieve the objective. Then I determined how many of the four styles' needs were being addressed by the education materials information, activities, and required reading and projects. Test design styles, objective versus subjective, were not included as part of this study.

\section{gandouts}

The handouts were reviewed as were the course outlines described above. An interpretation of the number of styles being addressed by the various activities and assignments of the course was made.

\section{Oral presentations}

I reviewed the videotapes after I returned from my data gathering trips and took notes. The notes included type of information given as well as strategies used, classroom design, and how the teacher performed in front of the class. The classroom design, strategies used, and the teachers' actions were interpreted according to the style needs being met or style behaviors used. This interpretation helped to answer the questions of how the teachers' and students' style needs were being addressed in the classroom situation and the learning environment. 
My dissertation chairperson reviewed those notes. He told me that I needed to review all of the videotapes again and be more detailed in noting my observations of what was transpiring in the class presentations. The videotapes of the four programs totalled more than ten hours viewing time. Upon re-evaluation of the revised notes my dissertation chairperson approved them and allowed me to begin my case study reports (chapters 4 through 7).

Teachers in Programs one and Four were interested enough in styles that they scheduled time for me to present the Energic Model of styles in the teaching and learning theory classes. Program one otherwise did not present styles information while Program Four had the most information on styles in its course. It was during my second visit to those programs to videotape student projects that my lecture was scheduled.

\section{Audiovisual Aids}

The use of handouts, slides, videotapes, overhead transparencies, and even reading assignments was noted and interpreted for comparison with the teachers' and students' styles. This made it possible to ascertain to what degree the style needs were being met.

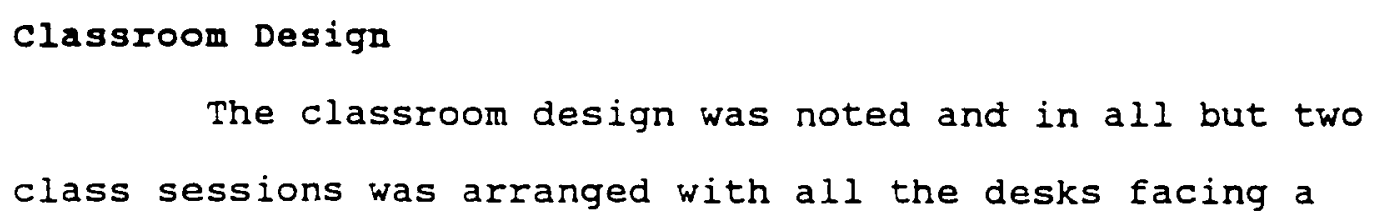


chalkboard in the front of the room. The teacher taught from the front portion of the classroom. If an overhead projector was used, the screen was at the front in the center or to one side. The two classroom exceptions used a circular arrangement of the students' and teacher's desks with all facing inward. These two formats were interpreted as to the style behaviors being elicited.

Each primary instructor reviewed and approved a later draft of their own program's case study. They were given the right to edit as they believed necessary. None of the primary instructors added or deleted any information. 
CHAPTER IV

\section{CASE STODY I}

I visited this baccalaureate physical therapy program on two separate occasions for data gathering. In my initial telephone contact with the program chairperson, he told me that styles information was not given to the students. The primary presentation of teaching and learning theory was made in the "Current Issues" class that met three times the first week I attended. The program chairperson, who also was the primary instructor in the course, videotaped the first two sessions before my arrival on campus. I videotaped the third session. I was given time to present my request for the students' participation in this research. The chairperson scheduled me to make a presentation of the Energic Model of Styles after completion of my data gathering. I gave that lecture during my second visit to the campus.

All of the 34 students and the three instructors in the education and teaching theory portion of the class volunteered to participate in my research. Each signed an informed consent and completed the Gregorc style Delineator ${ }^{M}$ Research Instrument (Gregorc, 1982 ${ }^{\circ}$ ). Teachers 
at this program have been called Dr. Allen, Ms. Boone, and Ms. Clark. These are fictitious names that I chose from the local telephone directory.

\section{Overview}

All the students and the three instructors in the teaching and learning theory portion of the course participated in my research. The primary instructor was a dominant ASCS; the other two instructors were dominant in CS. All the instructors used the lecture strategy, one of whom included other strategies that addressed all four styles' needs. of the other two instructors, one included strategies within her lecture that met dominant cs needs and the other included strategies that addressed CS, AS, and AR needs (see Appendices $A$ and $B$ ).

Over one half of the students were dominant in CS or in a combination of styles including CS. Less than one fourth of the students were dominant in a combination of styles including AS. Just over one half of the students were dominant in $\mathrm{AR}$ or in a comination of styles including AR. Almost one third of the students were dominant in $C R$ or in a combination of styles including $C R$.

The following outlines, in detail, how the various mind styles were addressed in the teaching and learning theory unit. 
Teachers' kind styles

Dr. Allen

Dr. Allen, the primary instructor and department chairperson, tested as dominant ASCS (Data Vol. 1, p. 86). The dominant As preference in teaching strategy is the lecture, which is what he used for all of his presentations included in this research (Gregorc, 1985). This dominance was also demonstrated by his going over the complete schedule for the semester. This gave the students the "big picture" of the course (Gregorc, 1985). This also could be interpreted as meeting his dominant cs point by giving the plan and time frame for the entire course (Gregorc, 1982"). He gave the students a rather complete handout requiring little or no notetaking. This would be in accordance with his dominant CS point (Gregorc, 1982"; Gregorc, 1985). He did not lecture, however, from behind the table or lectern in the front of the room. He held his notes in his hand as he lectured (Data Vol. 1, p. 90). He stood in the center aisle and moved up and down the aisle between the first two or three rows while lecturing (Data vol. 1, p. 39). I believe that this non-separation from his students was an expression of his AR point, which scored in the intermediate strength range (Data Vol. 1, p. 86). 
Ms. Boone

Ms. Boone, who lectured on audiovisual materials, scored as à dominant CS (Data Vol. 1, p. 87). She scored only one point below the minimum score for dominant as but still used the lecture method in her presentation. She stood either beside or behind the front table close to the overhead projector during her entire lecture (Data Vol. 1, p. 98). Ms. Boone illustrated each point with "good" and "bad" examples of transparencies and "good" examples of slides (Data Vol. 1, pp. 96, 98). She described and practiced proper behavior when using visual aids. Following the rules of behavior in her use of the visuals (Data vol. 1, p. 98) would be a dominant CS characteristic of performing in the acceptable way (Gregorc, 1982').

\section{Ms. Clark}

Ms. Clark was also dominant CS (Data Vol. 1, p. 88). She distributed detailed notes to the class which would be an expression of her dominant point (Gregorc, 1982'). She stated she could not cover all the material and objectives in the handout. This would be a statement of her completion standard and thus fulfill a dominant CS need (Gregorc, $\left.1982^{4}\right)$

Although her As score was just above the middle of the intermediate level, she still used the lecture method (Gregorc, 1985). Ms. Clark used transparencies during her 
71

presentation. She did allow student comments and responded to them--an AR behavior.

Ms. Clark had arranged that the students would watch a video the day before her presentation. She referred to this video during her lecture and some students also commented on it. The use of video would be an expression of her AR point (Gregorc, 1985). Her AR score was slightly higher than her AS score, but still in the intermediate range (Data Vol. 1, p. 38 ).

\section{students' Mind styles}

One hundred percent of the 34 students of this baccalaureate program participated in my research. See Table 1 for the distribution of styles within the class (Data Vol. 1, pp. 108, 109).

On examination of Table 1 one notes that $61.76 \%$, or 21 students, of the class tested as dominant in one or a combination of styles including concrete-sequential. only 17.65\%, or 6 students, tested as dominant in a combination of styles including abstract-sequential. Nineteen students, or $55.88 \%$ of the class, tested as dominant in one or a combination of styles including abstract-random. Ten students, or $29.41 \%$ of the class, tested as dominant in one or a combination of styles including concrete-random. 
Table 1

Dominant styles of Program one students

\begin{tabular}{||l|l|c|}
\hline One dominant style & $\mathrm{n}$ & 8 \\
\hline Concrete-sequential & 8 & $23.53 \%$ \\
\hline Abstract-random & 5 & $14.71 \%$ \\
\hline Concrete-random & 1 & 2.948 \\
\hline Two dominant styles & 6 & 17.658 \\
\hline CSAR/ARCS & 1 & 2.948 \\
\hline ASCR & 4 & 11.768 \\
\hline CSAS/ASCS & 5 & 14.718 \\
\hline CRAR/ARCR & 1 & 2.948 \\
\hline ARAS & 1 & 2.948 \\
\hline CSCR & 2 & $5.88 \%$ \\
\hline Three dominant styles & & \\
\hline CSCRAR & \multicolumn{3}{|l|}{} \\
\hline
\end{tabular}


None of the students tested as dominant in only abstract-sequential for which the lecture format is preferred. Three of the six with abstract-sequential in combination with another style scored highest in AS. One of the six scored equally with another styla. The remaining two scored higher in the other style than they did in AS. This leaves $11.76 \%$ of the class, four of 34 , for whom lecture might be a preferred style of learning.

The structure provided by lecture outlines and schedules should have addressed the CS needs of $61.76 \%$, or 21, of the students. The personal experiences and videotape should have met the preferred AR needs of $55.88 \%$, or 19 , of the students (Gregorc, 19824; Gregorc, 1985). The development of the presentations, as an independent study, should have met the $C R$ needs of $29.41 \%$, or 10 , of the students (Gregorc, 1982*; Gregorc, 1985).

One must remember that even if not dominant in a particular mind style, one will still have some characteristics of that style. This means that some nondominant AS students might still prefer lecture naturally. one also must consider, however, that after reaching this educational level the students who are not dominant in the same style as is being used in teaching have probably "learned to play the game of school." 


\section{The self study \\ Form E}

The Form E (Data Vol. 1, p. 1) lists eight courses as including information, practice of teaching, and learning theory or both. The primary course covering teaching and learning theory was "Current Issues in Physical Therapy." This course entry lists 19 of its objectives as directly addressing the physical therapy education competency.

\section{Course outlines}

The course outline listed 27 objectives for the "Current Issues" education and teaching portion. The above discussion of the Form E noted 19 of them. Dominant CS mind qualities were addressed by more objectives than were the combination of dominant CS and dominant AS mind qualities. Both the dominant $A R$ and dominant $A S$ mind qualities were addressed by the fewest objectives.

\section{Handouts}

Dr. Allen's handout (Data Vol. 1, pp. 67-71) on "educational techniques" describes 14 techniques and six subtechniques. Of those 20 techniques and subtechniques the most would appeal to dominant CS, dominant AR, and dominant CR styles. Fewer techniques would appeal to the two dominant styles CS and AS, to the two dominant styles AS and $A R$, to the three dominant styles $A S, A R$, and $C R$, and to the four dominant styles CS, AS, AR, and CR. The least number 
of techniques would appeal to the two dominant styles AS and $C R$, to the three dominant styles CS, $A S$, and $A R$, to the dominant AS style, to the dominant AR style, and to the two dominant styles $C S$ and $A R$. Some techniques described were the colloquy, the demonstration, the speech or lecture, the seminar, and the field trip.

Dr. Allen also distributed the criteria for the oral presentations (Data Vol. 1, p. 73) required in this class. Various criteria addressed the dominant styles of CS, AS, and AR. If one were to include the use of a variety of strategies used in addressing those three styles, it also could be said that dominant $C R$ needs for variety were being met. One of the basic needs of the dominant cs was met by the provision of standards or guidelines for completing the assignment (Gregorc, 1982').

The "Presentation Evaiuation Form" (Data Vol. 1, p. 74) was now also provided to the students. The statement of the standards of evaluation addresses the dominant cs needs (Gregorc, 1982'). This form also provided for evaluation of the visual and auditory modalities used in the presentation. The "Presentation Schedule" (Data Vol. I, p. 75) was given to the students. This addressed dominant cs desires for being able to plan on a set deadline for the task (Gregorc, 19824).

Ms. Boone did not provide any handouts for her lecture. She used overhead transparencies and slides. 
Ms. Clark's handout "The Physical Therapist as a Clinical Educator" (Data Vol. 1, pp. 76-85) had seven objectives, each of which addressed various dominant styles' needs. All four styles were addressed at least once each in that list of objectives. The first three topics of her outline, including definitions and descriptions, addressed the needs of the dominant CS individual. The fourth topic "Clinical Education/Teaching" addressed the needs of the dominant CS, AS, and AR. The last topic in the outline, "Issues in Clinical Education," addressed the needs of all four styles.

In summary, the objectives listed in the course outlines addressed the dominant CS, AS, and AR styles' needs while Dr. Allen's handouts addressed the needs of all four dominant styles. The objectives listed on Ms. Clark's handouts also addressed all four dominant styles' needs at least once. Ms. Boone did not distribute any handouts for her lecture.

oral Presentations

Dr. Allen

The physical therapist as educator was the topic addressed during the period of data gathering. During the first sessions, Dr. Allen, the first instructor for this topic, began by giving an overview of the entire course. The overview included discussing the topics and speakers (Data Vol. 1, pp. 89-91). This could be an expression of 
both his dominant AS "big picture" and CS, plan and schedule, points (Gregorc, 1982*; Gregorc, 1985). Another expression of his dominant cs point was that he reviewed the details of applications and practicality of each topic (Gregorc, 1982'). He made personal comments about some of the speakers (AR--[Gregorc, 1982*]). The course will include lectures (AS--[Gregorc, 1985]), a field trip (CS-[Gregorc, 1985]), and student presentations. After the introduction, he asked: "Is everybody asleep?" He then placed the schedule materials on the table and piuked up his lecture notes. At this point he announced that the topic was roles of the physical therapist (PT) as an educator gesturing briskly on the word "roles" (Data vol. 1, p. 91). This might be interpreted as AR behavior because of his natural use of gestures (Gregorc, 1982').

Instead of listing the persons comprising the "audience" of the physical therapist, he elicited it from the students and commented appropriately (Data Vol. 1, p. 92). This interaction could be considered AR behavior (Gregorc, 1982'). He checked his notes to insure that none of the "audience" members were left out and said: "that's about all I had." This attention to detail could be related to his CS dominance (Gregorc, 1982"). One should note that he appeared willing that any who wished to speak be allowed the opportunity, by a last question of: "Any other comments about that?" This allowance for class member participation 
might be interpreted as AR behavior (Gregorc, 1982'; Gregorc, 1985).

Dr. Allen then gave nine steps in providing an educational program (Data Vol. 1, pp. 92-95). This could be considered an expression of dominant AS "big picture" and dominant CS detailed sequence behavior (Gregorc, 1982*; Gregorc, 1985). During this part of the presentation he gave the example of a class that he took that required using this process. This example could be interpreted as AR behavior, sharing of personal experience, or as cS behavior of practical application (Gregorc, 1982*). When he finished the nine steps he said that each step had to be evaluated as it is developed. This is done to be certain that it fits in with everything else. This giving the "big picture fit" would be a demonstration of his dominant AS point (Gregorc, 1985). He used humor at times during his presentation which would be evidence of the AR point (Gregorc, 1982').

At the second session Dr. Allen introduced Ms. Boone by telling the students how to find Ms. Boone's office. He also reminded them that they would be required to prepare slides, overhead transparencies, or use some other educational technique to supplement their presentation lectures (Data Vol. 1, p. 95). This can be interpreted as dominant CS practicality (Gregorc, 1982'). He also described the three one-half hour sessions for the day's class. This could be interpreted as dominant As "big 
picture" behavior (Gregorc, 1985) and dominant CS predictability behavior (Gregorc, 1982*).

\section{Ms. Boone}

Ms. Boone used the lecture (dominant AS) approach to the class. She scored one point below dominant in As but scored dominant in CS (Data Vol. 1, p. 87). She described the function of her department and her job within that department. She also asked about the type of student presentations to be done and what they entailed. This could be interpreted as CS practical application (Gregorc, 1982'). She then started her discussion of overhead transparencies. She emphasized how quick and easy it is to make transparencies. She used several examples of "good" and "bad" transparencies and gave some principles in format design. The only mention of styles in the course to date, aside from Dr. Allen telling the students of my research and scheduled lecture to the class, was one of Ms. Boone's examples. Even at that, it was used only as an example of an overhead and not explained (Data Vol. 1, p. 96). At this point (Data Vol. 1, p. 97) Ms. Boone gave two purposes of using transparencies and then asked for questions. She noted the requirements and cost if her department or she were to make transparencies. She also gave alternate sources for help with transparencies. This 
would be dominant CS qualities of setting of standards and practicality (Gregorc, 1982').

She now asked for the slide projector to be switched on and began her discussion of slides. She gave some principles for slide format design and stated what supplies were available in her department. Dr. Allen asked Ms. Boone to describe the speaker's behavior while using visuals. She had been using those behaviors while doing her presentation (CS--expectations [Gregorc, 1982']) but did not mention them until this time (Data Vol. 1, p. 98).

$$
\text { Dr. Allen }
$$

Dr. Allen, continuing the second session, emphasized the purpose of Ms. Boone's presentation as a help to the students in improving their lectures with higher quality visuals. This could be dominant CS behavior (Gregorc, 1982'). In reviewing the schedule for the afternoon Dr. Allen discovered that the students had been informed of a different timetable. Some students had made plans for the last one-third of the scheduled class. Because of this, he accelerated his lecture so that the students could view the scheduled videotape. This was evidence of the $C R$ behavior of adaptability to change and of AR behavior of concern for others' needs (Gregorc, 1982').

Dr. Allen reviewed the oral presentation assignment sheet. During this description he referred to some past 
81

presentations. This is demonstrative of real life

situations and is attributable to dominant CS behavior (Gregorc, 1982'). He then described the educational

techniques in the handout (Data Vol. 1, pp. 100, 101). After this presentation, the students viewed a videotape of clinical education "do's" and "don'ts" (Data Vol. 1, p. 101). There was a handout for both parts of the videotape so the students would not have to take notes. Handouts are a product of dominant CS behavior and the videotape, AR behavior (Gregorc, 1985). The videotape completed the second session.

Ms. Clark

Ms. Clark conducted the third session and the topic was the physical therapist as clinical educator. She stated she would be unable to cover all material in handout (CS-predictability (Gregorc, 1982^]). She noted the source of the definitions of terms in the handout. The latter is evidence of her dominant cs style of using words as precisely defined (Gregorc, 1982"). She used an overhead transparency to illustrate responses to cues (Data Vol. 1, p. 102). She also asked the students if they had experienced certain situations. This relating of oneself to a situation would be evidence of $A R$ behavior and application to "real life" CS behavior (Gregorc, 1982"). 
Ms. Clark discussed chaining that was not in the handout. Chaining is a strategy that can be used in clinical instruction. It involves the clinical instructor (CI) helping the student to interpret a situation, a cue given to the patient, or a response. The response can be from the patient, student, or clinical instructor (Data vol. 1, p. 103). During this discussion she referred to the previous day's videotape.

Her discussion moved to teaching tactics which would be evidence of her dominant CS point in making the class practical (Gregorc, 1982"). During the "constructive criticism" portion of her lecture, a question arose about the incongruity of verbal and non-verbal communication (Data Vol. 1, p. 105). She then gave a personal example of the videotape situation, AR and dominant CS behavior (Gregorc, $\left.1982^{\circ}\right)$. She ended her class with an invitation to the students to come to see her for clarification if needed. This evidence of concern for her students would be an AR behavior (Gregorc, 1982").

Four weeks later I returned to videotape some student presentations. While there, I presented the Energic Model of Styles as a scheduled part of the "Current Issues" class (Data Vol. 1, p. 89). 


\section{Audiovisual Aids}

During the first session Dr. Allen did not distribute a lecture outline nor did he use the blackboard, overhead transparencies, or videotape (Data Vol. 1, pp. 8995). This would be evidence of dominant As behavior using the lecture approach (Gregorc, 1985). During his portion of session two (Data Vol. 1, pp. 99-101) he distributed a complete set of notes on teaching tactics. The students could then follow along during his lecture and take minimal notes. This could be evidence of the dominant As "big picture" mind quality and the dominant cs characteristic of attention to detail (Gregorc, 1982^).

The videotape was viewed during the third part of session two. The videotape illustrated "good" and "bad" clinical instructor-sturient relationships (Data Vol. 1, p. 101). This videotape/story approach could be interpreted as an AR teaching/learning situation (Gregorc, 1982"; Gregorc, 1985).

During Ms. Boone's portion of session two (Data Vol. 1, pp. 96-98) she used overhead transparencies and slides as appropriate for examples of use of those media. This was a demonstration of standards of media that would be attractive to the dominant CS learner. She did not distribute any lecture outline to the students. This might be considered an AS characteristic of lecture (Gregorc, 1985). 
Session three was taught only by Ms. Clark. She used overhead transparencies at certain points of her lecture to emphasize or illustrate a point. She distributed a complete set of notes including terminology with definitions. The notes, although not covered in their entirety in the lecture, included all the lecture topics except "chaining." This completeness would be an expression of her dominant CS point for detail and of her As point for the "big picture" (Gregorc, 1982"). She referred to the videotape from the previous session, which would be an expression of her AR point (Gregorc, 1985).

\section{Classroom Design}

The front wall of the classroom had the entrance door in it and a chalkboard mounted on it. In the front of the room was a long table with a lectern on the students' right end of it. When overhead transparencies were used, the projector was on the students' left end of the table. The desks were facing the front of the room and were arranged to include a center aisle (Data Vol. 1, p. 89). This design meets the format needs of the AS teaching medium of lecture (Gregorc, 1985). The videocamera was placed at the rear of the room just right of the center aisle (Data Vol. 1, p. 107) . 
summary

This program devoted a portion of one course to teaching and learning theory and did not present styles information. The department chairperson was also the primary instructor of the course. He was interested enough in style to schedule time for me to present the Energic Model of Styles after I completed my data gathering.

All the students and the three instructors in the teaching and learning theory portion of the course participated in my research. The primary instructor was a dominant ASCS; the other two instructors were dominant in CS. All the instructors used the lecture strategy, one of whom included other strategies addressing all four styles' needs. Of the other two instructors, one included strategies within her lecture that met dominant cs needs and the other included strategies that addressed CS, AS, and AR needs.

The classroom used by all three instructors was designed for the lecture format which is attractive to the dominant AS style. Dr. Allen's dominant styles were AS and cs but his handouts addressed all four styles' needs. During his first lecture he addressed CS, AS, and AR needs but during his second lecture he addressed all four styles' needs. His audiovisual aids addressed CS, AS, and AR needs. 
Ms. Boone's dominant style was $\mathrm{CS}$ and she did not distribute any handout materials. Her lecture and visual aids addressed dominant CS and AS needs.

Ms. Clark was dominant cS but her handout materials met the needs of all four styles. Her oral presentation and audiovisual aids met the behavioral needs of the CS, AS, and AR styles.

Almost $62 \%$ of the students were dominant in cs or in a combination of styles including CS. Just under 208 of the students were dominant in a combination of styles including As. Almost $56 \%$ of the students were dominant in AR or in a combination of styles including AR. Almost $30 \%$ of the students were dominant in $C R$ or in a combination of styles including $\mathrm{CR}$.

The baccalaureate program studied in Case one answered my research questions as follows:

1. In fulfilling the teaching and learning theory competency, how do physical therapy entry level programs address variation in mind styles?

Program one did not present any styles information to the students but did, considering all three sessions, model all four styles in the oral presentations.

2. Within the context of teaching and learning theory, how are objectives about styles expressed in the curriculum documents? 
There were no objectives related to styles expressed in the form $E$ or the course outlines.

3. How are the various mind styles of the physical therapy students addressed in the learning environment within the teaching and learning theory or styles unit or course?

Styles information was not presented to the students. The objectives were stated in such a fashion, however, as to address dominant CS, AS, and AR mind qualities. All four styles' points were addressed when considering all three teachers' handout materials. Dr. Allen and Ms. Clark addressed all four dominant styles' needs in their oral presentations, and Ms. Boone addressed both dominant CS and As qualities. Audiovisual aids of Dr. Allen and Ms. Clark were attractive to the dominant CS, AS, and AR styles while Ms. Boone's were attractive to the dominant CS learner. The classroom was arranged for the lecture format which would be most attractive to the dominant AS student.

4. How do the teachers address their own mind styles in the classroom situation within the teaching and learning theory or styles unit?

Dr. Allen was dominant AsCS and addressed his own style by using the lecture approach (dominant As) but based on organized class handout materials (dominant CS). Ms. Boone, who was dominant $C S$ and using the lecture strategy, 
used examples of appropriate and inappropriate visual aids which would address her CS needs. Ms. Clark, also dominant CS, used the lecture approach to her class and distributed detailed handouts that she followed closely. The only deviations from those materials were (1) her not covering all of the material in the handout (which she announced at the beginning of class) and (2) when she described chaining.

5. How are the mind styles of the physical therapy students addressed in the classroom situation within the teaching and learning theory or styles unit?

The students' styles were addressed by providing handouts, giving examples, relating real-life incidents, telling stories, involving the students in generating information, and some techniques that were to be learned by the students.

Although this program did not present styles material, they were interested enough in style to schedule a lecture for me to present that information. The faculty also asked me to present this information to them separately. The three instructors did, as a whole, model all four styles within the lecture format. 


\section{CHAPTER $\nabla$}

\section{CASE STODY II}

I visited this baccalaureate physical therapy program on two separate occasions for data gathering. In my initial contact the department chairperson told me that styles information was given to the students. I videotaped those sessions covering style information for use in this research. All the students in the class attended the first session. I was given time at the end of this first meeting to request that the students participate in my research. The next two videotaped sessions (seminars) included only part of the students because of the group discussion format. Each seminar was repeated so that all students had the opportunity to participate in a group discussion. The two seminar sessions met 2 weeks after the lecture session. on my second visit to the campus, after I finished gathering my data, I gave a voluntary attendance presentation of the Energic Model of styles.

of the 59 students, 54 ( $91.53 \%)$ participated in my research. The one instructor in the course also participated in this project (Data Vol. 2, p. 52). Each signed an informed consent and completed the Gregorc style 
Delineator ${ }^{\text {MM }}$ Research Instrument (Data Vol 2. pp. 55-108; Gregorc, $\left.1982^{b}\right)$.

\section{overview}

This program devoted a block of one coirse to teaching and learning theory and presented styles information in that block. The learning styles information included completion of the Myers-Briggs Type Indicator and an overview of that model. The teacher was dominant in CSAS. He used a lecture format when the entire class met together and included strategies addressing CS, AS, and AR needs. In each of the next two sessions, which included only part of the class, he used a group discussion format and included strategies addressing $C S, A S, A R$, and $C R$ needs (see Appendices $A$ and $B$ ).

Over one half of the students were dominant in CS or in a combination of styles including cs. One fifth of the students were dominant in a combination of styles including AS. Over one half of the students were dominant in $A R$ or in a combination of styles including AR, the same number as those for dominant $C S$ noted above. Almost one third of the students were dominant in $C R$ or in a combination of styles including $\mathrm{CR}$.

The following outlines, in detail, how mind styles were addressed in the teaching and learning theory unit at this program. 
Teacher's Mind style

Mr. Dennis was the only instructor for this course. He tested as dominant CSAS (Data Vol. 2, p. 37). His CS dominance was clear in his use of detailed overhead transparencies and detailed handouts for the students. He gave the schedule of material coverage that could be interpreted as CS--"planning" and AS--"big picture" (Gregorc, 1982 ). His dominant As point was clear by his starting the class with two questions to frame his material (Gregorc, 1982'). His AR point showed itself by his asking the students to interact with the notes, with him, and with each other (Data Vol. 2, p. 38; Gregorc, 1985).

Another AR behavior was his asking the students to help him generate a list of how we learn (Data vol. 2, p. 39; Gregorc, 1985). He wrote these on an overhead transparency so the students could see them. This class participation was an AR behavior; his basic lecture format was from his dominant AS point (Gregorc, 1985). He moved about and made eye contact with his students during his class, demonstrating a personal contact with his students (AR--[Gregorc, 19824; Data Vol. 2, pp. 38, 43]).

\section{students' Mind styles}

of the 59 students in this baccalaureate program, 54 (91.53\%) participated in my research. Table 2 shows the 
distribution of styles within the class (Data Vol. 2, pp. $52-54)$

Table 2 shows that 57.418 , or 31 students, of the class scored as dominant in one or a combination of styles including concrete-sequential. Only $18.52 \%$, or 10 students, tested as dominant in a combination of styles including abstract-sequential. Thirty-one students, the same as for CS figures, or $57.41 \%$, of the class tested as dominant in one or a combination of styles including abstract-random. Sixteen students, or 29.638 , tested as dominant in one or a combination of styles including concrete-random.

None of the students tested as dominant in only abstract-sequential for which the lecture format is preferred. Three of the $10 \mathrm{with}$ abstract-sequential, in combination with another style or styles, scored highest in AS. The AS score of the student with three dominant styles was equal to the other lower score. The remaining 6 scored higher in the other style than they did in AS. This leaves $5.56 \%$ of the class, or three of 54 , for whom lecture might be a preferred style of learning (Data Vol. 2, pp. 52-54). 
Table 2

Dominant styles of Program Two students

\begin{tabular}{|c|c|c|}
\hline One dominant style & $\mathrm{n}$ & 8 \\
\hline Concrete-sequential & 9 & 16.678 \\
\hline Abstract-random & 8 & 14.818 \\
\hline Concrete-random & 4 & 7.418 \\
\hline \multicolumn{3}{|l|}{ Two dominant styles } \\
\hline CSAR/ARCS & 12 & $22.22 \%$ \\
\hline CRAS/ASCR & 2 & 3.708 \\
\hline CSAS/ASCS & 6 & 11.118 \\
\hline CRAR/ARCR & 7 & 12.968 \\
\hline ARAS & 1 & 1.858 \\
\hline CRCS & 1 & 1.858 \\
\hline \multicolumn{3}{|l|}{ Three dominant styles } \\
\hline ARCSCR / ARCRCS & 2 & 3.708 \\
\hline ARCSAS & 1 & $1.85 \%$ \\
\hline \multicolumn{3}{|l|}{ No dominant style } \\
\hline $25 / 24 / 25 / 26$ & 1 & 1.858 \\
\hline
\end{tabular}


Eight of the students tested as dominant in only abstract-random for which the group discussion/seminar format is preferred. Nine of the 23 with abstract-random in combination with another style or styles scored highest in AR. Three students with two dominant styles scored equally in $A R$ and the other style. The remaining 11 scored higher in the other style than they did in AR. This leaves $37.04 \%$ of the class, or 20 of 54, for whom group discussion/seminar might be a preferred style of learning (Data vol. 2, pp. 52$54)$.

The structure provided by lecture outlines and schedules should have addressed the dominant CS needs of 57.418 , or 31 , of the students. The personal experiences and group discussions, in the seminar classes, should have met the dominant AR needs of $57.41 \%$, or 31 , of the students. The development of the solutions to the three clinical situations should have addressed the dominant $C R$ needs of $29.63 \%$, or 16 , of the students (Gregorc, 1982*; Gregorc, 1985).

As pointed out earlier even if a person is not dominant in a particular mind style some characteristics of that style will be present. This means that some students may still prefer lecture or group discussion/seminar though it is not characteristic of their natural style. Also one must consider, that by this time in their educational 
experience, students have probably "learned to play the game of school."

The self study

Form E

The Form E (Data Vol. 2, p. 1) lists two courses as including information on learning. Cited as addressing the teaching and learning accreditation standard are the

"Physical Agents II" and "Clinical Practice II" courses.

The primary course covering teaching and learning theory was "Clinical Practice II" which also included styles information.

\section{Course outlines}

The "Physical Agents II" course listed one objective (Data Vol. 2, p. 4) that encouraged students to become active lifelong learners. Student groups must present an electrotherapeutic topic to the remainder of the class using appropriate audiovisuals (Data vol. 2, p. 3).

The primary course covering teaching/learning theory and styles information was "Clinical practice II." It listed one objective as "Upon completion of the course the student will: Demonstrate effective relationships with patients and their families by: h. utilizing appropriate teaching style when instructing patients and their families" (Data Vol. 2, pp. 6, 7). This objective requires: (1) the abilities of the dominant CS, requiring appropriate 
attention to the details of the task; (2) As, recognizing how those details fit into the "big picture" of total rehabilitation; (3) $A R$, establishing rapport with the patient and family and relating the task to the patient's other functional requirements; and (4) $\mathrm{CR}$, the ability to change as needed and to be innovative rather than "cookbookish" in the teaching strategy (Gregorc, 1982"; Gregorc, 1985).

\section{Handouts}

Upon arrival on campus I found that the "clinical Practice I" and "Clinical Practice II" courses were a sequence. In fact, the topics in the two courses were continuous as if the two were one course. The sequence of topics in the two courses was sometimes changed from year to year, moving from one course to the other. This would occur without changes in the listed objectives of either course. Since the second course is a continuation of the first, this is a logical occurrence. I mention this because the course I used in my data collection was "Clinical practice I" and not "Clinical practice II." The self study materials did not reflect this change because of its completion before the date of my visit (Data Vol. 2, p. 9).

The objective discussing the education aspect of the two courses was listed in the "Clinical Practice II" materials (Data Vol. 2, pp. 7, 12). The handout material 
for "Clinical Practice I" did not list that objective. Seven of the 10 listed objectives could be interpreted as indirectly addressing teaching and learning. The teaching and learning theory and styles topics had been changed to this portion of the two-course sequence (Data Vol. 2, pp. 10, 131. The number of objectives requiring cs mind qualities far outnumbered those that required As mind qualities or both $C S$ and $A R$ mind qualities (Data vol. 2, p. 9 ; Gregorc, 1982*).

The handouts for the lecture, given to the students, consisted of copies of the overhead transparencies. These handouts can be interpreted as addressing dominant cs mind qualities because they provided the plan and detail (Data vol. 2, pp. 14-18; Gregorc, 1982') of the lecture and reduced notetaking. There was also a reference list, attractive to the dominant As learner who prefers reading and documentation (Data Vol. 2, p. 19; Gregorc, 1985).

The handout used in the seminar class giving the "correct" four or five responses to each clinical situation would be attractive to the dominant CS learner. This learner has a desire for guidance (Data Vol. 2, pp. 20, 21; Gregorc, 1982') .

The students had received a "Personal style Inventory" earlier in the term that included a section on interpretation of the results of the inventory. This inventory, developed by Champagne and Hogan in 1979, was an 
abbreviated form of the regular Myers-Briggs Type Indicator. Also included were materials on personality differences and learning style and effective working relationships (Data Vol. 2, pp. 22-36) .

\section{Oral Presentation}

Session Number one

The adult learner was the topic addressed during the regular class session. Mr. Dennis started the class with two questions. He then said that most clinical instructors (CIs) have not had any information about the adult learner. He also told the students that they may be able to pass this information on to their CIs. This was creating a personal interest in the future practicality of this information, thus evidence of CS behavior (Gregorc, 1982 ). As noted above he asked the students to interact with him and the information, an expression of his AR dominance (Data Vol. 2, p. 38).

He then announced that they were going to discuss the role of the PT as a facilitator of the learning process for students (Data Vol. 2, p. 38). He then asked them to think how they could use this information as a student, with their patients, and later when they have become CIs (Data Vol. 2, p. 38). This would be evidence of stimulating AS "big picture" behavior and CS "application" behavior (Gregorc, $1982^{4}$ ). 
His next idea was that the adult learning process is different from what most of us experience in the formal classroom setting. This then led to the mention of two works on multiple intelligences (Data Vol. 2, pp. 38-39). These were Steinberg's Triarchic Mind and Gardner's Frames of Mind. He then indicated that what is tested in the classroom and what is used in the workplace are not the same intelligences. These ideas would reflect his dominant AS point for referencing his information and his dominant cs point for practical application (Gregorc, 1982'). He then asked how many had finished their personal style inventory. All the students had and he exclaimed: "Fantastic, Everybody!" (Data Vol. 2, p 39). This involvement of the class and his use of the word "fantastic" are evidence of his AR point (Gregorc, 1982").

With mostly student participation he made a list of "ways that you learn best" (Data Vol. 2, p. 39). He prompted and gave feedback during the generation of this list which would be AR behavior (Gregorc, 1982'). He then presented overheads, information, and examples of situations in adult learner teaching and learning (Data Vol. 2, p. 40). This would be evidence of CS "practicality" (Gregorc, 19824). He also referred to a flowchart, from a conference he previously attended, which he had drawn on the chalkboard. The chart included, in circular fashion, "Motivation $\rightarrow$ Information $\rightarrow$ Practice $\rightarrow$ Feedback $\rightarrow$ 
Motivation" (Data Vol. 2, p. 41). This flowchart would be attractive to the dominant CS learners because of sequence (Gregorc, 19824).

He presented 10 principles and strategies (how to's) to facilitate adult learning (Data Vol. 2, p. 41). This structure was a demonstration of his dominant cs point (Gregorc, 1982'). On item number 1 he noted that this was the purpose of the learning style inventory (Data Vol. 2, p. 41). This is cs practical application (Gregorc, 1982'). At the end of the 10 principles he asked if there were any questions on those principles. This demonstrated his dominant cS characteristic of desiring completeness (Gregorc, 1982).

He then made the assignments for the next week's seminar classes. He discussed each assignment and related them to the students' possible future clinical experience either as a student or a CI (Data Vol. 2, p. 43). This again was CS practical application (Gregorc, 1982^). The assignment required the students to develop solutions to clinical problems and that addressed dominant $C R$ abilities (Gregorc, 1982*).

In general, he related various items in his lecture to his personal experiences (Data Vol. 2, p. 43). This was AR behavior of personal relationships (Gregorc, 19824) . He elicited student participation in generating lists of items and commented on their various contributions (Data Vol. 2, 
pp. 39-43). This showed his acceptance of the students' input from his AR point (Gregorc, 1982').

\section{Session Number Two}

This was the first of the two seminar sessions obseryed in my data gathering process. He started by standing in the front of the classroom where he made his announcements (Data Vol. 2, pp. 43-44). This is As behavior in the traditional classroom (Gregorc, 1985). He announced the schedule for that day's class, which would be his dominant CS point behavior planning and predictability (Data Vol. 2, p. 44; Gregorc, 1982*).

From the front of the classroom, standing next to the overhead projector, he went over the three situations that had been assigned at the last class session. He asked the students about what type of student was in each situation and what key principles from the last class period applied to each situation (Data Vol. 2, pp. 44, 45). The analysis of the student was AS and CS activity while the proposal of solutions was $C R$ problem solving behavior. Choosing the solutions from a list was cs behavior (Gregorc, 1982'). The student participation was appealing to the AR quality of sharing one's ideas (Gregorc, 1982'). He distributed to the students a list of three or four key principles to solve each of the situations. He emphasized that these were not the only solutions, but 
appropriateness would vary with the CI and the student. He also related to the class that he had shared these same situations the night before with CIs (Data Vol. 2, p. 46).

Mr. Dennis then seated himself in the circle and asked the students what they might disagree with on the handout. One of the students responded that he had a problem with this learning style "stuff." He believed that each clinical situation dictates the style used. Mr. Dennis then asked the others what they thought about that comment. This is AR behavior of sharing feelings, beliefs, and ideas (Gregorc, 1982'). After several student comments that generally disagreed with those of the first student, Mr. Dennis said there is no right or wrong learning style. He then asked what the student would do if his style and his CI's style differed (Data Vol. 2, p. 46).

Mr. Dennis announced that this was a good launch into the next week's class. His reference to a clinical situation and the leading into next week's class would be CS practicality and planning behavior (Gregorc, 1982'). Mr. Dennis demonstrated AS behavior in his ability to tie the students' comments together into a "big picture". His AR behavior was his personal (eye) contact with whatever student was speaking and the use of group discussion (Gregorc, 1982'). 
Session Number Three

A list and an assignment was written on the

chalkboard before the students arrived in class. Mr. Dennis started the class while sitting in the circle with the students (Data Vol. 2, p. 47). This is evidence of AR behavior, group discussion (Gregorc, 1985). He told the students how much information would be covered during this class period. This was an evidence of his dominant cs point of planning and prediction (Data Vol. 2, p. 47; Gregorc, 1982'). He assigned the students a task for the next seminar session and indicated about how far they would get during the next week's session (Data Vol. 2, p. 47). This would be planning behavior of his dominant cs point (Gregorc, 1982') .

A discussion of the students' learning styles and insights gained from studying their styles was the next topic. He asked the students for their reactions and gave them sufficient time to respond before saying anything else (AR class discussion behavior [Gregorc, 1985]). He related the teaching and learning styles (AS behavior [Data Vol. 2, p. 47 ; Gregorc, 1982']). He gave the students situations for problem solving. This stimulated CR behavior (Gregorc, 1982'). A CS practical application was used to illustrate the employment of styles information (Data Vol. 2, p. 48; Gregorc, 19824). 
One of the students suggested that a CI must have a wide variety of learning styles. Mr. Dennis responded to that comment by telling the students that he tries to help CIs develop a variety in the workshops he presents. He reminded the students that they must be tuned into their patients' learning styles (CS practical application [Data Vol. 2, p. 48]).

From his seated position he referred to a list written on the chalkboard. The list was labeled "Learning process." He then asked: "How would you [pause] react, how would you handle a situation where you had to interact with somebody who has a different personality type than yours? [pause] See the possibility for conflict there?" (Data Vol. 2, p. 48). This is AR involvement of the students' feelings and projecting themselves into a situation and $C R$ involvement of problem solving (Gregorc, 1982').

The discussion then moved to dealing with persons who are opposite styles of one's own. Moving to the chalkboard he then asked the students to identify his style and said that he and his wife were opposite styles (Data Vol. 2, p. 49). This would be AR relating personally with a situation (Gregorc, 1982'). After that he returned to his seat within the circle. He asked if there were any more comments on personality types or learning styles (Data vol. 2, p. 49). This might be considered AR behavior of wanting to allow all to speak who wish to speak (Gregorc, 1982"). 
At this point he moved the discussion to chapter 1 in the textbook. He gave a brief overview of the parts of the book (AS "big picture" behavior [Data Vol. 2, pp. 49-50; Gregorc, $1982^{\circ}$ )). He assured the students that though the book required them to think at a very personal level they would not have to share any feelings or thoughts with the class that they did not wish to. This showed AR concern for others (Data Vol. 2, p. 50; Gregorc, 1982).

Mr. Dennis gave a history of socialization into the profession of physical therapy. In the early days one was expected to "know how to act." The textbook provides a structure for the socialization process (Data Vol. 2, p. 50). He gave the purpose for using the textbook as helping the students to develop into more productive and effective PTs (Data Vol. 2, p. 50). At this point he praised them on their contributions during the last discussion. This was AR concern for feelings (Gregorc, 1982'). He asked the students to respond to the reading assignment. He gave plenty of time for response and then commented that he realized that they had a test that morning. This was an AR understanding of students' feelings (Data Vol. 2, p. 50; Gregorc, 1982').

The students were mixed in their responses to the book. Some comments were positive and others negative. Mr. Dennis admitted that he did not like chapter 1 either. He noted that most exercises would be discussed in class except 
a couple of assignments that were to be submitted to him (Data Vol. 2, pp. 50-51). He then reviewed the assignments for the next 2 weeks and dismissed the class. This review was CS planning behavior (Data Vol. 2, p. 51; Gregorc, $\left.1982^{4}\right)$.

This seminar class was conducted in a very AR "feeling" behavior, creating a nonthreatening environment. He conducted a successful group discussion, though the students were apparently somewhat fatigued from their earlier test (Data Vol. 2, p. 51).

\section{Audiovisual Aids}

Mr. Dennis distributed a detailed handout to the students, used overhead transparencies (Data Vol. 2, pp. 919), and used the chalkboard (Data vol. 2, p. 40) during the general lecture session (Data Vol. 2, pp. 38-43). The dominant CS learners would appreciate the detail of the handout (Gregorc, 1982'). The dominant AS learners would appreciate the same handout for the "big picture" that it gave of the lecture session (Gregorc, 1982'). The dominant CS learners would be attracted to the flow chart depicted on the chalkboard (Data Vol. 2, p. 40) because of its sequential nature (Gregorc, 1982"). The dominant AS learners would also appreciate the same illustration for being a "big picture" (Gregorc, 1982"). The instructor being dominant in both $C S$ and AS would tend naturally to 
express ideas based on both of those purposes (Gregorc, 1982'). The lecture format is a dominant As strategy. During the second session (Data Val. 2, pp. 43-47), he used the overhead transparencies (Data vol. 2, pp. 44, 45) to write the students' solutions to the three clinical situations (Data Vol. 2, p. 44). This behavior of inclusion of student input showed an AR concern for the seminar members. The itemization of the solutions demonstrated As "big picture" and CS detail behaviors (Gregorc, 1982"). After the discussion of the three situations, Mr. Dennis distributed a list of the three or four key principles that could be used to solve each situation (Data Vol. 2, p. 46). This immediate feedback appeals to the dominant cS style need to know the appropriate response (Gregorc, 19824).

During the third session Mr. Dennis used the chalkboard to note an assignment and to illustrate a list entitled "Learning process" (Data Vol. 2, pp. 47, 48) . These would be appealing to the dominant cs learner who likes sequence. The dominant CS also likes to know how to plan as well as have detailed information (Gregorc, 1982'). The textbook was used in the third session and he referred the students to the four objectives of chapter 2 . He related the objectives to the assignment for the next week (Data Vol. 2, p. 47). Relating them to the assignment 
gave guidance to the students for their studies which is desired by the dominant CS learner (Gregorc, 1982').

He again moved to the chalkboard and printed, vertically on the board, "I-N-T-P" and "E-S-F-J" (see Appendix $C)$. He proceeded to ask the students about dealing with opposites of themselves (Data Vol. 2, p. 49).

He then had the students refer to chapter 1 in the textbook for the remainder of the seminar session (Data vol. 2, p. 49). He emphasized the purpose of doing the exercises in the book (Data Vol. 2, p. 50). The use of a book appeals to the dominant AS style and the examination of one's feelings appeals to the dominant AR style (Gregorc, 1982"). He also asked the students what their opinion of the book was, also attractive to the dominant AR learner (Data Vol. 2, p. 50).

\section{Classroom Design}

Both classrooms had a chalkboard at one end, the entrance doors on one side, and windows on the other side. In the lecture room all the desks faced the front of the room where there was a chalkboard and an overhead projector (Data vol. 2, pp. 38, 43). This is the traditional design for the formal lecture that would be attractive to the dominant AS teacher and learner (Gregorc, 1982*, 1985). The videocamera was placed at the center rear of the classroom (Data Vol. 2, p. 43). 
The seminar room was designed for lecture but the seating was arranged in a circle so that all students could see each other (Data Vol. 2, p. 43, 47). This group discussion arrangement was conducive to sharing ideas and feelings and therefore appealing to a dominant AR teacher and learner (Gregorc, 1982*, 1985). Mr. Dennis scored in the low range of his AR point. The videocamera was placed at the center rear of the classroom (Data Vol. 2, p. 51).

\section{summary}

This program devoted a block of one course to teaching and learning theory and presented learning styles information in that block. The styles information included completion of the Myers-Briggs Type Indicator and an overview of that model. Fifty-four (91.53\%) of the 59 students and the instructor in the learning styles portion of the course participated in my research. The teacher was dominant in CSAS.

The classroom used by Mr. Dennis for session one was designed for the lecture format which is attractive to the dominant As style. In the classroom used for sessions two and three, the desks were arranged in a circle for group discussion which is attractive to the dominant AR style. Mr. Dennis' dominant styles were CS and AS and his handouts addressed those styles' needs. During his lecture, session one, he addressed CS, AS, and AR needs and with his 
110

assignment for the next session $C R$ needs. During his seminars, sessions two and three, he addressed all four styles' needs. His audiovisual aids addressed CS, AS, and AR needs.

Almost 608 of the students were dominant in CS or in a combination of styles including CS. Nearly 20 of the students were dominant in a combination of styles including AS. Almost $60 \%$ of the students were dominant in AR or in a combination of styles including $A R$, the same number as those for dominant CS noted above. Almost $30 \%$ of the students were dominant in $C R$ or in a combination of styles including $\mathrm{CR}$.

The baccalaureate program studied in Case Two answered my research questions as follows:

1. In fulfilling the teaching and learning theory competency, how do physical therapy entry level programs address variation in mind styles?

Program Two did present the Myers-Briggs Type Indicator model of styles information to the students and Mr. Dennis did model all four styles in the oral presentations.

2. Within the context of teaching and learning theory, how are objectives about styles expressed in the curriculum documents? 
There was one objective related to teaching styles in the Clinical Practice II course outline. This objective addressed aspects of each of the four mind styles.

3. How are the various mind styles of the piysical therapy students addressed in the learning environment within the teaching and learning theory or styles unit or course?

Teaching and learning styles information was presented to the students. The objectives were stated in such a fashion as to address qualities of all four mind styles. CS and AS styles' points were addressed in $\mathrm{Mr}$. Dennis' handout materials. Mr. Dennis addressed dominant CS, AS, and AR needs in the lecture session, the first of his oral presentations, and all four styles' abilities in his two seminar sessions. His audiovisual aids were attractive to the dominant CS, AS, and AR styles. For session one the classroom was arranged for the lecture format that would be most attractive to the dominant As student. For sessions two and three the classroom was arranged in a group discussion format which would be most appealing to the dominant AR learner.

4. How do the teachers address their own mind styles in the classroom situation within the teaching and learning theory or styles unit?

Mr. Dennis was dominant CSAS and addressed his own style by using the lecture approach (dominant As) based on 
organized class handout materials (dominant cs). He also conducted group participation (dominant AR) and problem solving (dominant $C R$ ) that addressed his non-dominant points.

5. How are the mind styles of the physical therapy students addressed in the classroom situation within the teaching and learning theory or styles unit?

The students' styles were addressed by providing (1) handouts, CS and AS, (2) suggesting application of information, CS, (3) asking the students to interact with him, the materials, and each other, AR, (4) providing a flowchart, CS, (5) providing problems to be solved by the students, CR, (6) giving the students the opportunity of sharing and responding to his and other students' comments, $A R$, and (7) involving the students in generating information, AR.

This program presented the role of the physical therapist as a facilitator of learning and applied one style model. 


\section{CHAPTER VI}

\section{CASE STUDY III}

I visited this post-baccalaureate physical therapy program once for data gathering. In my initial contact the department chairperson told me that styles information was not given to the students. I videotaped those sessions covering teaching and learning theory for use in this research. All the students in the class attended all four 1-hour sessions. I was given time to request that the students participate in this research.

I presented the Energic Model of Styles to the faculty between the second and third class sessions as well as to the students on the day following the third and fourth one-hour sessions (voluntary attendance). The faculty member presenting the teaching and learning theory did not attend the faculty presentation.

All 38 students participated in my research. The one instructor lecturing on teaching and learning theory also participated in this project (Data Vol. 3, p. 98). Each signed an informed consent and completed the Gregorc Style Delineator ${ }^{\mathrm{TM}}$ Research Instrument (Data Vol 3. pp. 100137 ; Gregorc, $1982^{b}$ ). 


\section{overview}

This program devoted a block of one course to teaching and learning theory, but did not present styles information. The combined objectives listed in the self study course outlines for these sessions addressed dominant CS, AS, and CR abilities. The teacher was a dominant CSAS. He used a lecture format in each of the class sessions and included strategies addressing CS, AS, and AR needs (see Appendices $A$ and $B$ ).

Just over one half of the students were dominant in CS or in a combination of styles including CS. Nearly one fourth of the students were dominant in AS or in a combination of styles including AS. Nearly one half of the students were dominant in AR or in a combination of styles including AR. About one fifth of the students were dominant in $\mathrm{CR}$ or in a combination of styles including $\mathrm{CR}$.

The following describes, in detail, how the various mind styles were addressed in the learning environment.

\section{Teacher's Mind Style}

Dr. Ellis was the only instructor presenting teaching and learning information in this course. He tested as dominant CSAS (Data Vol. 3, p. 82). His CS dominance was clear in his use of overhead transparencies and handouts for the students. He also used many examples. He gave the schedule of material coverage for each of the four 1-hour sessions. That could be interpreted as cs--"planning" and 
AS--"big picture" (Gregorc, 1982"). His dominant AS point was clear by his reference to the theories of Gagne and his use of the lecture strategy (Data Vol. 3, pp. 83-97; Gregorc, 1982'). His AR point showed itself in the use of some stories and anecdotes (Data Vol. 3, pp. 84, 94 ; Gregorc, 1985).

His basic lecture format was from his dominant As point (Gregorc, 1985). He moved about and made some eye contact with his students during his class showing a personal contact with his students--AR (Gregorc, 1982“; Data Vol. 3, pp. 37,89$)$.

\section{students' Mind styles}

All of the 33 students in this post-baccalaureate program participated in my research. Table 3 shows the distribution of styles within the class (Data Vol. 3, pp. $98-99)$.

Table 3 shows that $60.53 \%$, or 23 students, scored as dominant in one or a combination of styles including concrete-sequential. Nine students, $23.68 \%$, tested as dominant in one or a combination of styles including abstract-sequential. Eighteen students, $47.37 \%$, of the class tested as dominant in one or a combination of styles including abstract-random. Only eight students, 21.058, tested as dominant in one or a combination of styles including concrete-random. 
Table 3

Dominant styles of Program Three students

\begin{tabular}{|c|c|c|}
\hline one dominant style & $\mathbf{n}$ & 8 \\
\hline Concrete-sequential & 9 & $23.68 \%$ \\
\hline Abstract-sequential & 3 & 7.898 \\
\hline Abstract-random & 5 & $13.16 \%$ \\
\hline Concrete-random & 1 & 2.638 \\
\hline \multicolumn{3}{|l|}{ Two dominant styles } \\
\hline CSAR/ARCS & 7 & 18.428 \\
\hline CSAS/ASCS & 5 & $13.16 \%$ \\
\hline CRAR/ARCR & 5 & 13.168 \\
\hline ASAR & 1 & 2.638 \\
\hline $\mathrm{CSCR}$ & 2 & 5.268 \\
\hline
\end{tabular}


Three of the students, 7.898 , tested as dominant in only abstract-sequential for which the lecture format is preferred. Two of the 6 with abstract-sequential in combination with another style scored highest in AS. The remaining 4 scored higher in the other style than they did in AS. This leaves $13.16 \%$ of the class, 5 of 38 , for whom lecture might be a preferred style of learning (Data Vol. 3, pp. $98-99)$.

The structure provided by lecture outlines and schedules should have addressed the needs of $60.53 \%$, or 23 , of the students. Those were the students with one or more dominant styles including CS. The personal experiences should have met the needs of $47.37 \%$, or 18 students with one or more dominant styles including AR (Gregorc, 1982*, 1985).

As stated in the previous case studies one must remember that even if not dominant in a particular mind style, one will still have some characteristics of that style. Therefore some of the non-dominant As students might still prefer lecture naturally and some non-dominant AR students might prefer the relating of personal experiences. of course there is still the possibility that students at this educational level who are not dominant in the same style as that being used in the classroom may have "learned to play the game of school." 
The self study

Form E

The Form E used for this research was one used to address areas requiring response following the accreditation site team visit. The Form E (Data Vol. 3, p. 1) lists two courses including information on learning. Cited as addressing the teaching and learning accreditation standard are the "Rehabilitation II" and "Foundations for Neurophysiology of Motor Control" courses. The primary course covering teaching and learning theory was "Rehabilitation II."

\section{Course outlines}

The "Rehabilitation II" course lists two objectives (Data Vol. 3, p. 3) that address teaching and learning. These mention education activities used in the rehabilitation process and the need of a knowledge of education theory and its application (Data Vol. 3, p. 3). The primary course covering teaching/learning theory was "Rehabilitation II." It listed one objective as "Upon completion of this course, the student will be able to: 6 . Discuss the various activities and health care professionals utilized in the rehabilitation process to promote education, independence, socialization and reintegration into the community." (Data Vol. 3, p. 3). This objective requires the abilities of the dominant As mind style to weave those various professionals and their activities into the "big 
picture" of rehabilitation (Gregorc, 1982"; Gregorc, 1985). The second objective said: "7. Discuss educational theory and apply these principles to teaching the patient, the patient's family and other health care professionals" (Data Vol. 3, p. 3). This objective requires the theory development abilities of the dominant AS mind style and the application abilities of the CS mind style (Gregorc, 1982*). The course outlines had separate sections for the lecture and the laboratory sessions. Of the 12 lectures, numbers $1,4,5$, and 8 included objectives addressing teaching and learning (Data Vol. 3, pp. 9-19). Lecture 1 listed a teaching objective that required dominant cS abilities of answering "why" teaching patients is important (Data Vol. 3, p. 9). Lectures 4 and 5 were combined and listed six objectives of which some required the naming and defining abilities of the dominant CS mind qualities. One objective required the theory understanding of the dominant AS qualities. Other objectives required both dominant CS understanding of the parts of teaching and learning and AS abilities of evaluation of those parts. Another objective addressed the needs of the dominant cs knowledge of facts, the dominant AS understanding of concepts and principles, and the CR ability to problem solve (Data Vol. 3, p. 12). The two objectives addressing teaching and learning in lecture 8 both required dominant CS abilities of explaining 
"why" patient teaching and family education are important (Data Vol. 3, p. 15).

of the four lectures only one, lecture 8 , had a required reading assignment which is appealing to the dominant AS learner (Data Vol. 3, pp. 9, 12, and 15; Gregorc, 1982 ). I used lectures 4 and 5 for my research data gathering.

All eight laboratory sessions included objectives addressing teaching and learning (Data Vol. 3, pp. 20-26). The first six laboratory outlines listed two objectives each. One addressed the dominant CS abilities of correct application of technique and $C R$ abilities of problem solving in choosing those appropriate techniques and the other addressed the dominant cs learner application skills (Data Vol. III, pp. 20-25). The seventh and eighth laboratory sessions listed four objectives, all of which addressed the dominant CS application abilities (Data Vol. 3, p. 26). one unit of the six units in the "Foundations for Neurophysiology of Motor Control" is devoted to motor learning (Data Vol. 3, p. 29). Of the five objectives for that unit some require dominant cs abilities of defining and distinguishing, while others the dominant cs ability of distinguishing and AS abilities of dealing with concepts and comparison (Data Vol. 3, p. 35; Gregorc, 1982). The objective addressing neurophysiology of learning and memory 
requires dominant As mind qualities in dealing with theories (Data Vol. 3, p. 35; Gregorc, 19824).

\section{Handouts}

The handouts for the lecture included six objectives, copies of the overhead transparencies, and samples of various grade level reading materials (Data Vol. III, pp. 63-81). Most of the six objectives required dominant CS mind qualities while the others required dominant AS abilities (Data Vol. 3, p. 63). The handouts of some of the overhead transparencies can be interpreted as addressing dominant CS mind qualities. This is because they provided the plan and detail of the teacher's lecture and reduced notetaking (Data Vol. 3, pp. 63-81; Gregorc, 19824).

The reading samples were attractive to the dominant AS learner who prefers having additional information about topics (Data Vol. 3, p. 69-81; Gregorc, 1982'). The information on the Fry test, a readability test that can be used to determine approximate grade level of reading materials, would be attractive to the dominant cs learner (Data Vol. 3, p. 68; Gregorc, 1982*).

\section{oral Presentation \\ Session Number One}

The topic addressed during the regular class session was methodology used in inservice and staff instruction. Dr. Ellis started the class with an overview of the four 
sessions as well as a discussion of the handout materials. This was evidence of his dominant cSAs mind styles in giving the details and outline ahead of time so the dominant cs learners could plan. The benefit to the dominant As learners was his presenting a "big picture" (Data vol. 3, p. 83; Gregorc, 1982'). He asked the students to assume that they have to do an inservice or instruct the PT staff during their clinical affiliations. He noted that this was not an unlikely event (Data Vol. 3, p. 83). This was creating a personal interest in the future practicality of this information thus evidence of CS behavior (Gregorc, 1982").

Dr. Ellis announced that the first 3 hours of lecture would be based on a book by Gagne. This would stimulate the AS learner behavior of having a theoretical reference for further information (Data vol. 3, p. 83; Gregorc, 1982').

He placed a transparency on the overhead projector which was entitled "Teaching Sequence" (Data Vol. 3, p. 83). Such items listed were: "a. Define your responsibility; b. Define desired change in behavior; c. Plan teaching acts; $e$. Tell the student the objective," etc. (Data Vol. 3, p. 83). He discussed each item listed by asking questions and giving definitions or examples (Data Vol. 3, pp. 84-86). Using another transparency when discussing behavioral objectives, he described the various parts of an objective. He then 
gave an example of a behavioral objective, evidence of CS behavior in providing a standard (Data Vol. 3, p. 84). While discussing "Where is the student?" he used the chalkboard to illustrate movement of a student from one point of behavior to another. Dr. Ellis pointed out that the first four items were planning stage activities and that at "this point," pointing at the chalkboard, the student arrives on the scene (Data Vol. 3, p. 85).

First one must tell the students the objectives. Next something needs to be brought out of the long-term storage on which to base their new learning. He then indicated that the students' attention needs to be directed toward what they are doing. One must provide a role model to demonstrate what is to be done. These are evidences of CS behavior of performance standards (Gregorc, 1982 ). At this point he referred to a research project done by Gagne testing three instructional strategies (Data Vol. 3, p. 85). This would be attractive to the dominant AS learners who desire documentary support for information (Gregorc, 1982*). He gave his "favorite definition of teaching: teaching is the facilitation of learning and learning is a change in behavior" (Data vol. 3, p. 86).

The last two items that he covered in the teaching sequence were the provision of feedback and practice (Data Vol. 3, p. 86). He said there was some discouraging research on the subject. He stated students taught 
information forgot 428 of it by an hour later and 908 by a week later. Because of this, it is important to allow practice to move the information into long-term storage (Data Vol. 3, p. 86). He ended this session by asking if there were any questions. He waited.

While lecturing, Dr. Ellis moved about almost constantly. He used many examples and situations from his and his students' pasts which were evidences of AR behavior. He also referred to research which demonstrates his dominant AS behavior (Data Vol. 3, p. 86; Gregorc, 1982^).

Session Number Two

He started this session by reviewing the previous hour. He concluded the review with "and that leads into learning theory" (Data Vol. 3, p. 86). He placed a transparency on the overhead projector which listed domains of learning as topics. These were motor performance, verbal information, intellectual skills, cognitive strategies, and affective behavior. Dr. Ellis indicated that most of the hour would be devoted to intellectual skills (Data Vol. 3, p. 87). This is evidence of the dominant CS point desiring planning and predictability (Gregorc, 1982*).

There is a hierarchy of learning. What must the student know before one can teach him/her this other item? He used as an example that a knowledge of anatomy must precede teaching the evaluation of a joint (Data Vol. 3, p. 
87). One teaches a lesson in the order of the hierarchy, but one designs the lesson in the reverse. He wrote the last three items of the hierarchy in reverse order on the chalkboard to illustrate what he was saying. One starts teaching people by making sure that they understand the definitions of terms. This includes defining the names and lists. The identification process includes defining. The intellectual process starts with distinguishing which includes differentiating and ordering. The idea of concept formation is the next step. If one can classify objects into categories, one is forming concepts (Data Vol. 3, p. 88). These practical application ideas are evidence of his CS dominance (Gregorc, 1982').

The rule statement and application are actually, in more modern terminology, principle statement and application. Principles state relationships among concepts. He gave the example of a newspaper classified advertisement in two different word orders to demonstrate proper order of concepts. This was a humorous example and would be an example of his AR behavior (Gregorc, 1982"). To teach someone to solve problems, one must first teach them principles. Before that, teach them concepts. At this point he asked if there were questions and he answered those that were asked (Data Vol. 3, p. 89). He stressed the importance of providing both examples and nonexamples of the concepts in the teaching process. He 
finished the session with a statement that one plans his/her lesson from bottom to top and teaches it from top to bottom. As he said this, he referred to the overhead transparency (Data vol. 3, p. 90).

These two sessions completed the first day's presentations of teaching and education theory. The last two sessions were given two days later (Data Vol. 3, p. 83). Dr. Ellis used the lecture format which was his dominant AS teaching behavior (Gregorc, 1985). He used examples of real information found in physical therapy which would be his dominant cS teaching behavior (Gregorc, 1985). He also used stories and humor throughout his presentations which are examples of AR behavior (Gregorc, 1982, 1985).

\section{Session Number Three}

At the beginning of this session Dr. Ellis referred to the previous two hours on Tuesday. He did this to show that this was a continuation of the education topic. The accreditation standards were the reason he gave for this set of materials. He then noted that the first two hours addressed theory and teaching methodology related to students and hospital staff. The first hour this day was to deal with teaching motor skills to patients concentrating on home programs (Data Vol. 3, p. 90). This overview would be evidence of his dominant cs point for planning and his 
dominant AS point for giving the "big picture" (Gregorc, $\left.1982^{4}\right)$.

He based the first hour on a student's master's degree thesis studying Gagne's learning theory (Data Vol. 3, p. 90). Dr. Ellis noted that patient compliance with instructions for medication or exercise is not very good (Data Vol. 3, pp. 90). A "1983 survey suggested that 968 of all clinical PT's are involved in teaching exercises to patients" (Data Vol. 3, p. 91). This documentary reference is congruent with his dominant As point (Gregorc, 1982'). This reference also makes the topic practical, addressing a dominant CS need (Gregorc, 1982').

Gagne gives four basic principles for any kind of instruction. Dr. Ellis referred to the five domains discussed Tuesday as the first principle. The external events should match internal events and the external events are different for each of the five domains (Data Vol. 3, p. 91). This information tied together the earlier two hours into this day's session. This showed his dominant as point of developing a "big picture" and its theoretical base and $A R$ behavior for relating it to previous information (Gregorc, 1982*).

He then used a transparency, the left column of which listed instructional events (external conditions of learning); the right side gave motor examples (Data Vol. 3, pp. 66, 91). These included telling patients the objectives 
of task, stimulating recall of prior learning, presenting the stimulus, etc. (Data Vol. 3, pp. 66, 91). He explained each of the entries by giving examples of what might be said or done (Data Vol. 3, pp. 91, 92). This lecture, Dr. Ellis noted, was similar to the one on Tuesday except the differences in providing immediate feedback and demonstration (Data Vol. 3, p. 92). The application of the seven points on the above handout/overhead materials was evidence of his dominant CS point for practicality (Gregorc, $\left.1982^{2}\right)$.

The results of the thesis research were better performance and a better feeling about their physical therapy when the patients were taught using the seven steps (Data Vol. 3, p. 92).

He asked if there were questions or comments and then went on to the fourth session without a break.

$$
\text { Session Number Four }
$$

In this lecture Dr. Ellis discussed teaching patients who had low literacy skills (Data Vol. 3, p. 93). Dr. Ellis gave the demographics of Americans with low literacy skills. He also gave the grade level of reading materials typically used by Americans (Data Vol. 3, p. 93). He then referred to a bar diagram in the handout (Data Vol. 3, p. 67,93$)$. He noted that $50 \%$ of Americans read at or below the ninth-grade level. Sixty-eight percent of medical 
materials for distribution to patients are above the eighthgrade level (Data Vol. 3, p. 93). He then gave some examples of difficult reading patient materials (Data Vol. 3, p. 94). The presentation of data supporting literacy skills levels would be evidence of his dominant As point of providing theoretical support of his information (Gregorc, $\left.1982^{\circ}\right)$. The practical examples showed his dominant cs point (Gregorc, 19824).

Dr. Ellis then gave a description of the low literacy skill patient's processing and thinking strategies. This was based on a book by Doak, Doak, and Root (Data Vol. 3, p. 94). He then gave five points on developing materials for the low literacy skill level patient (Data Vol. 3, pp. $94,95)$.

The Fry readability test was the next subtopic. Dr. Ellis directed the students' attention to the next page of the handout which had a chart used in that test (Data vol. 3, pp. 68, 95). He then showed several examples of typical physical therapy patient materials and gave the grade levels for them. He then noted that the remainder of the handout was examples of various literacy levels of materials (Data Vol. 3, pp. 69-81).

He then summarized the literacy level materials giving hints on developing materials (Data Vol. 3, p. 96). Some hints were defining words, substituting several short, common words for sophisticated ones, etc. The practical 
suggestions were evidence of his dominant CS point (Gregorc, $\left.1982^{4}\right)$.

Dr. Ellis then discussed appropriate drawings, their use on patient materials, and the alignment of text with drawings (Data Vol. 3, p. 97). This practical application is evidence of his dominant CS point (Gregorc, 1982*). While doing this part of the lecture, he asked the students not to comment about his artistic skills which drew laughter (Data vol. 3, p. 97). This use of humor is a demonstration of his AR point (Gregorc, 1982'). He then asked if there were any questions and there were none.

\section{Audiovisual Aids}

Dr. Ellis distributed a handout to the students, which included copies of some transparencies he used (Data Vol. 3, pp. 63-81, 83-97). He also used the chalkboard (Data vol. 3, pp. 84, 87, 97) during the lecture sessions (Data Vol. 3, pp. 83-97). The dominant cs learners would appreciate the handout which served as a plan of the lectures (Gregorc, 1982'). The dominant As learners would appreciate the same handout for the "big picture" that it gave of the lecture sessions (Gregorc, 1982").

The dominant cs learners would be attracted to the prerequisite skills chart depicted on the chalkboard (Data Vol. 3, p. 87) because of its sequential nature (Gregorc, $\left.1982^{4}\right)$. The dominant As learners also would appreciate the 
same illustration for being a "big picture" (Gregorc, 1982'). The instructor, being dominant in both CS and AS, would tend naturally to express ideas with both of those purposes in mind (Gregorc, 1982').

\section{Classroom Design}

The classroom had a chalkboard at one end, the entrance doors on one side, and the windows on the other side. In the lecture room all the tables and chairs faced the front of the room where there was an overhead projector (Data Vol. 3, pp. 83-89, 91, 92). This is the traditional design for the formal lecture which would be attractive to the dominant AS teacher and learner (Gregorc, 1982"; Gregorc, 1985). Dr. Ellis was dominant CSAS (Data Vol. 3, p. 82). The videocamera used in this research was at the rear of the room to the left of center (Data Vol. 3, p. 97).

\section{Summary}

This program devoted a block of one course to teaching and learning theory but did not present styles information. All 38 of the students and the instructor in the teaching and learning theory portion of the course participated in my research. The combined objectives listed in the self study course outlines for these sessions addressed dominant CS, AS, and CR abilities. The teacher was a dominant CSAS. He used a lecture format in each of 
the four 1-hour sessions and included strategies addressing CS, AS, and AR needs.

The classroom used by Dr. Ellis for the four 1-hour sessions was designed for the lecture format which is attractive to the dominant As style. Dr. Ellis' dominant styles were CS and AS and his handouts addressed those styles' needs. His audiovisual aids addressed CS and AS needs.

Just over $60 \%$ of the students were dominant in CS or in a combination of styles including cs. Nearly one fourth of the students were dominant in AS or in a combination of styles including AS. Nearly one half of the students were dominant in $A R$ or in a combination of styles including AR. Just over $20 \%$ of the students were dominant in CR or in a combination of styles including $\mathrm{CR}$.

The post-baccalaureate program studied in Case Three answered my research questions as follows:

1. In fulfilling the teaching and learning theory competency, how do physical therapy entry level programs address variation in mind styles?

Program Three did not present any styles information to the students but Dr. Ellis did model the CS, AS, and AR styles in each of his four oral presentations. Teaching and learning objectives did address CS, AS, and CR abilities. 
2. Within the context of teaching and learning theory, how are objectives about styles expressed in the curriculum documents?

There were no objectives related to styles in any of the curriculum documents or course outlines.

3. How are the various mind styles of the physical therapy students addressed in the learning environment within the teaching and learning theory or styles unit or course?

The objectives in Dr. Ellis' handouts were stated in such a fashion as to address the dominant CS and As mind qualities. The handout materials and audiovisual aids addressed both the CS and AS styles' points. Dr. Ellis addressed dominant CS, AS, and AR needs in all four sessions of his oral presentation. For each session the classroom was arranged for the lecture format which would be most attractive to the dominant As student.

4. How do the teachers address their own mind styles in the classroom situation within the teaching and learning theory or styles unit?

Dr. Ellis was dominant CSAS and addressed his own style by using the lecture approach (dominant AS) based on organized class handout materials (dominant CS) and humor (dominant AR). The last strategy was not of his dominant style. 
5. How are the mind styles of the physical therapy students addressed in the classroom situation within the teaching and learning theory or styles unit?

The students' styles were addressed by providing handouts, cS; suggesting application of information, CS; providing a sequence of development of lessons, CS; and using stories and anecdotes, AR.

In the first 2 hours Dr. Ellis presented theory and teaching methodology related to students and hospital staff, $\mathrm{CS}$ and $\mathrm{AS}$. In the next hour he dealt with teaching motor skills to patients and concentrated on home programs. This was all presented in relation to Gagne's theories. The fourth hour was devoted to teaching patients with low literacy skills. 
CHAPTER VII

\section{CASE STUDY IV}

I visited this post-baccalaureate physical therapy program on two separate occasions for data gathering. In my initial contact with the program chairperson, he told me that learning styles information was given to the students. The primary presentation of styles information was made in the "Educational Processes for the Health Professional" class. It met twice the first week I attended and I videotaped both sessions. I was given tire to present my request for the students' participation in this research. The chairperson scheduled time for me to make a presentation of the Energic Model of Styles after completion of my data gathering. I made that presentation during my second visit to the campus.

All of the 21 students and the three instructors in the education and teaching theory class volunteered to participate in my research. Each signed an informed consent and completed the Gregorc style Delineator ${ }^{\mathrm{TM}}$ Research Instrument (Gregorc, $1982^{\mathrm{b}}$ ). 
overview

This program had an entire course devoted to teaching and learning theory and presented styles information in that course. The styles information included an overview of the field of learning styles as well as descriptions of several different models. The lecture was based on the various levels of styles according to claxton and Murrell (1987) .

The primary instructor was a dominant Ascs; of the other two, one was dominant ARCS, and the third instructor was dominant $C R$. The primary instructor used the lecture strategy including other strategies addressing CS, AS, and $A R$ needs. The second instructor used the lecture; the third instructor used the group discussion format, and both included strategies addressing $C S, A S, A R$, and $C R$ needs (see Appendices $A$ and $B)$.

Over one half of the students were dominant in CS or in a combination of styles including Cs. One third of the students were dominant in AS or in a combination of styles including AS. Slightly over one half of the students were dominant in AR or in a combination of styles including AR. Slightly over one fourth of the students were dominant in $C R$ or in a combination of styles including $\mathrm{CR}$.

The following describes, in detail, how the various mind styles were addressed during the styles unit of the course. 
Teachers' Mind styles

Dr. Franklin

Dr. Franklin, the primary instructor and department chairperson, tested as dominant Ascs (Data Vol. 4, p. 98). The dominant As preference in teaching strategy is the lecture. He used lecture for all of his presentations included in this research (Gregorc, 1985). He gave the basic organization of learning styles models according to Claxton and Murrell. This reflected his AS point by giving the "big picture" of this section. His CS dominance was clear in his going over the schedule for the week. This gave the students the sequence of the styles portion of the course (Gregorc, 1985). He left his notes on the lectern but moved about the room as he lectured, passing by his notes to check them occasionally (Data Vol. 4, p. 117). He used transparencies with detailed information from various sources. This would be in harmony with his dominant CS point for detail and his AS point for referencing documentation (Gregorc, 19824, 1985).

He did not lecture from behind the table or lectern in the front of the room. He moved back and forth across the front of the room (Data Vol. 4, pp. 109, 110, 113, 114, 117). I believe that this non-separation from his students was an expression of his AR point, which scored in the intermediate strength range (Data Vol. 4, p. 98). 
Mr. Gilbert

Mr. Gilbert, who lectured on the Kolb model, scored as a dominant ARCS (Data Vol. 4, p. 99). He scored in the intermediate range for AS but still used the lecture method in his presentation. He stayed close to his notes during most of the lecture but occasionally carried them with him as he moved about (Data Vol. 4, pp. 101-106). This might be evidence of his CS point in wanting not to miss any of the details of or not to get out of sequence in his lecture. This also could be in fulfillment of his role-based AS lecture format (Gregorc, 1985). He used the overhead projector (Data Vol. 4, pp. 101-106) with which he illustrated a chart to guide the students in determining their learning style. This would be attractive to the dominant cs learner because of the desire to do tasks correctly (Gregorc, 1982 ).

Ms. Hall

Ms. Hall was dominant $C R$ (Data Vol. 4, p. 100). She wrote the names of four groups on the chalkboard. She apparently had discussed these groups with the students earlier in the course. This would be an expression of her intermediate level AR point in relating the present topic to something already discussed (Gregorc, 19824). This also would be an expression of her intermediate level cs point for predictability giving direction to the discussion. Her 
intermediate level As point would be expressed by giving the "big picture" of the topic for the day (Gregorc, 1985).

Although her AR score was just above the middle of the intermediate level, she still used discussion. She elicited student comments and responded to them (Gregorc, 1985). Ms. Hall used transparencies during her presentation.

\section{students' Mind styles}

One hundred percent of the 21 students of this postbaccalaureate program participated in my research. Table 4 shows the distribution of styles within the class (Data Vol. 4, pp. 118, 119) .

From Table 4 one notes that 57.14\%, or 12 students, of the class tested as dominant in one or a combination of styles including concrete-sequential. Only 38.108 , or 8 students, tested as dominant in one or a combination of styles including abstract-sequential. Nine students, or $42.86 \%$, of the class tested as dominant in one or a combination of styles including abstract-random. Seven students, or $33.33 \%$, tested as dominant in one or a combination of siyles including concrete-random. 
Table 4

\section{Dominant Styles of Program Four students}

\begin{tabular}{|l|c|c|}
\hline One dominant style & $\mathrm{n}$ & 8 \\
\hline Concrete-sequential & 2 & $9.52 \%$ \\
\hline Abstract-sequential & 1 & $4.76 \%$ \\
\hline Abstract-random & 2 & $9.52 \%$ \\
\hline Concrete-random & 1 & $4.76 \%$ \\
\hline Two dominant styles & & \\
\hline ARCS & 3 & 14.298 \\
\hline ASCR & 1 & $4.76 \%$ \\
\hline CSAS & 5 & $23.81 \%$ \\
\hline CRAR/ARCR & 3 & 14.298 \\
\hline ASAR & 1 & $4.76 \%$ \\
\hline CSCR & 2 & $9.52 \%$ \\
\hline
\end{tabular}


only 1 student tested as dominant in only abstractsequential for which the lecture format is preferred. Two of the 7 with abstract-sequential in combination with another style scored highest in AS. The remaining 5 scored higher in the other style than they did in AS. This leaves 14.298 of the class, 3 of 21 , for whom lecture might be a preferred style of learning.

The structure provided by lecture outlines and schedules should have addressed the CS needs of $57.14 \%$, or 12, of the students. The personal experiences should have met the AR needs of $42.86 \%$, or 9, of the students (Gregorc, 1982 , 1985). The development of the presentations, as an independent study, should have met the $C R$ needs of $33.33 \%$, or 7, of the students (Gregorc, 1982*, 1985).

Even if a person is not dominant in a particular mind style, one will still have some characteristics of that style. This means that some non-dominant As students might still prefer lecture naturally, some non-dominant AR students might prefer hearing of personal experiences, and some non-dominant $C R$ students might prefer the development of presentations. However, students at this educational level who are not dominant in the same style being used in the learning environment may have "learned to play the game of school." 
The self study

Form E

The Form E (Data Vol. 4, p. 1) lists six courses as including information, practice of teaching, and learning theory or both. The primary course covering teaching and learning theory was "Educational processes for the Health Professional." This course entry lists 11 of its objectives as directly addressing the physical therapy education competency. I found an additional 11 objectives in the other course materials.

\section{Course outlines}

The course outline lists 23 objectives for the course "Educational Processes for the Health Professional" (Data Vol. 4, pp. 12, 13). The above discussion of the Form E noted 11 of them. Dominant CS mind qualities of practice, identification, and discussion of methods and skills can fulfill about one third of those objectives. Within the remaining objectives, two mind styles were addressed: (1) dominant $A R$ qualities of discussion of special features of patient education, and (2) dominant AS mind qualities of discussion of teaching role related to the health profession, and discussion of learning theory. Also addressed were a combination of dominant CS and dominant CR mind qualities of problem solving for special considerations of Iife stages, as well as dominant AS and dominant AR 
qualities in a discussion of how non-verbal communications and methods of communication affect teaching and learning.

\section{Handouts}

Dr. Franklin's handout (Data Vol. 4, pp. 18-22) was an updated copy of the syllabus described above. Unit 3 included 11 objectives addressing teaching and learning theory in addition to those already discussed in the first two units.

Mr. Gilbert's handouts consisted of the Kolb Learning style Inventory and graphing materials to plot the inventory scores. The materials are attractive to the dominant CS learner because of their hands-on nature and the dominant AR because of learning more about themselves (Gregorc, 1982^).

During my absence from the program, Ms. Hall had distributed the criteria for the two projects (Data Vol. 4 , pp. 23, 24) required in this class. Various criteria addressed the dominant styles of CS, AS, AR, and CR. One of the basic needs of the dominant CS was met by the provision of guidelines or expectations for completing the assignment (Gregorc, 1982).

The "Course Schedule" (Data Vol. 4, pp. 21, 22) was given to the students. This addressed dominant cs desires for being able to plan for completion of assignments and the dominant AS needs for the "big picture" (Gregorc, 1982"). 
The students purchased "Coursepaks" for use as reading materials for the class sessions (Data Vol. 4, pp. 26-95). The reading materials address the desire of the dominant AS learner for learning through reading (Gregorc, $\left.1982^{4}\right)$.

\section{oral Presentations}

Dr. Franklin

During the first sessions, Dr. Franklin, the first instructor addressing styles, began by giving an overview of the field of learning styles. The overview included the onion-skin model of claxton and Murrell that he had drawn on the chalkboard before the class session began (Data Vol. 4, p. 101). This was an expression of both his dominant AS "big picture" and dominant cs giving of structure. He then said: "The literature suggests that there are a lot of differences between learning style of students and instructors at the college level" (Data Vol. 4, p. 101). This not only is indicative of his dominant As point referring to documentation but also of his intermediate level AR point by relating it to something important for the students (Gregorc, 1985). He reviewed the schedule for the week which addresses the dominant CS point (Gregorc, 1982*, 1985). At this point he turned the class over to $M r$. Gilbert. 
Mr. Gilbert

Mr. Gilbert started by telling the class how he became interested in learning styles. This story addresses his AR point. He also described the research that he has done with the Kolb model. This historical perspective would be a reflection of his intermediate level As point. He then gave two clinical examples of how Kolb's model applies to physical therapy. This practical application of the model would be an expression of his low dominant level cs point. During this time he stayed close to his notes that were placed on the table in front of the classroom. This reflects his cs attention to detail.

He then moved to a discussion of the theoretical framework of the Kolb model which reflects his intermediate AS point. He gave the process of learning that is sequential in nature and thus attractive to the dominant cs individuals. Mr. Gilbert also discussed those areas that determine one's style. These include heredity, past life experiences, demands of environment, and socialization. This information would be attractive to the dominant AS learner because of the theoretical substrate of the model. He also discussed gender influence on style. At this point he discussed the acquisition, specialization, and integration stages of the human growth process. He emphasized that there are various areas of 
conflict that may enhance learning. This is a practical application of the dominant CS point.

Using the terms acquisition, specialization, and integration of information he moved into a description of the four modes of the styles of Kolb's model. Mr. Gilbert briefly mentioned challenge as it relates to changes in job responsibilities and then named the four learning styles: Diverger, Accommodator, Assimilator, and Converger. He then used a transparency which had a "target" overlay, and with it he showed that the closer to the center of the graph one scored, the more integrated a learner would be. The further toward the periphery of the graph one's score was, the more difficulty the learner would have with other learners of different styles (Data Vol. 4, p. 104).

Mr. Gilbert administered the Kolb Learning style Inventory to the students. This would be an expression of his dominant CS point by giving the students a hands-on experience. After the students completed their Learning style Inventories, he described his research project. This was an expression of his As point.

He then described each of Kolb's four learning styles in detail. This definition was in keeping with his dominant CS point and his dominant $\mathrm{AR}$ point by creating a personal relationship with the information for the students. He posed the problem that learning style could be influenced 
by the occupation of physical therapy. Problem solving is an expression of $\mathrm{Mr}$. Gilbert's intermediate level CR point.

He mentioned that some clinicai instructors have asked for the student's learning style or students of a particular learning style to be assigned to them. This is a practical example and expresses his dominant cs point. He stated some of his research results. There was no significance between grades assigned by the clinical instructor and congruence of the learning styles of the clinical instructor and the student. Also, learning style was not a predictor of clinical success. Reporting this research data would reflect his intermediate As point. As an expression of his dominant cs point he stated some of the practical problems of his research project. He then cautioned: "learning styles, while important, are not the end all and be all" (Data Vol. 4, p. 106).

Except for occasional open gestures, friendly facial expression, and his opening story, he did not teach in his dominant AR style. His lecture format was a role-based AS style in which he scored at an intermediate level. He occasionaliy gave information reflecting his backup dominant cs point.

\section{Ms. HaII}

Before class started, Ms. Hall wrote the names of four target groups of individuals on the chalkboard. After the third name, she asked the class if a fourth group had 
been discussed last time. This visual illustration would be attractive to the dominant CS individuals because of predictability of the class session. The illustration would provide the "big picture" for the dominant As learners, and her relating this day's lesson with previous topics in the class would be for the dominant AR students. Ms. Hall scored only at intermediate leveis in each of these three points, cs being only low intermediate level. She then used a transparency with six questions to consider in a presentation to each of these target groups. These questions included areas of information to be presented, goals of presentation, teaching methods, level of terminology, dress of presenter, and expected problems or difficulties. Ms. Hall elicited responses from the class during this session which would be a reflection of her intermediate level AR point preference for group discussion. She asked the students to compare the motivation of the various target groups. She asked if there were different opinions than those already expressed. This drawing out of information from the class is an expression of her intermediate level AR point. One student said that he was expressing the opinions of another student. She asked if the other student was a ventriloquist. This was a friendly tolerance of relationships in the class and congruent with her AR point. 
She asked for other comments. These centered around variability within each group. A prepackaged program, therefore, would not be meaningful to all of the group members. Terminology also must be chosen to match each group. This is setting a standard which is attractive to the dominant cs learners. A student made a categorical comment about two target groups and another student disagreed with that statement. Ms. Hall easily maintained control of the discussion (an AR mediation ability) and worked the comments into her lesson. This also reflects the problem-solving abilities of her dominant CR point.

She asked on what basis should media be chosen. She also did the same for dress and content. Her example for content was centered around the question, "How much does your group need to know about anatomy?" (Data Vol. 4, p. 108). She presented standards of dress for presenter and target groups' comfort and appropriateness. This is attractive to the dominant cs learners because it sets expectations. Although she was dominant in the $\mathrm{CR}$ point she used group discussion, from the AR point, almost exclusively in her session. Her gestures were natural and appropriate, also from the AR point. The classroom design, however, was for dominant AS (lecture) format (Data Vol. 4, p. 108).

\section{Dr. Franklin}

Dr. Franklin started his session by asking why one should be concerned about learning styles. He then stated 
that learning styles caused a great change in the way people thought about education.

He then set a historical perspective (an expression

of his dominant AS point) by saying that in the Bagavad Gita

it was said there were four ways to achieve Nirvana.

Interjecting a little humor he said that Thorndyke

made an "amazing" discovery that there is a relationship

between student achievement and intelligence. Humor is an

expression of his intermediate level AR point.

Learning styles has changed the approach to

education to using a variety of teaching strategies and not

limiting time. He continued to introduce styles by

reminding the students that they had completed the Myers-

Briggs Type Indicator last year. This relating of styles to their personal experience would be a reflection of his intermediate level AR point. He gave some historical perspective of the recency of learning styles research and reviewed claxton and Murrell's four levels of learning styles models. Both are reflections of his dominant AS point. He also indicated that personality is harder to change than instructional preference. This also reflects his dominant AS point by giving an overview cf the field of learning styles application.

Dr. Franklin then said that he would go through each of the levels of learning styles models so the students would have some idea how to use them. This is a sign of his 
CS need for prediction and application. He suggested that if an individual is not learning there may be a style mismatch and then began his descriptions of the various models. This was a reminder that styles can have practical application, a cS characteristic.

The first personality model Dr. Franklin discussed was the field-dependence/field-independence model. He described the three tests used to determine style as well as the attributes of the two groups of learners. This is characteristic of his dominant cs point in giving detail and characteristics of the model. He also described the "lumpers" and the "splitters" in the learning styles field. He completed his description of this model by indicating that the research has demonstrated little difference in learning with either a match or mismatch of teacher and learner.

The Myers-Briggs Type Indicator (MBTI) was the next personality model that he described. Dr. Franklin listed the four dichotomous scales and said that this inventory has high face validity and that it creates dialogue. This dialogue is probably very worthwhile although it does not give a basis for discussing a mismatch, but does recognize the possibility. Up to this point he had been giving the characteristics of the MBTI, which is in keeping with his dominant CS point. He suggested his personal bias in that Jung taught that we should learn about ourselves and then 
try to achieve a balance. Dr. Franklin's belief is that the result of the MBTI can be used as a self-fulfilling prophecy: this confirms the way $I$ and, so that is the way I will be.

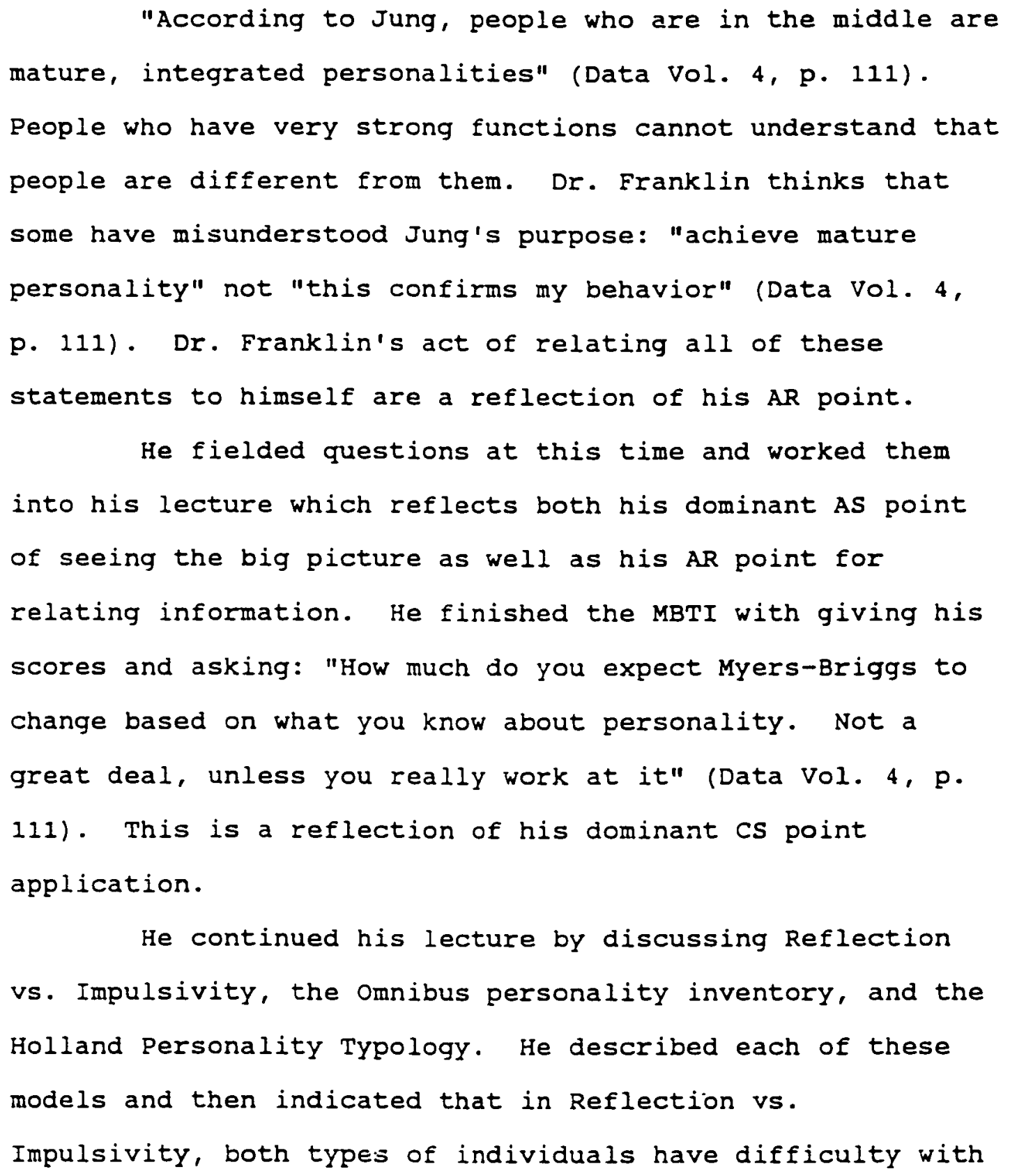

"According to Jung, people who are in the middle are mature, integrated personalities" (Data Vol. 4, p. 111). People who have very strong functions cannot understand that people are different from them. Dr. Franklin thinks that some have misunderstood Jung's purpose: "achieve mature personality" not "this confirms my behavior" (Data Vol. 4, p. 111). Dr. Franklin's act of relating all of these statements to himself are a reflection of his AR point. He fielded questions at this time and worked them into his lecture which reflects both his dominant As point of seeing the big picture as well as his AR point for relating information. He finished the MBTI with giving his scores and asking: "How much do you expect Myers-Briggs to change based on what you know about personality. Not a great deal, unless you really work at it" (Data Vol. 4, p. 111). This is a reflection of his dominant cs point application.

He continued his lecture by discussing Reflection vs. Impulsivity, the Omnibus personality inventory, and the Holland Personality Typology. He described each of these models and then indicated that in Reflection vs. Impulsivity, both types of individuals have difficulty with 
test questions. This reflects his dominant cs application. He used a transparency from claxton and Murrell during his description of the Holland model. This reflects his dominant CS point for detail. He also indicated that the Holland model can be used to help someone select an appropriate work environment. This is also his dominant cs application.

He then began his description of the Information Processing models. He started by reminding the students that they had already heard about Kolb's model and that I would be presenting Gregorc's model later in the quarter. Mentioning Kolb and Gregorc would be a reflection of his dominant CS completeness and predictability and his dominant AS big-picture orientation.

He then described the simplest model using the labels holists and serialists, which are also described as comprehensive and operations learners. Holists learn from the top, down and serialists from the bottom, up. Giving the characteristics is an expression of Dr. Franklin's dominant CS point. One student commented: "like the lumpers and splitters". Dr. Franklin agreed and said that the comprehensive learners would be the lumpers and the operations learners would be the splitters. Relating the students' comments to the material would be an expression of his AR mediation abilities. 
When naming the siegel and siegel model he smiled and said "not seagull" (Data Vol. 4, p. 112). This humor would be an expression of his AR mind qualities. He described the educational set as factual set and conceptual set. He applied this to the classroom by saying that teachers can teach facts first and concepts second some of the time and concepts first and facts second some of the time if they believe that their learners are of both types. This application would be a cs mediation ability.

When he started to describe Schmeck's model, he gave an anecdote about his previous APTA election campaign that was a humorous twist of the name. This example of humor is from the AR mind quality. Schmeck describes the shallow, reiterative learner and the deep elaborative learner. When describing the former Dr. Franklin smiled and said: "Now wouldn't you like to be identified as a shallow, reiterative learner?" (Data Vol. 4, p. 113). "One of the studies.. . showed that the deep elaborative learner had a better memory, was a faster learner, and had higher GPA's. Now are you surprised?" (Data Vol. 4, p. 113). He smiled and there was laughter from the class. This also was an expression of his AR point. He indicated that one can change the way a learner thinks by requiring him to use deep, elaborative thinking on tests. This is CS application.

He then briefly pointed out that kolb has applied Dewey's ideas the way Dewey intended. He also noted that 
management and nursing have used this model. This application comes from Dr. Franklin's dominant cs mind qualities. He then theorized four questions arising from information processing models. This theorizing would be a part of his dominant As mediation abilities. He indicated that Kolb has been used to reduce mismatches, a cS application. Having a knowledge of learning style may not help one to change learning style but probably helps improve satisfaction with final outcome. This also is from his dominant CS mind quality of practical application.

In the Social Interaction models Dr. Franklin included Mann's model. He defined the eight clusters of students that Mann found in the learning environment. Describing the characteristics of the clusters is part of Dr. Franklin's dominant CS mind qualities. He did exhibit some AR behavior when he smiled at the definitions of two of the clusters. One of those two clusters were the Heroes who felt superior, had high SAT scores, and low GPA's.

When describing the Grasha and Reichmann model he used a transparency from Claxton and Murrell which would be attractive to the dominant AS learner as documentation (Gregorc, 1982*). It is also an expression of his dominant CS point for completeness and detail and his dominant AS point for the big picture (Gregorc, 1982*, 1985). He indicated that Grasha and Reichmann noted that their findings demonstrated improved satisfaction in learning but 
did not increase learning (Data Vol. 4, p. 115). A student asked about the difference between teaching one on one and groups. Dr. Franklin responded that therapists must work to determino the style of the client and gave an example of the extremes of variability. The way he ixpressed it brought laughter from the class which could be considered AR behavior. The example is from his dominant cs mind qualities.

The Furman and Jacobs model examines teachers and students. Dr. Franklin used a transparency from claxton and Murrell to illustrate the descriptors of the dependent, collaborative, and independent teachers and learners (Data Vol. 4, p. 115). This was attractive to the dominant cs learners (Gregorc, 1982*, 1985).

The last Information Processing model Dr. Franklin described was the Learning orientation, Grade orientation (LOGO) model. He described each group which reflected his dominant cs point. His definition of the Low LO, Low Go was that the individual was in school for a good time and to avoid getting a job. The student was in school to spend time, not to learn anything. This brought a laugh from the students. The use of humor is an AR mediation ability.

Dr. Franklin started the category of social Interaction models with a description of the instrumental and developmental learners. The examples that he used were humorous to the class, demonstrating AR behavior. Since the 
class time was over he said that "If you can stand five minutes I can finish this.. . lock the door!" He pointed toward the door and laughed, a demonstration of AR behavior of using humor.

He began discussing the Instructional Preference models with Joseph Hill's model. He mentioned that a great deal was done to match students with the instructional styles of teachers. Hill's idea was to teach the students rather than faculty about styles because the students were more flexible than the faculty. This was a demonstration of Dr. Franklin's dominant As mind quality of interest in theory and his dominant CS mind quality of practical application. He gave an example of its use in medical education.

When he started his discussion of Canfield, he said that the physical therapy literature primarily used Kolb, then Canfield, and now Gregorc (he pointed to me and chuckled). This was As behavior referring to documentation and AR behavior using humor. Dr. Franklin stated that matching learning and teaching styles improves learning and that teaching needs to be based on other things than just learning styles. He also said that emphasizing the learners' behaviors always improves satisfaction with learning. These descriptive statements are from his dominant cs mind qualities. 
He finished the session by stating that if the therapist can adjust some as a teacher then one might be able to improve learning.

His lectures reflected theoretical information, (dominant AS style) and application of the information (dominant CS style). He would interject humor, personal examples, and respond to students' somments and questions. These all reflected his intermediate level AR point. He used transparencies that contained detailed iniormation. These would appeal to the dominant CS learners. At times he would respond to his own statements with a smile or halfsmile as though seeing a humorous interpretation. This also would be evidence of his intermediate level AR point. Although he used the dominant As lecture format he talked to the students rather than "lectured" to the students, again reflecting his AR point. This course gave the students a rather in-depth description of two style models and a general introduction to the field of styles. The general introduction was through a brief description of 13 models.

\section{Audiovisual Aids}

During the first session Dr. Franklin had drawn a cross-sectional illustration of the "onion-skin" model of Claxton and Murrell on the chalkboard (Data Vol. 4, p. 101). This would appeal to the CS structural needs and the As big picture needs. During his other lecture he used transparencies (Data Vol. 4, pp. 108-117). 
During Mr. Gilbert's portion of the course (Data Vol. 4, pp. 101-106) he used transparencies and handouts. The handout was the Kolb Learning style Inventory and graphing materials to determine learning style. This would be attractive to the dominant AR learner because of the interest in relating one's self to the material. It also could be addressing the dominant As learners' needs in providing evidence of a theoretical basis for the model. Mr. Gilbert also used transparencies to help students to graph their scores. This would be attractive to the dominant CS learner who wants specific directions (Gregorc, 1こ224, 1985).

Ms. Hall used the chalkboard to name the groups under discussion and to note important points. This would be an expression of her low intermediate level cs point for predictability of direction of the lecture and for her high intermediate ievel AS point for the "big picture" (Gregorc, 1982'). None of the teachers distributed lecture outlines to the students.

\section{Classroom Design}

All the desks faced forward except four or five that were against the left side of the classroom, relative to the students. There iras a chalkboard mounted on the front wall and a screen in the left front of the classroom, relative to the students. In the front of the room was a long table 
with a lectern next to the students' left end of it. When overhead transparencies were used the projector was near the center front of the room (Data Vol. 4, p. 117). This design meets the needs of the lecture format that is an As teaching medium (Gregorc, 1985). Dr. Franklin was dominant ASCS, Mr. Gilbert, dominant ARCS, and Ms. Hall, dominant CR; all used the same arrangement for their sessions (Data Vol. 4, pp. 98-100). The videocamera for this research was placed at the right rear of the room (Data Vol. 4, p. 117).

\section{Summary}

This program had an entire course devoted to teaching and learning theory and presented styles information in that course. The styles information included an overview of the field of learning styles as well as descriptions of several different models. The lecture was based on the various levels of styles according to claxton and Murrell (1987).

All the students and the three instructors in the styles portion of the course participated in my research. The classroom used by all three instructors was designed for the lecture format that is attractive to the dominant AS style. Dr. Franklin's (the primary instructor) dominant styles were AS and CS but his handouts addressed the dominant CS, AS, and AR styles' needs. During his first session, which was just introductory to learning styles, he addressed CS, $A S$, and $A R$ needs and during his second session 
he addressed those same three styles' needs. His audiovisual aids addressed dominant As needs. Mr. Gilbert's dominant styles were AR and $C S$ and his handout materials consisted of a learning style instrument and graphing materials for that instrument. His lecture addressed all four styles' needs and his visual aids addressed dominant CS, AS and AR needs. Ms. Hall was dominant $C R$ but her handout materials met the needs of all four styles. In her oral presentation she met all four styles' needs but with her audiovisual aids she met the behavioral needs of the cs and AS.

Almost $60 \%$ of the students were dominant in cs or in a combination of styles including cs. One third of the students were dominant in AS or in a combination of styles including AS. Slightly over one half of the students were dominant in AR or in a combination of styles including AR. slightly over one fourth of the students were dominant in $\mathrm{CR}$ or in a combination of styles including $C R$.

The post-baccalaureate program studied in Case Four answered my research questions as follows:

1. In fulfiling the teaching and learning theory competency, how do physical therapy entry level programs address variation in mind styles?

Program Four presented a considerable amount of styles information to the students and two of the three 
instructors modeled all four styles in the oral

presentations while the other modeled three of the styles.

2. Within the context of teaching and learning theory, how are objectives about styles expressed in the curriculum documents?

There were no objectives related to styles expressed in the form $\mathrm{E}$ or the course outlines.

3. How are the various mind styles of the physical therapy students addressed in the learning environment within the teaching and learning theory or styles unit or course?

There was a good deal of styles information presented to the students. The objectives were stated in such a fashion as to address all four dominant mind qualities. All four styles' points were addressed when considering all three teachers' handout materials. Dr. Franklin addressed dominant CS, AS, and AR needs in his oral presentation; Mr. Gilbert and Ms. Hall both addressed all four styles' abilities. The audiovisual aids of Dr. Franklin and Ms. Hall were attractive to the dominant CS and AS. Mr. Gilbert's were attractive to the dominant CS, AS, and AR styles. The classroom was arranged for the lecture format which would be most attractive to the dominant as student. 
4. How do the teachers address their own mind styles in the classroom situation within the teaching and learning theory or styles unit?

Dr. Franklin was dominant ASCS and addressed his own style by using the lecture approach (dominant AS) based on organized class handout materials (dominant CS). He also used humor from his intermediate level AR point. Mr. Gilbert, who was dominant ARCS, used the lecture strategY and did not address his AR style needs. Ms. Hall was dominant $C R$ and used a group discussion approach in her session, also not addressing her dominant style.

5. How are the mind styles of the physical therapy students addressed in the classroom situation within the teaching and learning theory or styles unit?

The students' styles were addressed by providing handouts, CS; using transparencies, CS and AS; testing the students for style, $C S$ and $A R ;$ giving examples, $A R$; telling stories and involving the students in generating information, AR.

This program presented an overview of the learning styles field, a relatively broad description of many of the styles models, and modeled all four of the mind styles of the Energic Model of Styles. 
CHAPTER VIII

\section{CROSS CASE ANAIYSIS}

I visited two oaccalaureate and two postbaccalaureate programs. When interpreting these results, one needs to remember that the data are from only four physical therapy programs. Neither of the baccalaureate programs had an entire course devoted to teaching and learning theory. They presented that information as a block within another course. Program 2, one of the baccalaureate programs, presented styles information and the other did not. Program 1 did not present styles material but was interested enough to schedule time within the class for a presentation of the Energic Model of styles as well as a special presentation to the faculty. Program 2 allowed a voluntary attendance presentation for the students. One of the post-baccalaureate programs, Program 4, had an entire course devoted to teaching and learning theory. Program 3 presented that information as a block within another course. Program 4 also presented styles information and Program 3 did not. Program 4, though they presented styles material, also was interested enough to schedule time within the class for a lecture on the Energic 
Model of Styles. Program 3 allowed a voluntary attendarice presentation for the students as well as a special presentation to the faculty.

All 34 students of Program 1 and 54 of the 59 students of Program 2, both baccalaureate programs, participated. All of the 38 students of Program 3 and all the 21 students of program 4, both post-baccalaureate programs, participated. This gave me 147 of 152 (96.71\%) student participants. All three instructors of Program 1 , the instructor of Program 2, the instructor of Program 3 , and the three instructors of Program 4, involved in the teaching and learning theory presentations, participated.

\section{Teachers' Mind styles}

The primary instructors of Programs 1 and 4 were both dominant ASCS and both taught using strategies addressing the mediation abilities of the CS, AS, and AR; only Program 1 addressed $C R$ (see Table 5). Both primary instructors were also the program chairpersons.

The instructors of programs 2 and 3 were both dominant CSAS and taught in the CS, AS, and AR styles (see Table 5).

The second and third instructors in Program 1 's course were both dominant CS. One taught in the CS and AS styles and the other taught in the CS, AS, and AR styles (see Table 5). 
Program 4's second instructor was dominant ARCS and taught in the CS and AS styles. The third instructor was dominant $C R$ and taught using $C S$ and $A R$ qualities (see Table 5) .

Program 4's instructor, Ms. Hall, was the only teacher who did not teach in her dominant style (see Tabie 5). All of the other instructors of the various programs taught at least part of the time in either their dominant style or backup dominant style.

Table 5

Dominant Styles of Teachers of Each program and Their Own Styles Addressed in Their oral presentations

\begin{tabular}{|c|c|c|c|}
\hline Program & Level & $\begin{array}{c}\text { Dominant } \\
\text { styles }\end{array}$ & $\begin{array}{c}\text { Styles } \\
\text { Addressed }\end{array}$ \\
\hline 1 & Baccalaureate & $\begin{array}{l}\text { AS, CS } \\
\text { CS } \\
\text { CS }\end{array}$ & $\begin{array}{lll}C S, & A S, A R, & C R \\
C S, A S & \\
C S, & A S, A R & \\
\end{array}$ \\
\hline 2 & Baccalaureate & CS, AS & $C S, A S, A R$ \\
\hline 3 & $\begin{array}{l}\text { Post- } \\
\text { baccalaureate }\end{array}$ & CS, AS & $C S, A S, A R$ \\
\hline 4 & $\begin{array}{l}\text { Post- } \\
\text { baccalaureate }\end{array}$ & $\begin{array}{l}\text { AS, CS } \\
A R, C S \\
C R\end{array}$ & 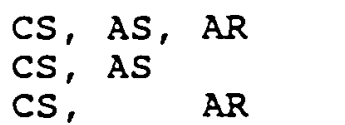 \\
\hline
\end{tabular}

All of the teachers of Programs 1, 2, and 3 addressed their own dominant styles while making their presentations. Mr. Gilbert, of Program 4, addressed his CS dominance but not his AR dominance during his lecture. Ms. 
Hall, also of Program 4, is the only teacher in my study who did not address her own dominant style during her class session.

The proportion of various styles addressed within the classroom is discussed in the section "Oral Presentation" below.

\section{students' Mind Styles}

Although $Y$ in (1989) does not agree with the pooling of data from multiple cases, this was done as a point of interest for parts of this summary.

of the 152 students in the four programs, 147

(96.718) participated in this research. The majority of the students, 87 or $59.18 \%$, were dominant CS or a combination of dominant styles including $c S$. Interestingly, the range among the four programs was from $57.14 \%$ to $61.76 \%$. This was the narrowest range among the four dominant styles or dominant style combinations. The next highest dominant style or combination of dominant styles was AR comprising 77 (52.38\%) of the students in the four programs. The program constituent figures ranged from $42.86 \%$ to $57.41 \%$, the third narrowest range. The third highest dominant style or combination of dominant styles was $C R$, with 41 (27.898) of the students in the four programs. The range for $C R$ was from $21.05 \%$ to $33.33 \%$, the second narrowest. The least dominant style or combination of dominant styles was AS with 
33 (22.45\%) students in the four programs. This style also had the widest range: $17.65 \%$ to $38.10 \%$.

It is evident that both the dominant $C S$ and $A R$ styles were represented by just over one half of all the students in the four programs. Dominant cs consistently made up about 608 of the classes. Dominant AR made up anywhere from 438 to $57 \%$ of the classes. Dominant $A S$ and $C R$ each made up about one fourth of the classes.

\section{The self study Form E}

Program 1 listed one primary course plus seven others that included teaching and learning theory. Program 2 listed two courses, one of which was the primary course, including teaching and learning theory and it also included styles information. Program 3 listed two courses that included teaching and learning theory, one of which was the primary course. Program 4 listed six courses with one primary one entirely devoted to teaching and learning theory and including learning styles information.

\section{Course outlines}

The primary course covering teaching and learning in Program 1 (see Table 6) listed 27 oijeciives specifically addressing teaching and learning. Those objectives included strategies attractive to CS, AS, and AR learners. 
Although the primary course covering teaching and learning theory in Program 2 (see Table 6) listed only one objective addressing teaching style, it was attractive to the CS, AS, AR, and CR styles. Program 3's (see Table 6) primary course listed two objectives addressing teaching and learning. The first one addressed AS mind qualities and the second both AS and CS mind qualities. This program's Self study document included individual lecture and laboratory session outlines and objectives. Of the lecture objectives, the CS, AS, and $C R$ mind qualities were addressed. Of the laboratory objectives, all but one addressed both CS and CR mind qualities. The remaining one addressed only CS qualities.

$$
\text { Program 4's (see Table 6) course outline for the }
$$
learning and teaching theory course listed 23 objectives. The CS, AS, $A R$, and $C R$ mind qualities were addressed at least once each among those objectives.

Table 6

Styles Addressed in the Self-study Report Course Outline objectives of Eaci Program

\begin{tabular}{|c|l|l||}
\hline Program & \multicolumn{1}{|c|}{ Level } & Styles Addressed \\
\hline 1 & Baccalaureate & CS, AS, AR \\
\hline 2 & Baccalaureate & CS, AS, AR, CR \\
\hline 3 & Post-baccalaureate & CS, AS, CR \\
\hline 4 & Post-baccalaureate & CS, AS, AR, CR \\
\hline
\end{tabular}




\section{Handouts}

Program I's teacher, Dr. Allen, distributed handouts listing 20 techniques and subtechniques that collectively addressed all four styles' needs. Ms. Boone did not distribute handouts but used slides and transparencies instead. Ms. Clark's handouts stated seven objectives among which all four styles' necds were addressed (see Table 7).

Table 7

Styles Addressed in the Handout Materials of Each Teacher in Each Program

\begin{tabular}{|c|l|l|l||}
\hline Program & \multicolumn{1}{|c|}{ Level } & \multicolumn{1}{|c|}{ Teacher } & \multicolumn{1}{c|}{$\begin{array}{c}\text { Styles } \\
\text { Addressed }\end{array}$} \\
\hline 1 & Baccalaureate & $\begin{array}{l}\text { Dr. Allen } \\
\text { Ms. Boone } \\
\text { Ms. Clark }\end{array}$ & $\begin{array}{l}\text { CS, AS, AR, CR } \\
\text { (no handout) } \\
\text { CS, AS, AR, CR }\end{array}$ \\
\hline 2 & Baccalaureate & Mr. Dennis & CS, AS, AR \\
\hline 3 & $\begin{array}{l}\text { Post- } \\
\text { baccalaureate }\end{array}$ & Dr. Ellis & CS, AS \\
\hline 4 & $\begin{array}{l}\text { Post- } \\
\text { baccalaureate }\end{array}$ & $\begin{array}{l}\text { Mr. Franklin } \\
\text { Ms. Hall }\end{array}$ & $\begin{array}{l}\text { CS, AS, AR, CR } \\
\text { CS, AR, AS, AR, CR } \\
\text { CS, AS, AR }\end{array}$ \\
\hline
\end{tabular}

Program 2's instructor used handouts with objectives indirectly addressing teaching and learning. collectively these objectives were congruent with the CS, AS, and AR styles (see Table 7). The handouts duplicating the transparencies were attractive to the CS learners. The handouts giving answers to problems were also addressing the cs needs of knowing the correct way to interpret situations. 
Program 3's instructor's objectives collectively addressed the dominant CS and AS abilities (see Table 7). Those handouts of the transparencies met the needs of the dominant cs learners. The instructions on the Fry test also addressed the dominant cS mind qualities of how to perform that test correctly. Program 4's syllabus addressed all four styles' mediation abilities (see Table 7). Mr. Gilbert's learning style materials addressed the dominant CS and AR needs. Ms. Hall's criteria for the two assigned projects for the class addressed all four styles' needs. The course schedule also fulfilled the predictability needs of the dominant Cs learners and the big picture needs of the dominant AS learners.

The handouts of Programs 1 and 4 met the needs of all four styles. The handouts of Program 2 addressed the CS, AS, and AR mind qualities. Program 3's handouts addressed the CS and AS mediation abilities.

\section{Oral Presentations}

Lecture was the primary As strategy observed in this research (see Tables 5 and 8 ). The organization and predictability factors within their presentations were the main CS qualities used. Group discussion, eye contact, addressing students' comments and questions, and standing close to the students' desks were the AR strategies used. Problem solving and variety of strategies were the main CR 
strategies used by the instructors, although $C R$ mind qualities was the least addressed of all the styles (see Table 8).

Although in Program 1 the lecture strategy was the primary one used, Dr. Allen incorporated strategies from the CS style frequently, other As strategies about one third as much as for CS, AR strategies about twice as much as for other AS strategies, and $C R$ the least (see Tables 5 and 8 ). Ms. Boone incorporated some CS strategies into her lecture (see Table 5). Ms. Clark included some strategies from CS and about half as many from $A R$ in her lecture (see Table 5).

Table 8

Dominant styles Addressed in the oral presentations of Each Program

\begin{tabular}{|c|l|c|}
\hline Program & Level & $\begin{array}{c}\text { styles } \\
\text { Addressed }\end{array}$ \\
\hline 1 & Baccalaureate & CS, AS, AR, CR \\
\hline 2 & Baccalaureate & CS, AS, AR, CR \\
\hline 3 & Post-baccalaureate & CS, AS, AR \\
\hline 4 & Post-baccalaureate & CS, AS, AR, CR \\
\hline
\end{tabular}

In Program $2 \mathrm{Mr}$. Dennis used two main strategies: lecture and group discussion. Within those strategies, he used $C S$ and $A R$ the most and about equally, AS about half as much as either CS or AR strategies, and about half as many $\mathrm{CR}$ strategies as AS (see Table 8 ). 
Dr. Ellis in Program 3 used lecture and incorporated strategies from CS the most, about three fourths as many AS as CS, AR about one half as much as $A S$, and none from the $C R$ style (see Tables 5 and 8 ).

Again the lecture was the primary strategy used in Program 4. Dr. Franklin included strategies from the CS style most frequently, about one half as many As, about $50 \%$ more $A R$ than $A S$, and none from $C R$ (see Table 5). Mr. Gilbert included one half again as many strategies from CS as from AS, and about one third as many AR as AS. He used CR strategies the least (see Table 8). Ms. Hall included strategies from $A R$ twice as much as from Cs, three times as much as $A S$, and $C R$ the least (see Table 8 ).

As noted in Table 8 , Programs 1,2 , and 4 addressed all four styles needs during the oral presentation. Only Program 3 did not address all four styles in the oral presentation, leaving out only dominant $C R$.

In summary, of the total number of strategies included in the oral presentations of each program, dominant CS strategies occurred just under one half of the time. Not inciuding lecture, dominant AS strategy frequency ranged from approximately one fifth to one third of the total strategies. Dominant AR strategy frequency ranged from less than one fifth to about one third of the total. Dominant $\mathrm{CR}$ strategies ranged from no use to less than one fifth of the total strategies used. 


\section{Audiovisual Aids}

The main visual aids used in the four programs were overhead transparencies and handout materials including copies of transparencies and lecture outlines. Also used were videotape and slides.

\section{Program 1}

Dr. Allen in Program 1 distributed notes which could address both CS and AS style needs and he used a videotape of various clinical scenarios which would be attractive to the dominant AR learners.

Ms. Boone did not distribute any handouts but did use transparencies and siides as examples of audiovisual materials. These would be attractive to the dominant Cs learners as examples of how those items should be properly developed.

Ms. Clark gave the students a very complete outline of her presentation that would be appealing to both the dominant CS and dominant AS learners. She referred back to the videotape from the previous session for the dominant AR learners. None of the instructors used audiovisual aids that addressed the needs of the dominant $C R$ learners.

\section{Program 2}

Mr. Dennis distributed a hardout to the students, used overhead transparencies, and the chalkboard during his presentation. The way he used them would be attractive to 
the cs learner for the flowchart generated on the chalkboard, the AS learner for the big picture development from the handout, and the inclusion of student input that he wrote on the transparencies would address the dominant AR learners' needs.

In the seminar groups he used the chalkboard to illustrate their input as they responded to nis challenge to identify his style according to the Myers-Briggs model. This use of the chalkboard would be consistent with dominant CR needs.

Program 3

Dr. Ellis used detailed handouts that included copies of some of his transparencies as well as examples of various levels of reading ability. The handout would be fulfilling the dominant CS and dominant AS learners' needs. He used the chalkboard to illustrate sequence which would fulfill dominant $C S$ and dominant AS needs. He did not use audiovisual aids in either dominant $A R$ or dominant $C R$ fashion.

\section{Frogram 4 \\ Dr. Franklin illustrated the field of learning} styles models by drawing the onion-skin model on the chalkboard. This gave the big picture to the dominant As learners. He also used transparencies during his other lecture to illustrate various tables of information which 
also would fulfill the documentation needs of the dominant AS as well as the detail needs of the dominant CS.

Mr. Gilbert used the Kolb Learning Style Inventory which would involve student activity and therefore be attractive to the expressive needs of the dominant AR. He also used transparencies and handout materials relative to the Kolb model. This would address the needs of the dominant CS for detail and the dominant As for documentation of theory.

Ms. Hall used the chalkboard to illustrate the topics under discussion during her session. This was attractive to the dominant CS and dominant As learners. None of the instructors distributed lecture notes to the class.

In summary, two of the three instructors of Program 1 used audiovisual materials which addressed dominant CS, AS, and AR needs while the other used materials appealing to only dominant CS. The instructor of Program 2 used visuals in a manner attractive to all four styles. The teacher at Program 3 used visuals addressing only the dominant CS and AS styles' needs. Two of the three instructors of Program 4 addressed the needs of the dominant CS and AS learners with their visual materials while the other instructor's visuals were used in a manner attractive to the dominant CS, AS, and AR students. 


\section{Classroom Design}

The classroom design for each of the four programs was that of the dominant As lecture format. Program 3 used tables and chairs while the other three programs had individual student desks. All had chalkboards at the front of the classroom as well as a screen for the transparencies at the front of the room.

Program 2 also conducted seminar sessions and the classroom was arranged with the desks in a circle so that each student faced all the other students. This is consistent with the dominant AR group discussion classroom design. Although the chairs were so arranged, from time to time Mr. Dennis would use the overhead projector and chalkboard which were at the "front" of the classroom. This was the exception during the discussion sessions, however.

\section{Summary}

In all four programs observed in this study the needs of all four dominant styles were met at least part of the time while addressing the teaching and learning theory competency of the accreditation standards (see Appendix B). Program 3 was the only program not meeting all four styles' needs in the classroom and then it addressed the CS, AS, and AR styles. It rid lack the CR strategies of games, simulations, and problem solving within the teaching and learning module in the classroom. Other portions of the programs' curricula were not evaluated, so this finding 
cannot and should not be applied to the other competencies within them.

Lecture by itself addressed the needs of less than one fourth of the students. Though lecture was used, over one half of the students still had their organizational and practical application, dominant CS needs met with handouts and overhead materials during those lectures. The same is true of the students, over one half of whom dominant AR desired stories and personal experiences. These needs were occasionally met within the lecture format. of the one fourth, dominant $C R$, preferring games, simulations, and problem solving, the latter were in many cases met within or in addition to the lecture.

Although lecture was the dominant presentation style in the classroom, dominant Cs strategies were incorporated into it more than any other styles' strategies. Nearly 60z of all of the students were dominant CS. Dominant AR strategies occurrad next in frequency of use, about one third more often than dominant As strategies. Just over one half of the total number of students were dominant AR, while just under one fourth of all of the students were dominant AS. When dominant $C R$ strategies were used, they were always the least frequent. Just over one fourth of the students were dominant $C R$.

Only two of the four programs included styles information before my arrival on campus, but all four 
modeled a variety of styles in their teaching strategies. one of the two which did not originally plan to include styles information did schedule a session into the class for a presentation of the Energic Model of Styles. This raised to three the number of programs actually presenting information on styles. Two programs' chairpersons thought the topic important enough to allow me to present to the students mind styles information outside of regular class time. Two programs' chairpersons also were interested enough to allow me to make a presentation to the faculty in a separate meeting.

These are all indicators that there is an interest in addressing normal variation in mind styles and its application to physical therapy. The level of cooperation of the faculties, without exception, could not have been higher. All were interested in what I was doing and many asked questions, as well as answered mine.

\section{Conclusions}

These conclusions are based on four programs and should be interpreted in light of that.

1. Two of the four programs studied, as well as several sites contacted during case selection, present styles information to the physical therapy students.

2. Lecture is the primary classroom strategy used in presentation of teaching and learning theory in the physical therapy education programs studied. 
180

3. Although lecture is the primary classroom strategy in the programs studied, other strategies are incorporated into it which address the needs of more than one mind style, although not in equal proportions.

4. Physical therapy teachers in all four programs studied model several ways to address a variety of mind styles within the teaching and learning theory presentations, regardless of whether styles information is presented or not.

5. There is an interest in mind styles among the teachers and students in the physical therapy programs studied as demonstrated by the teachers asking me to speak to their students and by the questions I was asked.

\section{suggestions for Further study}

1. Survey all of the accredited physical therapy programs in the United States as to whether they present styles information to their students.

2. Observe other modules within physical therapy programs to determine the presence or absence of modeling of a variety of styles strategies.

3. Observe physical therapists during patient treatment to determine the presence or absence of application of mind styles information.

4. Do a comparison of the proportions of mind styles among students to those of teachers. 
181

5. Do a comparison of the proportions of mind styles among students to those of the members of the admissions committees.

6. Determine the dominant mind styles of the members of the various sections, i.e., Research, Education, Pediatrics, Neurologic, etc., of the American Physical Therapy Association.

7. Compare those physical therapists who have a demonstrated understanding and accepting attitude toward the uniqueness of their own styles combination with physical therapists who have had no exposure to styles concepts relative to success in patient teaching.

8. Survey employers and develop two groups of individuals, one comprised of those who recognize and accept their own strengths and limitations and another comprised of those who do not. Then compare their level of effectiveness in dealing with variations in their environmental and interpersonal surroundings.

9. Compare the rehabilitation team's level of effectiveness and cohesiveness with the team members' awareness of the strengths and limitations of the other team members. Also determine the extent of complement of the various team members' strengths.

10. Determine the amount of time instructors devote to each style when addressing various physical therapy accreditation competencies. 


\section{Implications}

One can note in the physical therapy publications there are many positions available for clinicians and faculty. There also has been several comments in the last decade that the field of physical therapy must have more research conducted and published. This is to provide scientific support for the various procedures and modalities that we use in daily patient treatment. I cannot help wonder, based on the proportion of student mind styles in my study, if physical therapy programs are graduating enough therapists who have the natural talent and interest in research. With one half or more of the students in my case study being dominant in either CS or AR or a combination of styles including one or the other of those, I wonder.

My interpretation of the Energic Model of Styles leads me to believe that the dominant As generally has the gift of developing theory and the dominant $C R$ the gift of problem solving and accepting challenge. These two styles are in the lowest proportion in the four programs that I studied. It is also true there is a great need for clinicians. I am constantly receiving mail advertising job openings. The dominant AR's love of being with others and sharing of themselves and the dominant cs person's attention to detail should fulfill most of the needs of the physical therapist practitioner. If the proportions of my group of 
students reflects those nationally, then we are graduating many to fill those available positions.

I believe the key issue is that faculty must become well acquainted with their students so that they may help each student to unfold or develop his natural gifts. That faculty member, then, can help the student begin fulfilling his/her potential, whether it be in patient treatment, research, or academia. 


\section{APPENDIX A}

Preferred Teaching Strategies by Dominant Mind Style (from Gregorc, 1985)

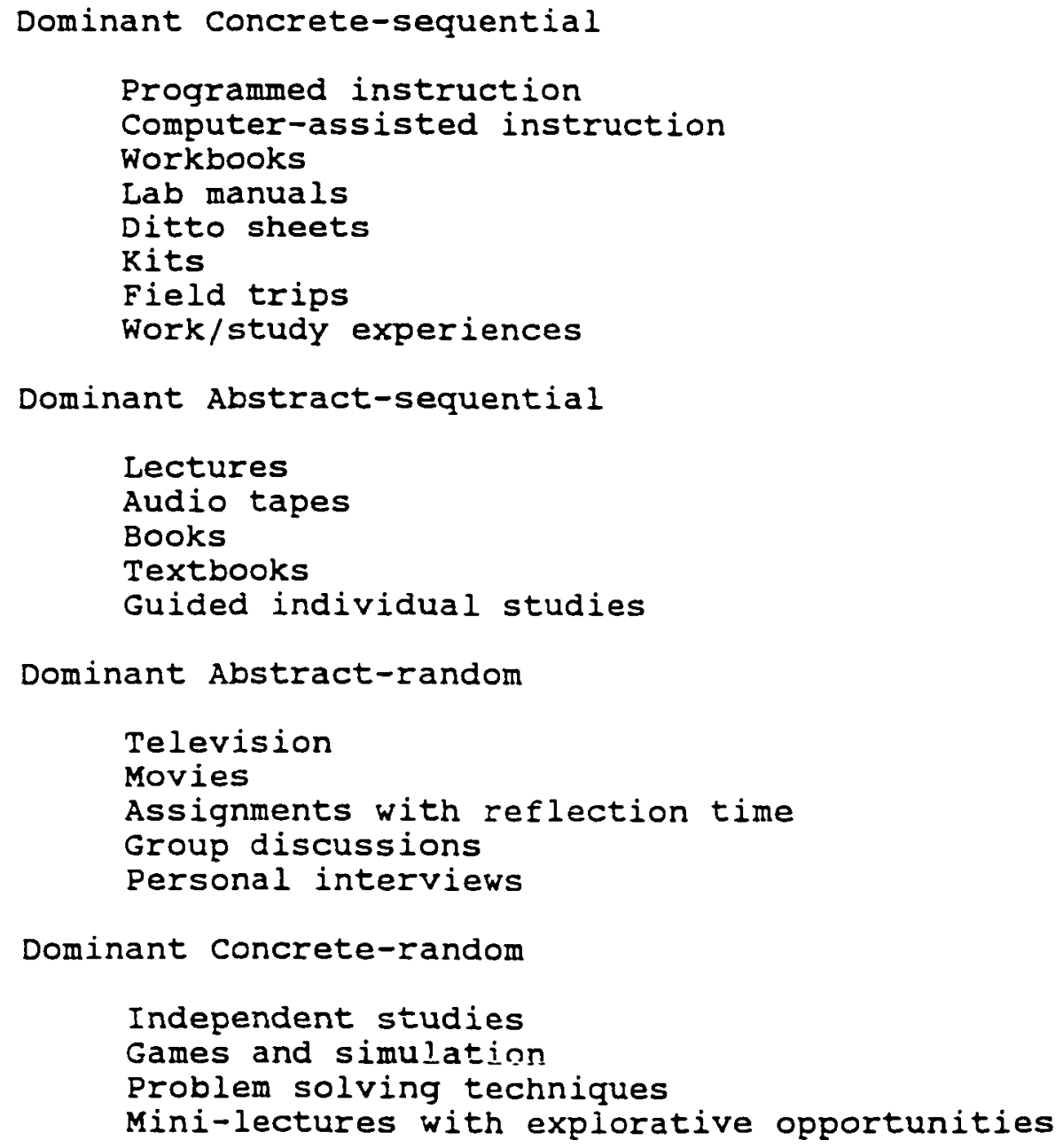




\section{APPENDIX B \\ Learner Behaviors, Attitudes, and Preferences \\ (from Gregorc, 1985)}

Dominant Concrete-sequential

Teacher in charge of class

Teacher to be skilled in subject matter

Expect to receive practical information

Prefer information in successively connected parts

Expect teachers to follow through on promises

Do not like sitting in a circle sharing ideas with

other students

Prefer concrete examples

Hands-on oriented

Prefer actual rather than contrived experiences

Computer-assisted instruction

Programmed instruction

Prefer short synopses to heavy reading assignments

concerned for precision, exactness, and sometimes perfection

Do not expect encouragement

Expect immediate feedback when mistakes are made ("No news is good news.")

Test papers to be returned promptly

Commentary to be sharp and precise and should include recommendations for improvement

Approach tasks as discrete parts (not the big picture)

Follow directions in step-by-step manner

will question if directions are unclear

Dominant Abstract-sequential

Prefer dealing with abstractions by lising models, ideas, concepts, and symbols

At times prefer vicarious experiences

Handles words very well (words are their tools)

Prefer substantive, logical, serious, structured, and sequential techniques

See the big picture very well

Prefer lectures

Expect teachers to be experts

Expect to reflect teachers expertise in testing seek answers

Some prefer not to use divergent approaches to learning

Prefer not pooling ignorance in group discussion

Analytical and evaluative

185 
Seek documentation and referent authority for ideas Follow reasoned guidelines

Low tolerance for distraction

Dominant Abstract-random

Like subjective, affective, and abstract experiences often use metaphors, poetry, and songs for expression Prefer options in learning task Prerer minimally structured guidelines Prefer guide-like or collegial relationship with others Shared decision-making is natural Demonstrate high empathy Can read body language and "vibes" Very subjective in reading stories and viewing movies Read between the lines See the gestalt (troubled with black/white, true/false options)

Prefer oral and subjective exams

May read more into situations than is really there Look for subjective signals of approval or disapproval Do not always follow directions carefully Want to know why they are doing something High tolerance for distraction Can psyche out teachers

Dominant Concrete-random

Prefer concrete applications of ideas through example and practice

Like to improve reality through experimentation

Prefer instructional options and alternatives

Can follow guidelines very well

like teachers who instruct and guide Demonstrate insight

known for their intuition and creative formulations Problem-solving, application oriented, experiential learners

Few are afraid to take risks or try new things Love variety

Dislike step-by-step directions and procedures May not read directions or may not read them carefully Favor stimulus-rich environment

concentrate well in moderately distractive environment 


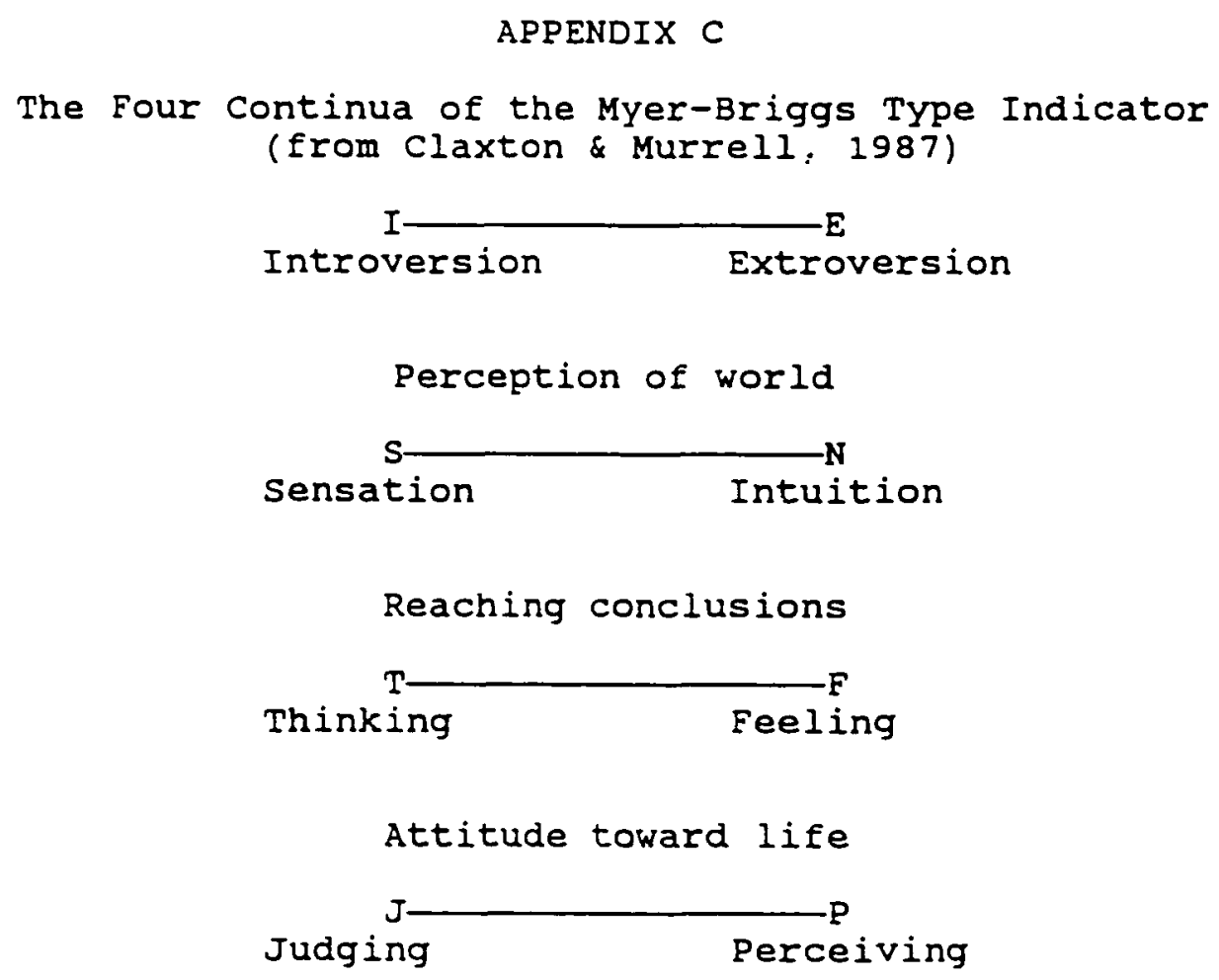




\title{
REFERENCE IIST
}

\author{
Abel, F. J., Herbster, D. L., \& Prince, R. H. (1989). \\ Learning style and inservice teacher stress: Is \\ there a relationship and what can be done about it? \\ Educational Resources Information Center (ERIC), \\ (ERIC Document Reproduction Service No. ED 304 419)
}

Atchison, M. K., \& Brown, D. M. (1988). The relationship between the learning styles and reading achievement of sixth-grade students in the state of Alabama. Educational Resources Information center (ERIC), (ERIC Document Reproduction Service No. ED 300772 )

Adams, J.F. (1983). The effects of the satisfaction of the learning style preference on achievement, attrition, and attitude of Palm Beach Junior College students. (Doctoral dissertation, Florida Atlantic University, 1983). Dissertation Abstracts International, 44/2A. (Abstract)

Barker, S. P. (1988). Comparison of effectiveness of interactive videodisc versus lecture-demonstration instruction. Physical Therapy, 68, (5), 699-703.

Bennet, C. (1979) Individual differences and how teachers perceive them. Social studies 70(2), 56-61.

(Abstract)

Bickley, H. C., McDougal1, R. V., \& Pepe, S. H. (1973). A comparison of programmed learning and conventional lectures in the teaching of general pathology to physical therapy students. Physical Therapy, $\underline{53}(7)$, $769-773$.

Bogue, S.D. (1982) Differential learning for verbal and pictorial presentations. (Doctoral dissertation, University of Michigan, 1982). Annotated

Bibliography: 1989, Center for the Study of Learning and Teaching Styles, St. John's University, Jamaica, NY, 1989. (Abstract) 
Brown, R. (1978). The effects of congruency between learning styles and teaching styles of college student achievement. College Student Journal, 12, 44-47. (Psych Abstracts)

Browne, D. ([1986]). Learning styles and native Americans. Educational Resources Information Center (ERIC), (ERIC Document Reproduction Service No. ED 297 906)

Bruno, J. (1988). An experimental investigation of the relationship between and among hemispheric processing, learning style preferences, instructional strategies, academic achievement, and attitudes of developmental mathematics students in an urban technical college. (Doctoral dissertation, st. John's University, New York, 1988). Annotated Bibliography: 1989 , Center for the Study of Learning and Teaching Styles, st. John's University, Jamaica, NY, 1989. (Abstract)

Bukowski, M. A., Jensen, R. H. \& Morrison, M. A. (1980). Comparison of textbook and self-instructional learning methods. Physical Therapy, 60(2), 179-183.

Caine, R., \& Caine, G. (1991). Teaching and the human brain. Alexandria, VA: ASCD.

Campbell, S. K., \& Kohli, M. A. (1970). Audio-tutorial independent study of goniometry. Physical Therapy, 50(2), 195-200.

Claxton, C., \& Murrell, P. (1987). Learning styles: Implications for improving education practices. ASHE-ERIC Higher Education Report No. 4. Washington, D.C.: Association for the study of Higher Education.

Commission on Accreditation in Physical Therapy Education [CAPTE]. (1986). "The standards for accreditation of physical therapy educational programs" (rev. ed.). Alexandria: American Physical Therapy Association.

Commission on Accreditation in Physical Therapy Education [CAPTE]. (1990). "The standards for accreditation of physical therapy educational programs" (rev. ed.). Alexandria: American Physical Therapy Association.

Day, J. A. (1985). Beyond lecture and laboratory in the physical therapy classroom. Physical Therapy, 65(8), 1215-1216. 
Dempsey, R. A., \& Gregorc, A. F. (1988). Rev up department heads by revising their job descriptions. ExecutiveEducator, 10(12), 25 .

Dunn, R., \& Dunn, K. (1978). Teaching students through their individual learning styles: A practical approach.

Englewood Cliffs, NJ: Prentice-Hall.

Dunn, R., \& Dunn, K. (in press). Teaching elementary children through their individual learning styles: A practical approach.

4MAT A Framework for Excellence in Education, [1991]. Barrington, IL: Excel.

4MAT Because Great Minds Don't Think Alike, [1991]. Barrington, II: Excsl.

Gregorc, A. F. $\left(1982^{\circ}\right)$. An Adult's Guide to Style, Columbia, CT: Gregorc Associates.

Gregorc, A. F. $\left(1982^{\mathrm{b}}\right)$. "Gregorc style Delineator" Research Instrument." Columbia, CT: Gregorc Associates.

Gregorc, A. F. (1984') . Gregorc Style Delineator:

Development, Technical, and Administration Manual, Columbia, CT: Gregorc Associates.

Gregorc, A. F. $\left(1984^{\mathrm{b}}\right)$. "Style as a symptom: A phenomenological perspective" in "Matching teaching \& learning styles." Theory into practice. Columbus, ohio: The ohio state University, 23, No. 1.

Gregorc, A. F. (1985). Inside styles: Beyond the basics, Columbia, CT: Gregorc Associates.

Gregorc, A. F., \& Butler, K. A. (1984). Learning is a matter of style. VocEd, $\underline{59}$ (3) 27-29.

Gregorc, A. F. , \& Ward, H. B. (1977). A new definition for individual: Implications for learning and teaching. NASSP Bulletin, February.

Guild, P. , \& Garger, S. (1985). Marching to different drummers, Alexandria, VA: ASCD.

Herbster, D. L., Abel, F. J., Hargrove, J. A., \& Weems, D. (1987). Integrating learning styles, critical thinking and models of teaching. Educational Resources Information Center (ERIC), (ERIC Document Reproduction Service No. ED 303462 ) 
Hilgersom-Volk, K. (1987). Celebrating students' diversity through learning styles. oregon school study council Bulletin, 30, (9). Educational Resources Information Center (ERIC), (ERIC Document Reproduction Service No. ED 284321 )

Johnson, G. R. (1974). Physical therapy education. Physical Therapy, 54(1), 37-42.

Joniak, A. J., \& Isaksen, S. G. (1988). The Gregorc style Delineator: Internal consistency and its relationship to Kirton's adaptive-innovative distinction. Efucationa? and Psychological Measurement, 48, 1043-1049.

Keirsey, ป., \& Bates, M. (1984). Please understand me: Character and temperament types. Del Mar, CA: Prometheus Nemesis Book Company.

Kolb, D. A. (1984). Experiential learning. Englewood Cliffs, NJ : Prentice-Hall.

Mccain, F., Jr., \& Brown, L. D. (1969). The effect of cognitive style in verbal and pictorial concept formation tasks. (ERIC Document Reproduction Service No. ED 030 553) (Abstract)

Mccarthy, B. (1987) The 4MAT system: Teaching to Learning Styles with Right/Left Mode Techniques. Barrington, IL: Excel.

Mccarthy, B. (1989). The 4MAT system Awareness Workshop, Part A: Introduction to Learning styles. Barrington, IL: Excel.

Myers, I. B., \& McCaulley, M. H. (1985). Manual: A quide to the development and use of the Myers-Briggs type indicator. Palo Alto, CA: Consulting Psychologists Press.

O'Brien, T. P. (1990). Construct validation of the Gregorc Style Delineator: An application of lisrel 7 . Educational and Psychological Measurement, 50, 631636 .

Payton, O.D., Hueter, A. E., \& McDonald, M. E. (1979). Learning style preferences: Physical therapy students in the United States. Physical Therapy, 59(2), 147-152. 
Radebaugh, M. R., Nicely-Leach, J., Morrill, C., Shreeve, W., \& Slatton, S. (1988). Reading your professors: A survival skill. Journal of Reading, 31(4), 328-332.

Rahr, R. R. (1987). Basic learning styles and the relationships to achievement in allied health and nursing. (Doctoral dissertation, University of Houston, 1987). Dissertation Abstracts International, 49/04A. (Abstract)

Restak, R. M. (1991). The brain has a mind of its own. New York: Harmony Books.

Rutan, F. M. (1973). Comparison of self-instruction and lecture-demonstration in learning a physical therapy skill. Physical Therapy, 53(5), 521-526.

Sewall, T. J. (1986). The measurement of learning style: A critique of four assessment tools. Educational Resources Information center (ERIC), 1-67 (ERIC Document Reproduction Service No. ED 267 247)

Shmaefsky, B. R. (1987). College science student cognitive style as a factor for student evaluation of college instruction (Doctoral dissertation, Southern Illinois University at Edwardsville, 1987). Dissertation Abstracts International, 48/12A. (Abstract)

Thompson, M. J., \& O'Brien, T. P. (1991). Learning styles and achievement in postsecondary classrooms. Educational Resources Information Center (ERIC), (ERIC Document Reproduction Service No. ED 331 554)

Wheeler, P. J. R. (1991). Style mismatch or learning disability: A case study. (ERIC Document Reproduction Service No. ED 336 359)

Wolfe, D. M., \& Kolb, D. A. (1979). "Career Development, Personal Growth, and Experiential Learning." In organizational Psychology: A Book of Readings, edited by D. A. Kolb, I. M. Rubin, \& J. M. McIntyre, 3: 535-563. New Jersey: Prentice-Hall.

Yin, R. K. (1989). Case study research. Newbury Park, CA: Sage Publications. 
VITA

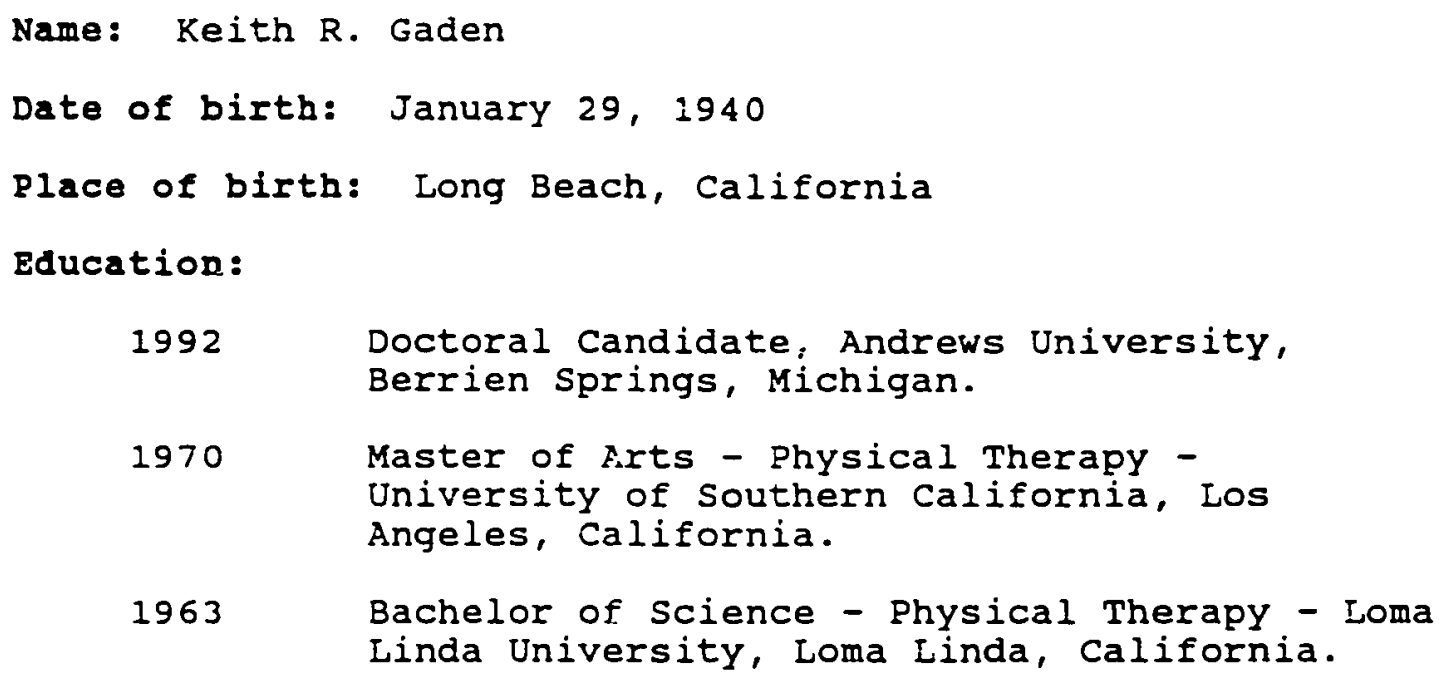

1963 Bachelor of Science - Physical Therapy - Loma Linda University, Loma Linda, California.

\section{Professional experience:}

\begin{tabular}{|c|c|}
\hline 1984-pres & $\begin{array}{l}\text { Associate Professor of Physical Therapy, } \\
\text { Andrews University, Berrien Springs, } \\
\text { Michigan }\end{array}$ \\
\hline $1982-1984$ & $\begin{array}{l}\text { Manager of Physical Therapy Department, } \\
\text { Sonora and Sierra Community Hospitals, } \\
\text { Sonora, California }\end{array}$ \\
\hline $1978-1982$ & $\begin{array}{l}\text { Assistant Clinical Professor of Physical } \\
\text { Therapy, Loma Linda University Medical } \\
\text { Center, Loma Linda, California }\end{array}$ \\
\hline $1972-1978$ & $\begin{array}{l}\text { Assistant Professor of Physical Therapy, } \\
\text { Loma Linda University, Loma Linda, } \\
\text { California }\end{array}$ \\
\hline $1968-1972$ & $\begin{array}{l}\text { Instructor of Physical Therapy, Loma } \\
\text { Linda University, Loma Linda, California }\end{array}$ \\
\hline $1963-1966$ & $\begin{array}{l}\text { Staff Physical Therapist, Clinical } \\
\text { Supervisor, Loma Linda Sanitarium and } \\
\text { Hospital, Loma Linda, California }\end{array}$ \\
\hline
\end{tabular}

